\title{
Strategies of coronary reperfusion in acute myocardial infarction for patients admitted to hospitals without angioplasty facilities
}

Citation for published version (APA):

Oude Ophuis, A. J. M. (2000). Strategies of coronary reperfusion in acute myocardial infarction for patients admitted to hospitals without angioplasty facilities. [Doctoral Thesis, Maastricht University]. Universiteit Maastricht. https://doi.org/10.26481/dis.20000526ao

Document status and date:

Published: 01/01/2000

DOI:

10.26481/dis.20000526ao

Document Version:

Publisher's PDF, also known as Version of record

Please check the document version of this publication:

- A submitted manuscript is the version of the article upon submission and before peer-review. There can be important differences between the submitted version and the official published version of record.

People interested in the research are advised to contact the author for the final version of the publication, or visit the DOI to the publisher's website.

- The final author version and the galley proof are versions of the publication after peer review.

- The final published version features the final layout of the paper including the volume, issue and page numbers.

Link to publication

\footnotetext{
General rights rights.

- You may freely distribute the URL identifying the publication in the public portal. please follow below link for the End User Agreement:

www.umlib.nl/taverne-license

Take down policy

If you believe that this document breaches copyright please contact us at:

repository@maastrichtuniversity.nl

providing details and we will investigate your claim.
}

Copyright and moral rights for the publications made accessible in the public portal are retained by the authors and/or other copyright owners and it is a condition of accessing publications that users recognise and abide by the legal requirements associated with these

- Users may download and print one copy of any publication from the public portal for the purpose of private study or research.

- You may not further distribute the material or use it for any profit-making activity or commercial gain

If the publication is distributed under the terms of Article $25 \mathrm{fa}$ of the Dutch Copyright Act, indicated by the "Taverne" license above, 
(9) AJM Oude Ophuis, Maastricht 2000 ISBN 9090137203

Vormgeving en druk: Datawyse by Mastricht 


\title{
Strategies of coronary reperfusion in acute myocardial infarction for patients admitted to hospitals without angioplasty facilities
}

\author{
PROEFSCHRIFT \\ ter verkrijging van de graad van doctor \\ aan de Universiteit Maastricht, \\ op gezag van de Rector Magnificus, \\ Prof. dr. A.C. Nieuwenhuijzen Kruseman, \\ volgens het besluit van het College van Decanen, \\ in het openbaar te verdedigen \\ op vrijdag 26 mei 2000 om 14.00 uur \\ door \\ Anthonius Josephus Maria Oude Ophuis \\ geboren te Rotterdam in 1962
}


Promotores:

Prof. dr. F.W.H.M. Bär

Prof. dr. H.J.J. Wellens

Co-promotor:

Dr. F. Vermeer

Beoordelingscommissie:

Prof. dr. M.P. van Dieijen-Visser (voorzitter)

Prof. dr. A.P.W.M. Appels

Prof. dr. M.J.A.P. Daemen

Prof. dr. J.J. Piek (Universiteit van Amsterdam)

Prof. dr. F.W.A. Verheugt (Katholieke Universiteit Nijmegen) 
Voor Carole, Sanne en Bas Aan mijn ouders 


\section{Table of contents}

CHAPTER 1

Introduction

CHAPTER 2

Historic overview

CHAPTER 3

Rescue PTCA following failed thrombolysis and primary PTCA:

A retrospective study of angiographic and clinical outcome.

J Tbromb And Tbrombolysis 1997;4:281-288

CHAPTER 4

Early referral for intentional rescue PTCA after initiation of thrombolytic therapy in patients admitted to a community hospital because of a large acute myocardial infarction.

Am Heart Joumal 1999; 137: 846-854

CHAPTER 5

Angiographic assessment of prospectively determined non-invasive reperfusion parameters in acute myocardial infarction: Can the number of acute angiography and subsequent angioplasty be reduced?

Heart 2000 accepted for publication

CHAPTER 6

The LIMI Protocol.

CHAPTER T

Prospective randomised comparison berween thrombolysis, rescue PTCA and primary PTCA in patients with extensive myocardial infarction admitted to a hospital without PTCA facilities:

A safery and feasibility study.

Heart 1999:82:426-43I 
Cost-effectiveness analysis of the LIMI protocol:

A prospective comparison berween thrombolysis, rescue PTCA and primary PTCA in patients with acure myocardiain infarction intially admitted to a hospital without PTCA facilities.

Submitred for publication

SUMMARY AND CONCLUSIONS

SAMENVATTING EN CONCLUSIES

DANKWOORD

CURRICULUM VITAE 


\section{Introduction}

Our understanding of the pathophysiological mechanisms of acute myocardial infarction (AMI) and the treatment of this disease evolved considerably during the past two decades. Whereas in the seventies the treatment mainly was directed towards control of cardiac arrhythmias, in the eighties and thereafter the therapy of patients with acute myocardial infarction focussed more on reperfusion of the culprit coronary artery leading to limitation of infarct size and improved clinical ourcome.

At present, two reperfusion techniques have proven their efficacy; 1) the administration of fibrinolytic agents and 2) mechanical reopening of the occluded vessel followed by percutaneous transluminal coronary angioplasty (PTCA). Rescue PTCA after failed thrombolysis is likely to be beneficial, but definite proof is not available. The purpose of this thesis is to compare three strategies of management of acute myocardial infarcrion; a) thrombolytic therapy, b) thrombolytic therapy followed by acute coronary angiography and (if indicated) rescue PTCA, and c) primary PTCA.

So far, angioplasty in acure myocardial infarction has primarily been studied and practiced in parients who were admitred directly to a PTCA center (Chapter 3). However, the majority of patients with an acute myocardial infarction present to hospitals without PTCA facilities. We first studied retrospectively the possible benefit of early transfer for rescue PTCA (Chapter 4). Based on these findings, a prospective randomised multicenter trial was started comparing the three above mentioned reperfusion strategies in patients who were initially admitted to a hospital without angioplasty facilities (Chapter 6). The feasibility and safety of such an approach was evaluated (Chapter 7) and the cost effectiveness of these reperfusion strategies is assessed in chapter 8.

In order to avoid unnecessary acute coronary angiography and subsequent angioplasty in patients with successful reperfusion, either spontaneously or after successful thrombolysis, the value of non-invasive parameters of reperfusion has to be evaluated. For that purpose simple and widely available non-invasive reperfusion parameters have been suggested. In chapter 5 presence or absence of these reperfusion markers was evaluated just before the first intracoronary injection of the infarct-related vessel and correlated to coronary flow allowing evaluation of the reliability of these markers.

In chapter 9 conclusions are given.

Therefore, this thesis aims to answer the following questions:

1. Are there differences in clinical and angiographic outcome between rescue or primary PTCA? (Chapter 3) 
$10 \mid$ CHAPTER 1

2. Can unnecessary acute corotiary angiography and subsequent angioplasty be avoided by accurate and simple reperfusion parameters? (Chapter 5)

3. Do patients with acute myocardial infarction initially admitted to a hospital without angioplasty facilities benefit from early transfer to an angioplasty center for emergency angioplasty: (Chapters 4,6,7)

4. What is the cost-effectiveness ratio of three different reperfusion strategies in patients with acute myocardial infarction admitted to a hospital without angioplasty facilities? (Chapter 8) 


\section{CHAPTER 2}

\section{Historic overview}

\section{'THROMBOLYTIC ERA"}

Findings at autopsy indicate that approximately $90 \%$ of patients dying from acure myocardial infarction have a thrombotic coronary artery occlusion, frequently caused by local rupture of the intima of the atherosclerotic vessel wall (1). Since it became clear that thrombosis plays an important role in the pathofysiology of acute myocardial infarction, interest was directed towards drug therapy that could dissolve the coronary clot. Already in 1933, fibrinolytic activity of beta-hemolytic streptococci was described by Tilett and Garner (2). This observation led to the first therapeutic attempt to dissolve a fibrinous pleural effusion by Tillett and Sherry in 1948 (3). In the late sixties, dose finding studies with streptokinase were conducted $(4,5)$, but results were variable and therefore streptokinase was not used widely thereafter.

In the early eighties large randomised studies confirmed the value of thrombolytic therapy in acute myocardial infarction. Initially thrombolytic therapy was directly given into the infarct-related artery, resulting in reperfusion and reduction of mortality of approximately $30 \%$ if patients were treated within 4 hours (6). This approach was complex, time consuming, expensive and resulted not uncommonly in bleeding complications at the puncture site. In contrast to the initial expectation, a systemic thrombolytic effect was observed. This was reason to switch to the intravenous administration of the drug, which resulted in an acceptable benefit/risk ratio (7-11). As shown angiographically, reperfusion of the culprit artery resulted, as defined in the Thrombolysis In acute Myocardial Infarction (TIMI) study, in $50-90 \%$ at 90 minutes after the start of therapy and myocardial salvage was documented (11-27).

The GISSI trial was the first large trial of thrombolytic therapy. In 11,806 patients with acute myocardial infarction this study demonstrated that intravenous thrombolytic therapy was effective, although less than with the intracoronary route, saving approximately $20 / 1000$ patients (7). Randomised studies demonstrated a clear correlation between infarct related vessel patency, mortality and preservation of left ventricular function. Even in case of late reperfusion the incidence of malignant arrhythmias decreased, and fatal embolic intracerebral stroke due to thrombus formation in the left ventricle was seen less frequently. The price to pay was more bleeding complications of which the intracerebral haemorrhage was feared most. Time delay between onset of AMI and thrombolytic therapy showed to be of significant importance. In the GISSI trial a reduction in mortality was only observed in patients who presented with acute myocardial infarction within 3 hours of the onset 
of chest pain (7). This finding was confirmed by three more recently published trials, using prehospital thrombolysis (28-30). The earlier this therapy is given, the greater the benefit. The European Myocardial Infarction Project (EMIP) enrolled approximately 6000 patients who were randomised and treated with prehospital thrombolysis or with thrombolysis after admission to a hospital (29). When compared to the pre-hospital thrombolysis group, a median time delay of 55 minutes of the administration of a thrombolytic agent was observed in the hospital thrombolysis group. Adverse events like ventricular fibrillation, shock, symptomatic hypotension and bradycardia were seen more often in the prehospital thrombolysis group. These events usually occurred during the period before hospitalization. However, with the exception of symptomatic hypotension, the overall incidence of these events when including the hospital phase were similar for both groups. Thirteen percent further reduction in mortality of the prehospital thrombolysis group underlines the value of early administration of thrombolytic agents. The EMIP investigators concluded that prehospital thrombolytic therapy for patients with suspected myocardial infarction is both feasible and safe when administered by well-equipped and well-trained mobile emergency staff and results in a better clinical ourcome.

\section{FINE TUNING OF THROMBOLYTIC AGENTS}

At present, several thrombolytic agents are available. There are some differences in speed and completeness of reperfusion as well as in side effects. To improve reperfusion, attention is also given to concomitant medication. The ISIS-2 study assessed the separate and combined effects of intravenous streptokinase and oral aspirin (8). In a randomised study of 17,187 patients it was concluded that the combination of streptokinase and aspirin in suspected myocardial infarction is beneficial in clinical ourcome in terms of mortality and reinfarction rate. However even with the most agressive thrombolytic agent alteplase combined with aspirin and intravenous heparin, complete (TIMI grade 3 ) reperfusion is achieved in only $54 \%$ of all patients treated within 6 hours after the onset of pain (23). Newer thrombolytic agents result in higher patency rates. When combined with IIB/IIIA glycoprotein receptor antagonists further improvement is expected.

Risks of thrombolytic therapy, especially bleeding, have been reported in several studies (31). Since thrombolytic agents do nor discriminate between an intracoronary thrombus and a clot at a potential bleeding site, hemorrhages can occur. Most bleeding complications consist of prolonged bleeding at the puncture site. When cardiac catheterization is performed, bleeding complications are seen in $20-40 \%$ of patients. Life-threatening intracerebral bleedings have been reported. The International Study Group investigated the clinical course in 20,891 patients with AMI randomized to alteplase or streptokinase with and without heparin (32). The risk of stroke was $1.3 \%$ with rt-PA as compared to $1 \%$ with streptokinase, 
however the cause of stroke could not be established in all cases. For patients with contraindications to thrombolytic therapy (mainly patients with enhanced risk of bleeding) mechanical reopening by PTCA was found to be a good alternative. Later this approach was also evaluated for patients without contraindications to thrombolytic therapy.

\section{CORONARY ANGIOGRAPHY IN ACUTE MYOCARDIAL INFARCTION}

DeWood and coworkers in 1980 were the first to show that coronary angiography is feasible in acute myocardial infarction (33). In 126 patients they demonstrated that within 4 hours of symptom onset $87 \%$ of infarct related vessels were occluded. They also showed the safety of such a procedure wirh only little increased risk from the procedure itself as compared to elective coronary angiography. Later, acute coronary angiography became common practice in thrombolysis trials to determine infarct related vessel patency.

\section{THROMBOLYSIS AND IMMEDIATE PTCA}

The combination of thrombolytic therapy with immediate PTCA independent of the reperfusion status of the vessel was investigated in the past $(34,35)$. The assumption was that the two-step process of fibrin dissolvement and plaque compression would be superior to only attacking thrombus formation. However it was found that immediate PTCA after thrombolysis, independent of reperfusion status, did not improve cardiac function and led to a higher complication rate. The TIMI II A study showed that the 24 hour complication rate using the immediate invasive strategy was significantly higher $(8.5 \%)$ than a delayed invasive strategy $(4.6 \%)$ in case of persisting or recurrent ischemia (35). This negative outcome was considered to be the result of the "sick artery", conceptualized as an infarct vessel with a destabilized plaque, marked plateler aggregration and residual thrombus after thrombolytic therapy. Under such conditions PTCA did not show to be favorable (36). The SWIFT (Should We Intervene Following Thrombolysis) trial compared an invasive strategy with a conservative approach after thrombolytic therapy. The invasive strategy was early elective angioplasty (within 48 hours). Patients in the conservative group had angiography only if they had recurrent ischemic symptoms or positive results on exercise tests. At three months, mortality rates were not significantly different between the conservative (3.2\%) and the invasive group (4.8\%); the mean left ventricular ejection fraction was also similar. Thus, the results of the SWIFT trial were in line with other studies (37). However, in the TAMI-5 study an aggressive strategy of immediate catheterization and angioplasty for failed thrombolysis was better when compared to a strategy of deferred predischarge catheterization on days 5-10 (24,38). The strategy of immediate catheterization and angioplasty was associated with improved regional wall motion in the infarct region 
$(p=0.004)$ and fewer adverse outcomes $(p=0.004)$. When more and more study results became available the concept of "watchful waiting" was preferred in the patients treated with a thrombolytic agent, as indicated in 1990 by Meier (39).

\section{RESCUE PTCA}

From the randomized clinical trials, it became clear that patients with reperfused coronary arteries have a better clinical outcome than patients with failed thrombolysis. This observation led to the concept of rescue PTCA, a strategy using a mechanical approach immediately following failed thrombolysis. In 1992 Belenkie et al. reported a small randomized study in 29 patients between conservative therapy and rescue PTCA without significant difference in clinical outcome (40). In $\mathbb{1} 994$ Ellis et al. published the results of the RESCUE study evaluating PTCA after failed thrombolysis for patients with acute anterior myocardial infarction (41). In this study one hundred fifty-one patients with first anterior AMI, treated with intravenous trombolytic therapy and an angiographically demonstrated occluded infarct vessel, were randomised to either conventional treatment or acute balloon angioplasty. In the latter group, angioplasty was technically successful (final TIMI flow grade 3 and percent stenosis $<50 \%$ ) in $92 \%$. This study demonstrated a limited reduction in mortality and heart failure as well as improved left ventricular function on exercise at 30 days follow-up, favoring rescue PTCA. However, this study consisted of a selected group of patients. Patients could be included up to eight hours after the onset of chest pain. A patient log showed that a strong investigator bias had been present. Patients presenting early in the course of their infarction or patients with extensive ischaemia usually were not included in the study. Possibly, this bias and the wide-open inclusion time window led to inclusion of patients with only a limired amount of salvagable tissue. In the RESCUE study 151 patients were included in three years with recruitment from 20 centers. Many angioplasty centers did not participate because potential investigators considered it unethical to refrain at the end of the acure coronary angiography from mechanical intervention after failed thrombolysis. A meta-analysis of studies with rescue PTCA by Ellis showed success rates in achieving infarct related artery parency ranging from $71 \%$ to $92 \%$ (42). There was little beneficial effect as to recovery of left ventricular function at the time of hospital discharge. However, patients with successful angioplasty had a considerably lower mortality rate than patients with unsuccessful coronary angioplasty (43-46). It should be stressed that in many patients rescue PTCA was done many hours after the start of thrombolytic therapy. Secondly, the decision to perform rescue PTCA was frequently taken in case of further deterioration of the clinical situation of the patient. These factors influenced the outcome of such therapy in a negative way.

Reocclusion rates after successful rescue angioplasty have been reported to be as high as $29 \%$, but appear to be considerably lower when streptokinase, which induces 
low fibrinogen levels during 24 to 48 hours ("general lytic state") is used $(24,47-48)$. In a retrospective study comparing rescue and primary PTCA during acute myocardial infarction Bär et al. showed much lower reocclusion rates, $3 \%$ versus $3.9 \%$ for rescue and primary PTCA, respectively (49). Until today, only small randomised and observational studies have been published. As a consequence of this, the general application of rescue PTCA has not yet been accepted as a proven beneficial strategy.

\section{PRIMARY PTCA}

Direct or primary coronary angioplasty was first intoduced by Hartzler et al. in 1983 (44). Patients with acute myocardial infarction are catheterized as soon as possible, the occluded artery is opened by PTCA. The use of a guide wire and angioplasty balloon seemed to result in more rapid reperfusion than thrombolysis. Ar present, five randomised clinical trials have been conducted comparing thrombolytic agents and primary PTCA in acute myocardial infarction (50-54). These trials demonstrated lower death and non-fatal reinfarction rates during hospital stay and after 6 month-follow up in the patients treated with primary PTCA. The Zwolle group and Gibbons et al. showed also an improvement of left ventricular function $(52,54)$. In these studies primary angioplasty resulted in a higher acure and late patency rate of the infarct related vessel, in a smaller infarct size as evident from cumulative enzymatic release and left ventricular ejection fraction measurements, and in a better immediate and long term clinical outcome. Moreover, a shorter hospital stay, lower mortality, less reinfarction and fewer readmissions were observed.

Thus, under ideal circumstances primary PTCA leads to a faster and more complete vessel patency and avoids the need of a thrombolytic agent thereby limiting the risk of bleeding complications and paradoxic thrombin generation. Clearly these results can only be achieved in the patients with acute myocardial infarcrion who are admitted to an experienced PTCA center. Larger scale studies show that primary PTCA in the "real world" does result in no or minimal differences in clinical outcome when compared to thrombolytic therapy (55). The prolonged benefit of primary PTCA might among orher reasons be the result of less residual coronary artery stenosis when compared to thrombolytic therapy only. A high residual coronary artery stenosis may be a risk factor for future reocclusion (51).

Although meta-analyses suggest that primary PTCA may be more beneficial than thrombolytic therapy in AMI, these data have to be interpreted cautiously until confirmed by larger studies (55).

\section{PTCA FACILITIES IN THE NETHERLANDS}

Since Andreas Gruntzig performed the first PTCA in 1977 surgical standbye has been an important companion of coronary angioplasty (56). Among his first 50 patients 14\% required emergency bypass surgery because of acute ischemia. In 1988 
Guidelines for Percutaneous Transluminal Coronary Angioplasty by the joint ACC/AHA Task Force stated that "an experienced cardiac surgical team should be available within the institution for emergency surgery for all angioplasty procedures" (58). Basically, these guidelines were followed by the Dutch government and the Dutch Working group of Interventional Cardiology. Only 13 centers (less than $10 \%$ of all hospitals in the Netherlands) have permission to perform PTCA-procedures. In the United States approximately $20 \%$ of hospitals do have PTCA facilities. The others are not equipped to perform such interventions. Thus for acute PTCA they have to depend on the services of PTCA centers. Many of these centers do not accept such patients or they are not able to perform PTCA as a 24 hour service. In view of the reports on the beneficial outcome of primary and possibly also rescue PTCA, the treating physician in a non-PTCA center is faced with the issue whether or not his patient with acute myocardial infarction should be transferred for emergency angioplasty elsewhere. The decision to transfer a patient for PTCA will depend on timedelays, extent and localisation of the acute myocardial infarction, transport, PTCA center and pretreatment with a thrombolytic agent (59).

\section{LOGISTICAL PROBLEMS ARISING WITH PATIENT TRANSFER BETWEEN HOSPITALS WITH AND WITHOUT PTCA FACILITIES}

The current reports on the beneficial outcome of primary PTCA are encouraging, but still to small to draw general conclusions with respect to the optimal treatment of patients admitted with AMI. Recently, Zijlstra et al. showed that primary PTCA resulted in a better clinical outcome at 6 months compared to thrombolysis even in a low risk patient (60). One should keep in mind that this was found in patients directly admitted to a PTCA center. In the Netherlands approximately 27,000 patients are admitted with AMI per year (61). A substantial number of these patients are treated with thrombolytic agents, and no further action is taken. Of these 27,000 only approximately 3000 patients are admitted to centers with PTCA facilities. If primary or rescue PTCA is the most effective treatment in patients with AMI admitted in PTCA centers, it is still unclear whether the large proportion of patients admitted to hospitals without PTCA facilities can also profit from such intervention. It has to be considered that the time interval between onset of complaints and possible interventional treatment will lengthen because these parients need transport from one to another hospital. The logical question therefore then will be, "is emergency PTCA elsewhere useful in AMI patients who are admitted to a hospital without PTCA facilities"? Due to the expected rime delays of transport and its potential risks, it is unclear whether thrombolytic therapy alone in such patients would be inferior to transport followed by either primary PTCA or rescue P'TCA if indicated. 
In the acure phase of myocardial infarction coronary artery bypass grafting (CABG) can limit myocardial necrosis $(62,63)$. However, $C A B G$ has a very limited place in the management of the acute phase of myocardial infarcrion. It may be indicated in $2 \%$ to $5 \%$ of patienrs initially referrred for PTCA, either because PTCA thas failed, or PTCA is not feasible (62). Furthermore, it is limited to patients who are not eligible for thrombolytic treatment or who have failed thrombolysis within 4 to 6 hours after the onset of acute myocardial infarction (64). The intraoperative use of aprotonin after thrombolytic treatment may reduce haemorrhage related to the use of thrombolytic agents (65). Deferred CABG 3 to 7 days after myocardial infarction may be carried out with operative mortality approaching that for elective $\mathrm{CABG}$ (66-68).

\section{STENTING IN ACUTE MYOCARDIAL INFARCTION}

Although intracoronary stent implantation is an effective technique for the treatment of selected de novo lesions and for the management of abrupt closure, the use of stents in patients with acute myocardial infarction was not commonly accepted because of concerns regarding stent thrombosis (69-71). Non-randomised observational studies reported use of intracoronary stents to treat both suboptimal results and complications occurring in patients undergoing primary PTCA during AMI. Due to the thrombogenic nature of intracoronary stenting, combined antiplatelet therapy is recommended after stent placement in patients with acute myocardial infarction (72). Recently, two trials comparing primary PTCA and primary stenting in AMI have shown less mortality, angina and re-interventions after intracoronary stenting $(73,74)$.

\section{NON INVASIVE REPERFUSION MARKERS IN ACUTE MYOCARDIAL INFARCTION}

If rescue PTCA is considered indicated in case of failed thrombolysis, unnecessary coronary angiography can be avoided if non-invasive signs of reperfusion are of value to select the patient who is (no) candidate for acute coronary angiography. Several tests have been proposed to diagnose reperfusion, all having limited specificity and sensitivity (75-77). To date no thrombolytic agent or combination of agents has consistently achieved reperfusion rates in excess of $75 \%$ to $80 \%$ when evaluated at up to 90 minutes after administration. Establishing successful thrombolysis is important. In recent years much research thas been directed towards development of sensitive non-invasive reperfusion markers (75-77).

A rapid and complete resolution of ST-segment elevation correlates most accurately with reperfusion. This was found to occur in only $6 \%$ of patients with AMI (76). Partial reduction of ST-segment deviation to $\geq 50 \%$ of the initial level of 
ST-segment elevation occurs more frequently and has, especially in combination with other ECG criteria, also, important predictive value with respect to reperfusion and prognosis $(76,78)$. Other clinical indicators (decrease of chest pain) or electrocardiographic signs (development of terminal negative $T$-wave in infarct leads, accelerated idioventricular rhythm (AIVR), restoration of atrioventricular conduction, increase in ventricular arrhythmia's) have either a low sensitivity or a low specificity to predict infarct vessel patency $(79,80)$. Many small sized studies evaluating the value of reperfusion parameters have been conducted. The limited number of patients, the variable interval between non-invasive evaluation and angiographic validation of reperfusion status, and the frequently retrospective nature of these studies indicate the need to find new ways to obtain rapid and reliable non-invasive parameters of reperfusion.

\section{FUTURE DEVELOPMENTS}

One of our largest problems is that even aggressive therapy for myocardial infarction can prevent only $5 \%$ of the total number deaths from acute myocardial infarction, because most patients will die suddenly before any type of treatment can be initiated (81). Swift hospitalization, fast therapy (prehospital thrombolysis) will certainly be beneficial in reducing total death. However the majority of the patients do not experience cardiac complaints before the onset of acute myocardial infarction and therefore cannot be recognized beforehand.

Considerable effort and large sums of money are spent on constructing a risk profille for sudden death in the myocardial infarction survivor at the time of discharge from hospital. However the majority of sudden death victims cannot be identified before the event $(81,82)$.

Future developments might influence the outcome of the treatment strategies performed in the three treatment groups as discussed previously. Newer thrombolytic agents with different points of action resulting in higher patency will soon be available $(83,84)$. Newer thrombin inhibitors might replace heparin, and platelet aggregation inhibitors like glycoprotein IIb/IIIa receptor antagonists added to heparin can lead to higher sustained patency and lower reocclusion rates (85-90). This development can improve the outcome of patients treated with thrombolytic therapy and might decrease the need for rescue PTCA. On the other hand the implementation of new indications of coronary stenting may positively influence success rate of both primary and rescue PTCA $(74,91)$. The net effect of these changes will have to be demonstrated in future studies. 


\section{REFERENCES}

1. Davies MJ. Anatomic fearures in victims of sudden coronary deach: coronary artery pathology. Circulation 1992;85:suppl 1:119-124.

2. Tilet WS, Garner R. The fibrinolyric activity of hemolytic streptococci. J Exp Med 1933; 58:485-502.

3. Tilert WS, Sherry S. The effect in parients of streprococcal fibrinolysin and streptococcal desoxyribonuclease on fibrinous,purulent and sanguinous pleural exsudations. J Clin Invest $1949 ; 28: 173-1.90$.

4. Verstraete $M$, Vermylen $\mathbb{J}$, Amery $A$, et al. Thrombolytic therapy with streptokinase using a standard dosage scheme. Br Med \1966:85:4544-45:6.

5. Hirsh J, O' Sulliwan EF, Martin M. Evaluation of a standard dosage schedule with streptokinase. Blood 1970;35:341-349.

6. Simoons ML, et al. Long-term benefit of early thrombolytic therapy in patients with acute myocardial infarction: 5 year follow-up of a trial conducted by the Interuniversity Cardiology Institute of The Netherlands. JACC 1989;14: 1609-1615.

7. Gruppo Italiano per lo Studio della Streptochinasi nell'infarto Miocardico (GISSI): Effectiveness of intravenous thrombolytic treatment in acute myocardial infarction. Lancet 1986;1:397-402.

8. ISIS-2 (Second International Study of Infarct Survival). Collaborative Group: Randomized trial of intravenous streptokinase, oral aspirin, both, or neither among 17,187 cases of suspected acute myocardial infarction: ISIS-2. Lancet 1988;2:349-60.

9. Wilcox RG, von der Lippe $G$, Olson $C G$, et all. Trial of tissue plasminogen activator for mortality reduction in acute myocardial infarction. Lancet 1988;2:525-530.

10. Schröder $\mathbb{R}$, Neuhaus $K{ }_{\text {; }}$ Leizorovicz $A$, et al. A prospective placebo-controlled double blind multicenter trial of intravenous streptokinase in acute myocardial infarction (ISAM): Long-term mortality and morbidity. J Am Coll Cardiol 1987;9:197-203.

11. AIMS Trial Study Group: Effect of intravenous APSAC on mortality after acute myocardial infarction: Prelininary report of a placebo-controlled clinical trial. Lancer 1988;1:545-549.

12. Kennedy JW, Ritchie JL, Davis KB, Friz JK. Western Washingron randomised trial of intracoronary streprokinase in acute myocardial infarcrion. N Engl J Med 1983;309:1477-1482.

13. Simoons ML, Serruys PW, van den Brand M, er al. Early thrombolysis in acute myocardial infarction: limitarion of infarce size and improved survival. J Am Coll Cardiol 1986;7:717-728.

14. Topol EJ, Califf RM, George BS, er al. A randomised trial of immediare versus delayed elective angioplasty after intravenous tissue plasminogen activator in acute myocardial infarction. $N$ EngL J Med 1987;317:581-588.

15. TIMI Study Group: Thrombolysis in Myocardial Infraction (TIMI) trial. N Engl J Med $1985 ; 312: 932-936$.

16. Neuhaus $\mathrm{KL}$, Tebbe $\mathrm{U}$, Gottwik $\mathrm{M}$, et al. Intravenous recombinant tissue plasminogen activator (rt-PA) and urokinase in acute myocardial infarction: results of the German Actiwator Urokinase Study (GAUS). J Am Coll Cardiol 1988;12:581-587.

17. Hogg, $\mathbb{K J}$, Gemmill JD, Burns JM, et al. Angiographic patency study of anistreptilase wersus streprokinase in acute myocardial infarction. Lancet 1990;335:254-258. 
18. Verstracte $M$, Bernard $R$, Bory $M$, et al. Randomised trial of intravenous recombinant tissue-type plaminogen activator versus intravenous streptokinase in acute myocardial infarcrion: report from the European Cooperarive Study Group for Recombinant Tissue-Type Plasminogen Activator. Lancet 1985;1:842-847.

19. Topol E], Califf RM, George BS, et al, and the TAMI Study Group. Coronary arterial thrombolysis with combined infusion of recombinant tissue-type plasminogen activator and urokinase in patients with actute nayocardial infarction. Circulation 1988;77:1100-1107.

20. Neuhaus KI, Feuerer W, Jeep-Tebbe $S$, et al. Improved thrombolysis with a modified dose regimens of recombinant rissue-type plasminogen activator. I Am Coll Cardiol 1989;14: 1566-1569.

21. PRIMI trial study group. Randomized double-blind trial of recombinant prourokinase against streptokinase in acute myocardial infarction. Launcet 1989;1:863-868.

22. Bär FW, for the SESAM study group. Comparison of saruplase and alteplase in myocardial infarction. Am J Cardiol 1997;79:727-732.

23. The GUSTO Angiographic Investigators. The effect of tissue plasminogen activator, streptokinase, or both on coronary patency, ventricular function and surwival after acute myocardial infarction. $\mathrm{N}$ Engl J Med 1993;329:1615-1622.

24. Califf RM, Topol EJ, Stack RS, et al. Ewaluation of combination thrombolytic therapy and timing of cardiac catheterization in acute myocardial infarction: results of thrombolysis and angioplascy in acute myocardial infarction- phase 5 randomized trial. Circulation 1991;83:1543-1556.

25. Topol E], Morris DC, Smalling RW, et al. A multicenter,randomised, placebo-controlled trial of a new form of recombinant tissue-type plasminogen activator (Activase) in myocardial infarction. If Am Coll Cardiol 1987;9:1205-1213.

26. Chesebro JH, Knatterud $G$, Roberts $R$, et al . Thrombolysis in Myocardial Infarction (TIMI) trial, phase 1: a comparison between intravenous tissue plasminogen activator and intravenous streptokinase. Circulation 1987;76:142-154.

27. The GUSTO Investigators. An interventional randomized trial comparing four thrombolytic strategies for acute myocardial infarction. N Engl] Med 1993;329:673 -682.

28. Weaver WD, Cerqueira $A_{*}$ Hallstrom AP, et al. Prehospital initiated versus hospital associated. thrombolytic therapy. The myocardial infarction triage and interventional trial. IAMA $1993 ; 270: 1211-1216$

29. The European Myocardial Infarction Project Group. Pre-Hospital thrombolytic therapy in parients with suspected acute myocardial infarction. N Engl J Med 1993;329:383-389.

30. Great group. Feasability, safery, and efficacy of domiciliary thrombolysis by general practitioners: Grampian Region Early Anistreptolase Trial. BMJ 1992;305:548-553.

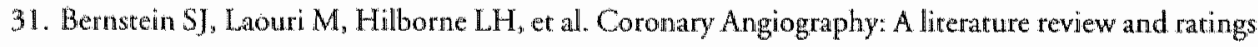
of appropriateness and necessity. Santa Monica, CA: RAND,1992.

32. The International Study Group. In-hospital mortality and clinical course of 20.891 pacients with suspected acute myocardial infarction randomised between alteplase and streptokinase with and without heparin. Lancet 1990;336:71-75.

33. DeWood MA, Spores J. Notske R, et al. Prevalence of total coronary occlusion during the early hours of transmural myocardial infarction. N Engl J Med 1980;303:897-902. 
34. Simoons ML, Arnold AER, Betriu A, et al. Thrombolysis with tissue plasminogen in acute myocardiall infarction: no additional benefit from immediate percutineous angioplasty. Lancet 1988;1:197-203.

35. The TIMI Research Group. Immediate wersus delayed catheterization and angioplasty following thrombolytic therapy for acute myocardial infarction. TIMI 2A results. IAMA 1988;260: 2849-2858.

36. Topol E], Textbook of interventional cardiogy. Philadelphia: Saunders, 1993.

37. SWIFT trial of delayed elective intervention ws conservative treatment with anistreptolase in acute myocardial infarction. SWIFT (Should We Intervene Following Thrombolysis?) Trial Study Group. BMJ 1991:302:555-60.

38. Muller DW, Topol EJ, Eilis SG, et al. Dererminants of the need for early acute intervention in patients treated conservatiwely after thrombolytic therapy for acute myocardial infarction. TAM1-5 Study Group. I Am Coll Cardiol 1991;18:1594-601.

39. Meier B. Balloon angioplasty for acute myocardial infarction. Was it buried alive? Circulation $1990 ; 82: 2243-2245$.

40. Belenkie I, Traboulsi M, Hall CA, et al. Rescue angioplasty during myocardial infarction has a beneficial effect on mortality: a tenable hyporhesis. Can J Cardiol 1992;8:357-62.

41. Ellis SG, Ribeiro-daSilva $E$, Heyndrickx $G$, et al. Randomized comparison of rescue angioplasty with conservative management of patients with early failure of thrombolysis for AMI. Circulation 1994:90:2280-2284.

42. Ellis SG, Werf van de F, Ribeiro-daSilva $\mathrm{E}$, er al. Present status of rescue coronary angioplasty: Current polarization of opinion and randomized trials. I Am Coll Cardiol 1992;19:681-681.

43. Ellis SG, Oneill WW, Bates ER et al. Implications for patient triage from survival and left ventricular functional recovery analysis in 500 patients treated with coronary angioplasty for acute nyocardial infarction. J Am Coll Cardiol 1989;13:1251-1259.

44. Hartzler GO, Rutherford BD, McConahay DR et al. Percutaneous transluminal coronary angioplasty with and without thrombolytic therapy for treatment of acute myocatial infarction. Am Heart J 1983; 106:965-73.

45. Papapietro SE, Maclean WAH, Stanley AWH, et al. Percutaneous transluminal coronary angioplasty after intracoronary screptokinase in evolving acute myocardial infarction. Am J Cardiol 1985;55:48-53.

46. Fung AY, Lai P, Topol EJ et al. Value of percutaneous transluminal angioplasty after unsuccessful intravenous streptokinase therapy in acure myocardial infarction. A.m J Cardiol 1986:58:686-691.

47. Abbottsmith CW, Topol E], George BS et al. Fate of patients with acute myocardial infarction with patency of the infarct related vessel achieved wirh successful thrombolysis versus rescue angioplasty. 1 Am Coll Cardiol 1990;16:770-778.

48. Topol EJ, Califf RM, George BS, et al. and the TAMI Study Group. Coronary artery thrombolysis with combined infusion of recombinant tissue type plasminogen acrivator and urokinase in parients with acute myocardial infarcrion. Circulation 1988;77:1100-11.07.

49. Bär FW, Oude Ophuis AJM, Frederiks J, et al. Rescue PTCA following failed thrombolysis and primary PTCA: A retrospective study of angiographic and clinical outcome. J Thrombosis and Thrombolysis 1997:4:281-288. 
50. DeWood MA, for the Spokane Heart Rescarch Group. Direct PTCA yersus intravenous a-tPA in acute myocardial infarction: Preliminary results from a prospecrive randomized trial. Circulation $1989 ; 80: 2-1663$.

51. Grines $\mathrm{CL}_{\text {. Browne }} \mathrm{KF}^{2}$, Marco J, et all, for the Primary Angioplasty in Myocardial Infarction Study Group. A comparison of inmediate angioplasty with thrombolytic therapy for acnte myocardial infarction. N Engl J Med 1993;328:673-679.

52. Gibbons RJ, Holmes DR; Reeder $G S$, et al. Immediate angioplasty compared with the administration of a thrombolytic agent followed by conservative treatment for myocardial infarction. N Engl J Med 1993;328:685-691.

53. Ribeiro EE, Carnetro R, Dóliveira LG, et al. A randomised trial of direct PTCA versus intravenous streptokinase in acute myocardial infarction. J Am Coll Cardiol 1991:17:152.

54. Zijlstra F, de Boer MJ, Hoorntje JCA, et al. A comparison of immediate coronary angioplasty with intravenous streptokinase in acute myocardial infarction. N Engl J Med 1993;328:680-684.

55. The Global Use of Strategies to open occluded coronary arceries in acute coronary syndromes (Gusto IIb)angioplascy substudy investigators: A clinical trial comparing primary coronary angioplasty with tissue plasminogen activator for acute myocardial infarction. $\mathbb{N}$ Eng J Med $1997 ; 336: 1621-8$.

56. Michels KB, Yusuf S. Does PTCA in acute myocardial infarction affect mortality and reinfarction rates. Circulation 1995;91:476-485.

57. Reifart N, Schwartz F., Preusler W, et al. Results of PTCA in more than 5000 parients wirhout surgical standby in the same center. J Am Coll Cardiol 1992;19:229A.

58. Ryan T], Gunnar RM, et al. Guidelines for PTCA. A report of the ACC/AHA Task Force on assesment of diagnostic and therapeutic cardiovascular procedures. I An Coll Cardiol 1988;12:529.

59. Oude Ophuis AJ, Bär FW. Rescue PTCA in Nederland. War, Waar, Whe en Wanneer? Cardiologie 1998,5:233-237.

60. Zijlstra F, Beukema WP, van't Hof As er al. Randomised comparison of primary coronary angioplasty with thrombolytic therapy in low risk patients with acute myocardial infarction. J Am Coll Cardiol 1997:29:908-912.

61. Hart en watziekten in Nederland 1995. Cijfers ower ziekte en sterfte Nederlandse Hartstichting. Gegevens wan het Central Bureau voor de Staristiek, SIG Zorginformatie en her Rijksinstituut woor de volksgezondheid en milieulinggiene. Den Haag, 1995.

62. Craver IM, Weintraub WS, Jones EL, et al. Emergency coronary artery bypass surgery for failed percuraneous coronary angioplasty: a 10-year experience. Ann Surg 1992;21 5:425-434.

63. Borkon AM, Failing TL, Piehler JM, et al. Risk analysis of operative intervention for failed. coronary angioplasry. Ann Thorac Surg 1983;35;325-529.

64. Barner HB, Len JW, Naunheim KS, et al. Emergency coronary bypass not associated with preoperative cardiogenic shock in failed angioplasty, after thrombolysis, and for acute myocardia! infarction. Circulation 1989;79:I-152-I-159.

65. Efstratiadis T, Munsch C, Crossman $\mathrm{D}_{3}$ er al. Aprotonin used in emergency coronary operation afrer streptokinase treatment. Ann Thorac Surg 1991;52:1320-1321. 
66. Kirklin JK, Akins CW, Blackstone $\mathbb{E H}$ et al. Guidelines and indications for coronaty artery bypass graft surgery. J AM Coll Cardiol. 1991;17:543-589.

67. Creswell LL, Moulton MJ, Cox JL, et al. Revascularization after acute myrocardial infarction. Ann Thorac Surg 1995; 60:19-26.

68. Braxton JH, Hammond GL, Letsou GV, et al. Optimal timing of coronary artery bypass graft surgery after acute myocardial infarction. Circulation 1995;92:1166-68.

69. Neumann FJ, Walter H, Richardt G, et al. Coronary Palmat Schatz srent implantation in acute myocardial infarction. Heart 1996;75:121-126.

70. Rodriguez AE, Fermandez $M$, Santaera $O_{n}$ et al. Coronary stenting in patients undergoing percuraneous transluminal coronary angioplasty during acute myocardial infarction. Am I Cardiol 1996;77:685-689.

71. Garcia E, Spaulding C, Corcos T, et al. Stent implantation in acute myocandial infarcrion. Am J Cardioll $1996: 77: 451-454$.

72. Schomig A, Neumann FJ, Walter $H$, et al. Coronary stent placement in parients with acute myocardial infarction: Comparison of clinical and angiographic outcome after randomization to antiplareler or anticoagulant therapy. I Am Coll Cardiol 1997;29:28-34.

73. Antoniucci D, Santoro GM, Bolognese L er al. A prospective randomised trial of elective stenting in acute myocardial infarction. Preliminary resulrs of the FRESCO study. Circulation $1997 ; 96,8: 1-327$.

74. Suryapranata $\mathrm{H}$, Hoornge JCA, Boer MJ de et al. Randomised comparison of coronary stenting with balloonangioplasty in selected patients with acute myocardial infarction. Circulation $1998 ; 97: 2502-2505$.

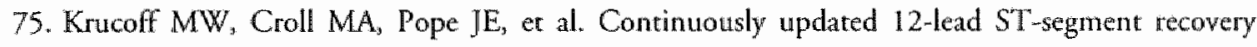
analysis for myocardial infarct artery patency assessment and its correlation wich multiple simultaneous early angiographic observations. Am J Cardiol 1993; 71: 145-151.

76. Doevendans PA, Gorgels AP, Van der Zee R, et al. Elecrrocardiographic diagnosis of reperfusion during thrombolytic therapy in acute myocardial infarction. Am J Cardiol 1995:75:1206-1210.

77. Klootwijk P, Langer $A_{\text {. }}$ Meij $S$, et al. Non-invasive prediction of reperfusion and coronary artery patency by continuous ST-segment monitoring in the GUSTO-1 trial. Eur Heart I $1996 ; 17: 689-698$.

78. Hof van het AW, Liem A, Boer de MJ, Zijlstra F. Clinical walue of 12-lead electrocardiogram after successful reperfusion therapy for acute myocardial infarction. Lancet 1997:350:615-619.

79. Califf RM, O'Neill W, Stack RS, et al. Failure of simple clinical measurements ro predict perfusion status after intrawenous thrombolysis. Ann Intern Med 1988; 108: 658-662.

80. Kircher RJ, Topol EJ, ONeill WW, et al. Prediction of infarct coronary artery recanalizarion after intravenous thrombolytic therapy. Am J Cardiol 1987:59:513-515.

81. Wellens HJJ, de Vreede J, Gorgels AP. Sudden cardiac death. How to reduce he number of wictims? Eur Heart J 1995; 16:7-9.

82. Manfredini R, Portaluppi F, Grandi $\mathbb{E}$, et all. Our of hospital sudden death referring to an emergency department. J Clin Epidimiol 1996;49:865 868.

83. Bär FW, Meyer J, Vermeer F, et al. Comparison of saruplase and alteplase in acute myocardial infarction. Am J Cardiol 1997;79:727-732. 
84. Hejer den P, Vermeer F, Ambrosioni $E$ ex al. Evaluation of a weight-adjusted single-bolus plasminogen activator in patients with myocardial infarction: a double-blind, randomized angiographic trial of lanetoplase wersus alteplase. Circulation 1998;98(20):2117-2125.

85. Topol E], for the GUSTO investigators. A compatison of recombinant hirudin with heparin for the trearment of acute cotonary syndromes. N Engl J Med 1996;335:775-782.

86. The EPIC investigators. Use of a monodonal antibody directed against the plateler glycoprotein IIb/IIIa receptor in high risk coronary angioplasty. N Engl J Med 1924;330:956-961.

87. Epilog Investigators. Effect of the platelet glycoprotein IIb/IIla receptor inhibiror abciximab with lower heparin dosages on ischemic cornplicarions of percutaneous coronary revascularization. $N$ Engl J Med 1997;336:1689-96.

88. Brener S1, Barr LA, Cohen ED er al. Abciximab reduces urgent target revascularization at 30 days after primary angioplasty, independently of acute angiographic results. The RAPPORT trial. I Am Coll Cardiol 1998:31:54A.

89. Antman EM, Giugliano RP, MoCabe er al. Abciximab (Reopro) potentiates thrombolysis in $5 T$ elevation myocardial infarction: results of the TIMI 14 trial. J Am Coll Cardiol 1998;31:191.A.

90. The EPISTENT investigators. Randomised placebocontrolled and balloon-angioplasty-controlled trial to alssess safety of coronary stenting with use of platelet glycoprotein IIb/IIIa blockade. Evaluation of platelet IIb/IIla inhibitor for stenting. Lancet 1998;352:87-92.

91. Gibson $M$, Rizzo MJ, Mdean $C$ et al. Adjunctive stenting following thrombolysis in TIMI 10A8xB. Circulation 1997;96,8:1-328. 
CHAPTER 3

\section{Rescue PTCA following failed thrombolysis and primary PTCA}

A retrospective study of angiographic and clinical outcome

Bär FW, Oude Ophuis AJ, Frederiks J, Swart de HB, Ommen van VG, Zwaan de $C_{\text {, }}$ Vermeer F, Gorgels AP, Wellens HJJ

Department of Cardiology, University Hospiral Maastricht, Maastricht, the Netherlands 


\section{ABSTRACT}

Background: Evidence is increasing that a patent culprit artery improves the prognosis of patients with acute myocardial infarction (AMI). Primary PTCA has shown to be more effective than thrombolytic therapy alone. How effective is rescue PTCA after failed thrombolytic treatment?

Methods: In a retrospective analysis, 176 consecutive patients with AMI and TIMI 0 or 1 perfusion grade were included. Patients had either rescue PTCA after failed thrombolysis (100 patients) or primary PTCA (76 patients). Angiographic data and in-hospital and one year outcome were analyzed.

Results: Comparison of baseline data of the two groups showed a higher proportion of long standing angina and use of nitrates and aspirin in the primary PTCA group, also the delay between anset of pain and PTCA was not significantly different: rescue PTCA mean 222 minutes, primary PTCA mean 245 minutes $(p=0.52)$.

The angiographic outcome in the rescue PTCA group and the primary PTCA group was identical: the intervention was successful (TIMI 3 flow and residual stenosis $<50 \%$ ) in $86.0 \%$ and $85.5 \%$ respectively. Complication rates of the procedure were also similar except for bleeding complications. Blood transfusion was only needed after rescue PICA: $3.0 \%$ vs $0.0 \%$ in primary PTCA patients. Clinical outcome during hospital stay in terms of death rate $(4.0 \%$ and $6.6 \%)$, re-infarction $(6.0 \%$ and $3.9 \%)$, recurrent angina $(16.0 \%$ and $11.8 \%$ ) and repeat interventions were comparable as was the first year outcome. Failed PTCA was the most important predictor of a poor one year outcome: $28.0 \%$ died after failed PTCA versus $4.6 \%$ after successful PTCA ( $p<$ $0.001)$.

Conclusion: In this retrospective analysis with 176 AMI patients, angiographic and dinical outcome, including a one year follow-up in patients who had rescue PTCA after faited thrombolysis were of the same magnitude of patients in whom primary PTCA was performed. These findings suggest that in this subset the outcome of patients with rescue PTCA because of failed thrombolysis is goad and comparable to patients who underwent primary PTCA. 


\section{INTRODUCTION}

In recent years it has become clear that re-opening of the occluded coronary artery in acute myocardial infarction (AMI) is a key factor determining clinical outcome (1), Because thrombosis is the most common cause for the obstruction, thrombolysis has become the therapy of choice. This type of treatment has shown to be reasonably effective: patency (TIMI 2-3) of the culprit vessel can be achieved in 50-90\% at 90 minutes after the start of therapy, but drawbacks of thrombolytic therapy are severe bleeding complications like intracranial hemorrhage (2-22).

Therefore, primary PTCA was advocated as a safe, fast, but also as a more successful alrernative (19). After primary PTCA, patency rates above $90 \%$ and a low incidence of complications were reported (23-29). In addition, three studies have been published indicating that also in randomized trials primary PTCA is more effective than thrombolytic therapy (30-32).

The value of rescue PTCA in addition to failed thrombolysis has so far inadequately been studied. The RESCUE study $(33,34)$ and the TAMI V study (23) suggest that thrombolysis and rescue PTCA if indicated might be better than thrombolytic therapy only.

One of the questions remaining is, how effective is rescue PTCA after failed thrombolysis when compared with primary PTCA. To study safety and efficacy of both strategies, a retrospective analysis was performed of patients with AMI. All patients admitted between 1986 and 1992 who had PTCA in the acute phase of AMI were included. One hundred patients had rescue PTCA and 76 patients in whom thrombolytic therapy was withheld primary P'TCA was done. Not only on the clinical outcome, but also on the complications of the angiography and PTCA will be reported because conflicting data have been published on the angiographic outcome of immediate P'TCA after thrombolysis (19,30,33-54).

\section{METHODS}

In our hospital, patients with typical clinical and electrocardiographic signs of an AMI are treated with thrombolytic therapy if the chest pain lasts for $\geq 30$ minutes. Initially, only patients $\leq 70$ years were treated with thrombolytic therapy in case treatment delay was $\leq 4$ hours. At later stage, the upper age criterium increased to 85 years and the delay to 6 hours. Electrocardiographic criteria for an intervention were: ST-segment elevation $\geq 1 \mathrm{~mm}$ in at least two extremity leads and ST-segment elevation $\geq 2 \mathrm{~mm}$ in at least two precordial leads. Most of the patients in this retrospective analysis were included in thrombolysis studies $(16,17,48)$. AMI parients, who had a contra-indicarion for thrombolysis or in whom this therapy was withheld for orher reasons, had primary PTCA in case the ECG was suggestive for a moderate to large AMI.

In our institution, catheterization service is available on a 24 -hour basis. 


\section{MEDICATION}

Rourine trearment of our infarct population was as follows: parients were given intravenous nitroglycerin, heparin as a bolus of $5,000 \mathrm{U}$ before thrombolytic therapy, followed by an intravenous heparin drip titrated according to the activated partial thromboplastin time (2-2.5 times normal value). Since 1988, patients were also pretreated with aspirin. Thrombolysis patients received one of the following thrombolytic agents: streptokinase, alteplase, APSAC or saruplase in the recommended dosages. In approximately $20 \%$ of the thrombolysis patients admitted to our hospital rescue PTCA was performed in the period analyzed.

\section{CARDIAC CATHETERIZATION}

All patients had cardiac catheterization within 90 minutes after admission. At that time, another $5000 \mathrm{U}$ of heparin was given. If thrombolytic therapy was withheld or if this treatment failed, PTCA was performed routinely when the TIMI perfusion grade was 0 or 1 . Patients with higher perfusion grades were not considered to be candidates for acute PTCA because of the results of the TIMI 2 Trial and the European Cooperative Study $(34,35)$ PTCA was also not performed if it appeared unlikely that the patient would benefit from PTCA because of a small area perfused by the occluded artery. In patients with significant main stem disease bypass surgery was recommended. Rescue PTCA was performed 90 minutes after the start of thrombolytic therapy, primary PTCA as soon as possible.

Successful PTCA was defined as good flow (TIMI 3) and a residual stenosis of $<50 \% 10$ minutes after the last balloon inflation. After successful PTCA, an addirional bolus of $15,000 \mathrm{U}$ heparin and $300 \mathrm{mg}$ iv aspirin was given.

\section{CLINICAL FOLLOW-UP}

All parients were followed during the first year after myocardial infarction in the out patient clinic. Data on outcome during admission and the period thereafter during the first year will be given separately. Follow-up angiography was only done when clinically indicated.

\section{STATISTICAL ANALYSIS}

Continuous variables are expressed as mean $\pm \mathrm{SD}$ and are compared by use of Student's $\mathrm{t}$ test. Non-continuous variables were compared by use of the chi square rest. A p value $<0.05$ was considered statistically significant. 


\section{RESULTS}

Baseline characteristics of the 176 patients are given in table 1 . The reasons to withhold thrombolytic treatment and to perform primary PTCA are listed in table 2 . Patients with primary PTCA had more frequent long standing angina and, as a consequence, more medication. Due to the presence of long standing angina, 17 patients had a recent catheterization. The decision to perform primary PTCA in these 17 patients was partially based on the higher risk of a bleeding complication in the groin, but also because coronary anatomy was already known. Their outcome was similar to the total group. Time delay between onset of chest pain and admission was significantly longer in the patients with primary PTCA, mainlly due to the 8 patients with a long delay ( $>6$ hours) berween onset of chest pain and admission. All 8 patients still had signs of ongoing ischemia. The mean delay between pain and start of PTCA for the rescue PTCA patients was 222 minutes ( \pm 124 minutes) and 245 minutes ( \pm 282 minutes) for primary PTCA patients ( $\mathrm{p}=0.52$ ).

\section{ANGIOGRAPHIC OUTCOME}

The angiographic outcome in the two PTCA groups was comparable (Table 3). We were able to open more than $90 \%$ of the occluded arteries. However, not uncommonly such thrombotic or dissected lesions had a tendency to reocclude. Therefore, final patency at the end of the procedure was slightly lower: approximately $86 \%$ for both groups. Complication rates during this procedure were also similar.

\section{CLINICAL AND ONE YEAR OUTCOME}

During hospital stay, 3 patients, all treated with a thrombolytic agent, had a severe bleeding complication and needed blood transfusion (Table 4). Other clinical events were equally distributed between both groups. None of the patients suffered a cerebrovascular accident. In the patients who were offered rescue PTCA, 4 parients thad re-PTCA because of recurrent myocardial infarction 2 other patients had re-PTCA because of recurrent angina; in the primary PTCA group 3 patients had re-PTCA all 3 because of re-infarction. Coronary artery bypass surgery was performed on an elective basis in one patient in each group because of failed PTCA and in 4 patients ( 1 rescue PTCA and 3 primary PTCA patients) on an emergency basis, because of acute recurrent ischemia without Q-wave infarction. Total in-hospital mortality was low $(5.1 \%)$ and there were no significant differences between the two groups. In the first year after discharge, clinical outcome was also comparable between both groups. Interestingly, in the first year total mortality was slightly lower in patients treated with rescue PTCA: 5 patients $(5.0 \%)$, versus 9 primary PTCA patients (11.8\%) ( $\mathrm{p}=0.17)$. 
$30 \mid$ CHAMTER 3

Table 1. Demographic, clinical, and angiographic data of the 176 myocardial infarction patients having acure PTCA with or without thrombolytic therapy

\begin{tabular}{|c|c|c|c|c|c|}
\hline & \multicolumn{2}{|c|}{ Rescue PTCA } & \multicolumn{2}{|c|}{ Prúmary" PTCA } & \multirow[b]{2}{*}{ P-vallue } \\
\hline & $\mathrm{N}$ & {$[\%]$} & $N$ & {$[\%]$} & \\
\hline All patients & 100 & {$[100]$} & 76 & {$[100]$} & \\
\hline Mean age (years $\pm S D$ ) & 58 & {$[ \pm 11]$} & 57 & {$[ \pm 12]$} & 0.56 \\
\hline Males & 80 & {$[80.0]$} & 62 & 81.6 & 0.94 \\
\hline Previous MI.>1 month & 26 & {$[26.0]$} & 26 & [34.2] & 0.31 \\
\hline Long-standing angina & 41 & {$[0.41]$} & 47 & {$[61.8]$} & 0.01 \\
\hline Recent-onset angina & 6 & {$[6.0]$} & 5 & $\llbracket 6.6]$ & 0.87 \\
\hline Dyspreat & 5 & {$[5.0]$} & 8 & {$[10.5]$} & 0.27 \\
\hline \multicolumn{6}{|l|}{ Medication before admission } \\
\hline Nitrate & 18 & {$[18.0]$} & 29 & {$[38.2]$} & 0.005 \\
\hline Calcium antagonist & 21 & {$[21.0]$} & 21 & $27.6]$ & 0.39 \\
\hline Beta-blocker & 23 & {$[23.0]$} & 25 & {$[32.9]$} & 0.19 \\
\hline Asprin & 10 & {$[10.0]$} & 20 & {$[26.3]$} & 0.008 \\
\hline No medication & 57 & {$[57.0]$} & 35 & {$[46.0]$} & 0.19 \\
\hline \multicolumn{6}{|l|}{ Infarci locarion } \\
\hline Anterior & 52 & {$[52.0]$} & 42 & {$[55.2]$} & 0.78 \\
\hline Inferior & 48 & {$[48.0]$} & 34 & {$[44,7]$} & \\
\hline \multicolumn{6}{|l|}{ Delays } \\
\hline Pailn-admission (mean $\pm S D$ ) & 100 & \pm 98 & 175 & \pm 280 & 0.03 \\
\hline Pain-admission (median) & 60 & & 90 & & 0.03 \\
\hline Pain-thrombolysis (mean $\pm \mathrm{SD}$ ) & 132 & \pm 110 & \multicolumn{3}{|c|}{ not performed } \\
\hline Pain-PTCA (mean + SD) & 222 & \pm 124 & 245 & \pm 282 & 0.52 \\
\hline Pain-PTCA (median) & 190 & & 155 & & 0.52 \\
\hline \multicolumn{6}{|l|}{ Culprit wessel } \\
\hline RCA & 34 & {$[34.0]$} & 22 & {$[28,9]$} & \\
\hline LAD & 47 & {$[47.0]$} & 40 & {$[52.6]$} & \\
\hline $\mathrm{CX}$ & 12 & $\llbracket 12.0 \rrbracket$ & $\llbracket 3$ & {$[17.1]$} & 0.53 \\
\hline Graft & 7 & {$[7.0]$} & 1 & {$[1.3]$} & \\
\hline
\end{tabular}

$\mathrm{RCA}=$ right coronary artery; $\mathrm{LAD}=$ left anterior descending artery; $\mathrm{CX}=$ circumflex artery. PTCA $=$ percutaneous trans/uminal coronary angioplasty. 
Table 2. Reasons to withhold thrombolytic therapy in the 76 inyocardial infarction patients who underwent primary PTCA

\begin{tabular}{lcc}
\hline & N & {$[\%]$} \\
\hline Recent cathererization & 17 & {$[22.4]$} \\
Recent gastro-intestinal bleeding & 17 & {$[22.4]$} \\
Prolonged resuscitation & 12 & {$[15.8]$} \\
Delay pain-admission >6 hours & 8 & {$[10.5]$} \\
Recent cerebro vascular accident & 4 & {$[5.3]$} \\
Indury due to collaps & 4 & {$[5.3]$} \\
Recent surgery & 1 & {$[1.3]$} \\
Possible aortic dissection & 1 & {$[1.3]$} \\
Personal preference & 12 & {$[15.8]$} \\
\hline
\end{tabular}

Table 3. Angiographic results of acute PTCA in the 176 myocardial infarction parients with or without thrombolyric therapy

\begin{tabular}{lcccccc}
\hline & \multicolumn{2}{c}{ Rescue PTCA } & & \multicolumn{2}{c}{ Immediate PTCA } & \\
\cline { 2 - 3 } & $\mathrm{N}$ & {$[\%]$} & & $\mathrm{N}$ & {$[\%]$} & P-value \\
\hline All & 100 & {$[100]$} & & 76 & {$[100]$} & \\
Initiall success & 92 & {$[92.0]$} & & 70 & {$[92.1]$} & 0.79 \\
Final success* & 86 & {$[86.0]$} & & 65 & {$[85.5]$} & 0.89 \\
Diameter stenosis last view $( \pm S D)$ & 38.2 & \pm 29 & & 38.3 & \pm 30 & 0.98 \\
Severe dissection & 5 & {$[5.0]$} & & 3 & {$[3.9]$} & 0.97 \\
Reocclusion & 3 & {$[3.0]$} & & 3 & {$[3.9]$} & 0.93 \\
Coronary emboh & 3 & {$[3.0]$} & & 5 & {$[6.6]$} & 0.44 \\
\hline
\end{tabular}

* TIMI flow 3 and srenosis $<50 \%$.

\section{PREDICTORS FOR ONE YEAR MORTALITY}

Fourteen of 176 patients $(8.0 \%)$ who underwent PTCA died during the first year after myocardial infarction (Table 5). In this limited group of patients failed PTCA was the only predictor for death: 7 of 25 patients $(28.0 \%)$ with an unsuccessful procedure died versus only 7 of 151 patients $(4.6 \%)$ with a successful PTCA. Other well known factors influencing mortality, like anterior wall AMI, PTCA of a graft, and recurrent infarction were of insufficient power to predict mortality, indicating the overwhelming influence of failed PTCA on mortality. 
$32 \|$ CHAMTER 3

Table 4. Clinical outcome of acute PTCA in the 176 myocardial infarction parients with or without thrombolytic therapy

\begin{tabular}{|c|c|c|c|c|c|}
\hline & \multicolumn{2}{|c|}{ Rescue PTCA } & \multicolumn{2}{|c|}{ Primary PTCA } & \multirow[b]{2}{*}{$P$-value } \\
\hline & $N$ & {$[\%]$} & $\mathrm{N}$ & {$[\%]$} & \\
\hline All & 100 & {$[100]$} & 76 & {$[100]$} & \\
\hline \multicolumn{6}{|l|}{ During admission } \\
\hline Death & 4 & $\llbracket 4.0 \rrbracket$ & 5 & {$[6.6]$} & 0.67 \\
\hline Recument myocardial infarction & 6 & {$[6.0]$} & 3 & {$[3.9]$} & 0.79 \\
\hline Recurrent angina & 16 & {$[16.0]$} & 9 & {$[11.8]$} & 0.57 \\
\hline CABG or (re)-PTCA & 8 & {$[8.0]$} & 7 & [9.2] & 0.99 \\
\hline Blood transfusion & 3 & {$[3,0]$} & 0 & {$[0.0]$} & 0.35 \\
\hline Alive at discharge & 96 & $\llbracket 100 \rrbracket$ & 71 & {$[100]$} & \\
\hline Death & 1 & {$[1.0]$} & 4 & [5.6] & 0.20 \\
\hline Recurrent mylocardial infarction & 3 & [3.1] & 2 & {$[2.8]$} & 0.73 \\
\hline Recuirent angina & 24 & {$[25.0]$} & 13 & {$[18.3]$} & 0.40 \\
\hline $\mathrm{CABG}$ or re-PTCA & 10 & {$[10.4]$} & 5 & {$[7.0]$} & 0.63 \\
\hline
\end{tabular}

$\mathrm{CABG}=$ coronary artery bypass graft; $\mathrm{PTCA}=$ percutaneous transiluminal coronary angioplasty.

Table 5. Predictors for one year mortality of the 176 patients who underwent acute PTCA with or without thrombolytic therapy

\begin{tabular}{|c|c|c|c|c|c|c|}
\hline & & \multicolumn{2}{|c|}{ Survivors } & \multicolumn{2}{|c|}{ Non-survivors } & \multirow[b]{2}{*}{ P-valu } \\
\hline & & $N$ & {$[\%]$} & $N$ & {$[\%]$} & \\
\hline \multirow[t]{2}{*}{ Previous MI } & Yes & 45 & {$[86.5]$} & 7 & {$[13.5]$} & \multirow[t]{2}{*}{0.14} \\
\hline & $\mathrm{Na}$ & 117 & {$[94.3]$} & 7 & {$[5.7]$} & \\
\hline \multirow[t]{2}{*}{ Thronbolysis } & Yes & 95 & {$[95.0]$} & 5 & {$[5.0]$} & \multirow[t]{2}{*}{0.16} \\
\hline & No & 67 & {$[88.2]$} & 9 & {$[11.8]$} & \\
\hline \multicolumn{2}{|c|}{ Anterior myocardial infarction } & 86 & [91.5] & 8 & {$[8.5]$} & \multirow[t]{2}{*}{0.99} \\
\hline \multicolumn{2}{|c|}{ Inferior myocardial infarecion } & 76 & {$[92.7]$} & 6 & {$[6.3]$} & \\
\hline \multicolumn{2}{|c|}{ Single vessel disease } & 84 & {$[88.4]$} & 11 & {$[11.6]$} & \multirow[t]{2}{*}{0.10} \\
\hline \multicolumn{2}{|c|}{ Multi vessel disease } & 78 & {$[96.3]$} & 3 & [3.7] & \\
\hline \multicolumn{2}{|c|}{ PTCA succesful } & 144 & {$[95.4]$} & 7 & 44.6 & \multirow[t]{2}{*}{0.001} \\
\hline \multicolumn{2}{|c|}{ PTCA unsuccesful } & 18 & {$[72.0]$} & 7 & {$[28,0]$} & \\
\hline \multicolumn{2}{|c|}{ Maximal ASAT in U/L (SD) } & 381 & {$[ \pm 251]$} & 440 & {$[ \pm 468]$} & 0.44 \\
\hline \multicolumn{2}{|c|}{ Age in years $(S D)$} & 57 & {$[ \pm 11]$} & 62 & {$[ \pm 11]$} & 0.10 \\
\hline \multicolumn{2}{|c|}{ Delay pain-PTCA ir min (SD) } & 238 & $\lfloor \pm 2 \| 1]$ & 160 & {$[ \pm 100]$} & 0.17 \\
\hline
\end{tabular}

MI=myocardial infarction; PTCA=percuaneous transluminal coronary angioplasty; ASAT=aspartare aminotransferase. 


\section{DISCUSSION}

Michels and Yusuf (55) performed a meta-analysis of randomized clinical trials on the value of PTCA in AMI. They concluded that primary PTCA might be more beneficial than thrombolytic therapy. However, this strategy has to be confirmed by larger studies. Various other strategies of PTCA to thrombolytic therapy do not convincingly indicate an improved outcome than if more conservative straregy is followed after thrombolytic treatment like immediate P'TCA (at 6-24 hours) or subacute PTCA (at 4-12 days). Only if PTCA is used when clinically indicated, like

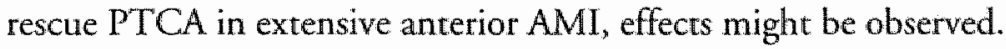

As seen in the Study in Europe with Saruplase and Alteplase in Myocardial infarction (SESAM trial), a vessel opened by rescue PTCA carries a higher risk of reocclusion compared to a vessel which is successfully opened by thrombolysis and then left untouched (17). This finding suggests that PTCA of an already open artery probably increases the risk of reocclusion. For the present analysis, the reocdusion rate is not known because the patients did not systematically have a repeated angiography.

The angiographic data from the present study indicate that successful PTCA was independent of previous thrombolytic therapy: over $90 \%$ of the culprit lesions could inirially be opened. However, the complexity of such a procedure in AMI is underlined by early reocclusions at the end of the catheterization in $6.8 \%$. An additional $8 \%$ of patients had clinical signs of reocclusion during hospital stay.

No major differences were found in the feasibility and safety of the PTCA procedures between the two groups. This contrasts with the findings of others, who have suggested a deleterious outcome after rescue PTCA when compared with primary PTCA $(45,46)$.

\section{CLINICAL OUTCOME}

Although thrombolytic therapy alone probably is inferior to primary PTCA (30-32), debare continues about the clinical value of rescue PTCA if thrombolytic therapy alone fails to reopen the infarct related artery $(19,54,55)$. In the present retrospective analysis, patients with rescue PTCA had a good dinical outcome. One has to keep in mind that in this study rescue PTCA was performed in the group of patients in whom the highest complication rates could be expected. They received thrombolytics which failed and then had PTCA because a large area was still at risk. Also most patients of the primary PTCA group were at higher risk, for example, because they had contra-indications to thrombolytic agents. These patients also had a large area at risk. The outcome of the rescue PTCA was clinically comparable to the patients who underwent primary PTCA. One has to keep in mind, that there was a selection bias between the two groups. 
A high mortality rate after failed acute PTCA (28.0\%) is well known, death rates of $24 \%-40 \%$ are reported in the literature $(36-41)$. The delay between onset of pain and PTCA was longer in the survivors (median $238 \mathrm{~min}$ ) than in the non-survivors (median $160 \mathrm{~min})(\mathrm{p}=0.17)$. Unexpectedly, this difference in delay did not result in an improved outcome. The explanation might be, that non-survivors had more extensive AMI and therefore more complaints resulting in an earlier admission. Recurrences of ischemia were not uncommon but comparable in both groups. The diagnosis of recurrent ischemia was not only diagnosed by spontaneous chest pain but also by the outcome of exercise testing, which was performed before discharge. This explains why recurrences of ischemia were more frequent in our study population than in some other studies $(30-32)$.

\section{ONE YEAR OUTCOME}

All surviving patients had were followed in the outpatient clinic during the first year after myocardial infarction. One year outcome (table 4) was not statistically different between the two groups, although total death rate at one year was higher in the primary PTCA group (11.8\%) than in the rescue PTCA group $(5.0 \%)(\mathrm{p}=0.17)$. This difference is probably explained by the different patient groups in both treatment allocations. This is also the case for the differences in morbidity during the one year follow-up. In that year respectively $6.6 \%$ and $7.0 \%$ had recurrent myocardial infarction; $27.6 \%$ and $40 \%(\mathrm{p}=0.12)$ recurrent angina; and $15.8 \%$ and $18.0 \%$ $(\mathrm{p}=0.85)$ re-PTCA or $\mathrm{CABG}$.

\section{STUDY LIMITATIONS}

Several factors limit the value of this study. It was a retrospective, non-randomized, single center study in a limited group of patients, which probably created an important bias. The study includes the period between 1986 to 1992 indicating that increasing experience and changes of techniques might influence the outcome in the present period. Candidates for primary PTCA usually were patients in whom thrombolytic therapy was contra-indicated. They tended to be more clinically ill because they had a contra-indication to thrombolytic therapy. The patients undergoing rescue PTCA were also a selection, because thrombolytic therapy failed. They are not representative for the total group of parients with AMI treated with a thrombolyric agent. In randomized trials where primary PTCA is one of the treatment allocations, in approximately $10 \%$ of the patients PTCA is not feasible for anatomical reasons or because of the finding of a patent artery during angiography. In the present study, due to the protocol, all PTCA patients had an occluded artery. PTCA was performed only if the operator felt that the procedure was useful, which varied from doctor to doctor. The complexity of the lesion was no argument to remain conservarive if the ischemic area was extensive. On the other hand, patients with a 
small occluded artery were not dilated and therefore were not included in this analysis. This selection bias indicates that the clinical results of the PTCA groups would probably have been better if in all patients such intervention had been attempted.

\section{POSSIBLE IMPLICATIONS}

During the daytime, primary PTCA is probably the best option in centers where PTCA is available, especially in patients with extensive ischemia $(51,56,58)$. However, only $18 \%$ of the hospitals in the United States and $10 \%$ of the hospitals in the Netherlands do have the capability to perform angioplasty, and fewer can do this on a round the clock basis (59). Logistical problems, especially during out of office hours, will cause a time delay before PTCA can be offered. "This delay can be used meaningfully when the combined strategy of thrombolytic therapy and rescue PTCA, if indicated, is chosen. Using this approach, the need for acute angiography and intervention can be limited in case of reperfusion $(59,60)$. At the moment a randomized study (the Limburg Myocardial Infarction Study) is in progress to investigate prospectively safety and feasibility of three treatment modalities: rescue PTCA after failed thrombolysis; primary PTCA; and thrombolysis only in patients with extensive AMI admitted to a hospital without PTCA facilities. This pilot study will later be followed by a large scale efficacy study (Holland Myoardial Infarction Study)

In conclusion, the present study shows that in patients with AMI reopening of the culprit lesion either by rescue PTCA or primary PTCA was safe and effective. It is still unclear how the present data should be extrapolated to the management of patients with AMI. Currently, the use of angioplasty is primarily limited by logistic problems. In centers in which angioplasty can be routinely applied, primary PTCA appears to be an attractive alternative to thrombolytic therapy. The question is whether this form of therapy should also be applied to parients primarily admitted to non-PTCA centers. Hopefully this last question will be answered by the Holland Myocardial Infarction Study.

\section{REFERENCES}

1. Lincoff AM, Topol E]: Illusion of reperfusion. Does anyone achieve optinal reperfusion during acute myocardial infarction? Circulation 1993;87:1792-1805.

2. Kennedy $\mathbb{J W}$, Ritchie $\mathrm{JL}, \mathrm{Davis} \mathbb{K B}$, Frizz $\mathrm{JK}$ : Western Washington randomized trial of intracoronary streptokinase in acute myocardial infarction. N Eng J Med 1983;309:1477-1482.

3. Simoons ML, Serruys PW, van den Brand $M$, et al: Early thrombolysis in acute myocardial infarction: limitarion of infarct size and improved survival. J Am Coll Cardiol 1986;7:717-728.

4. Schroder R, Neuhaus K-L, Leizorovicz A, Linderer T, Tebbe U: A prospecrive placebo-controlled double-blind multicenter trial of intravenous streprokinase in acure myocardial infarction (ISAM): Long-term mortality and morbidity. J Am Coll Cardiol 1987;9:197-203. 
5. Gruppo Italiano per lo Studio della Streptochinasi nell infarro Miocardico (GISSD): Effectiveness of intravenous thrombolytic treatment in acute myocardial infarction. Lancet 1986; 1:397-402.

6. Wilcox $\mathrm{RG}_{3}$ won der Lippe $\mathrm{G}$, Olsson $\mathrm{CG}$, et al: Trial of tissue plasminogen activator for mortality reduction in acute myocardial infarction. Anglo-Scandinavian Study of Early Thrombolysis (ASSET). Lancet 1988;2525-530.

7. ISIS-2 (Second: International Study of Infarct Serwival). Collaborative Group: Randomized trial of intrawenous streptokinase, oral aspirin, both, or neither among 17,187 cases of suspecred acure myocardial infarction: ISIS-2. Lancer 1988;2:349-360.

8. AIMS Trial Study Group: Effect of intravenous APSAC on mortality after acute myocardial infatction: Prelimininary report of a placebo-controlled clinical trial. Lancet 1988;1:545-549.

9. Topol EJ, Califf RM, George BS, et al: A randomized trial of immediate versus delayed elective angioplasty after intravenous rissue plasminogen actiwator in acute myocardial infarction. $\mathrm{N}$ Engl J Med 1987:317:581-588.

10. TIMI Study Group: Thrombolysis In Myocardial Infarction (TIMI) trial. N Engl I Med $1985 ; 312.932-936$.

11. Neuhaus K-L, Tebibe U, Gortwik M, et al; Intravenous recombinant rissue plasminogen activator (rt-PA) and urokinasie in acute myocardial infarction: results of the German Activator Urokinase Study (GAUS). J An Coll Cardiol 1988;12:581-587.

12. Hogg KJ, Gemmill JD, Burns JM, et al: Angiographic patency study of anistreplase versus streptokinase in acure myocardial infarction. Lancet 1990;335:254-258.

13. Verstraete $M$, Bernard $R$, Bory $M$, et al: Randomised trial of intravenous recombinant tissue-type plasminogen activator versus intravenous streptokinase in acute myocardial infarction: report from the European Cooperative Study Group for Recombinant Tissue - type Plasminogen Actiwator. Lancet $1985 ; 1: 842-847$.

14. Topol EJ, Califf RM, George BS, et al, and the TAMI Study Group: Coronary arterial thrombolysis with combined infusion of recombinant tissne-type plasminogen activator and urokinase in patients, with acute myocardial infarction. Circulation 1988;77:1100-1107.

15. Neuhaus K-L, Fenerer W. Jeep-Tebbe S, et al: Improved thrombolysis with a modified dose regimes of recombinant tissue-type plasminogen actiwator. J Am Coll Cardiol 1989;14:1566-1569.

16. PRIMI trial study group: Randomized double-blind trial of recombinant pro-urokinase against streptokinase in acute myocardial infarction. Lancet 1989;1:863-868.

17. Bär IVW, for the SESAM study group: Early patency and reocclusion in acure myocardial infarction. A comparison berween thrombolytic agents saruplase and alteplase. Results of the SESAM-Trial. J Am Coll Cardiol 1994;405A:954.

18. The GUSTO Angiographic Investigators: The effects of tissue plasminogen activator, streptokinase, of both on coronary-artery patency, ventricular function, and survival after acute myocardial infarction. N Engl J Med 1993;329:673-682.

19. Califf RM, Topol EJ, Stack RS, et al: Evaluation of combination thrombolytic therapy and timing of cardiac catheterization in acute myocardial infarction: results of thrombolysis and angioplasty in myocardial infarcrion - phase 5 randomized trial, Circulation 1991:83:1543-1556. 
20. Topol EJ "Morris DC, Smalling RW, et al: A multicenter, randomized, placebo-controlled trial of a mew form of intravenous recombinant tissue-type plasminogen acrivator (Accivase) in myocardial infarction. ] Am Coll Cardiol 1987; 9: 1205-1213.

21. Chesebro JH, Knatterud $G$, Roberts $R$, et al: Thrombolysis In Myocardial Infarction (TIMI) trial, phase I: a comparison berween incravenous tissue plasminogen acrivator and intrawenous streptokinase Circulation 1987,76:142-154.

22. The GUSTO Investigators: An interventional randomized trial comparing four thrombolytic strategies for acute myocardial infarction. N Engl J Med 1993;329:673-682.

23. OKefe JH Jr, Rutherford BD, McConahay, et al: Early and late results of coronary angioplasty without antecedent thrombolytic therapy for acure myocardial infarction. Am J Cardiol $1989 ; 64: 1221-1230$.

24. Rothbaum DA, Limnemeier TJ, Landin RJ, et al: Emergency percutaneous transluminal coronary angioplasty in acute myocardial infarction: a 3 year experience I Am Coll Cardiol 1987;10:264-272.

25. Miller PF, Brodie BR, Weintraub RA, et al: Emergency coronary angioplasty for acute myocardial infarction: results from a community hospital. Arch Intern Med 1987:147:1565-1570.

26. Perrigo ES, Leguizamon E: Management of acute myocardial infarction (AMI) using immediate percuraneous transluminal angioplasty (I-PTCA). Med Sci Sports Exer 1989;21:S55.

27. ONeill WW, Brodie BR, Knopf W, et al: Initial report of the Primary Angioplasty Revascularization (PAR). Multicenter Registry. Circulation 1991;84:Suppl II:II-536.

28. Kahn JK, Rutherford BD, McConahay DR, et al: Catheterization laboratory events and hospital outcome with direct angioplasty for acute myocardial infarcrion. Circulation 1990;82:1910-1915.

29. Meier B: Balloon angioplasty for acute myocardial infarction: was it buried alive? Circulation $1990 ; 82: 2243-2245$

30. Grines CL, Browne KF, Marco Jo et al, for the Primary Angioplasty in Myocardial Infarction Study Group: A comparison of immediate angioplasty with thrombolytic therapy for acute myocardial infarcrion. N Engl J Med 1993;328:673-679.

31. Zijlstra F, de Boer MJ. Hoomtje JCA, et al: A comparison of immediate coronary angioplasty with intravenous streptokinase in acute nyocardial infarction. N Engl ] Med 1993;328:680-684.

32. Gibbons RJ, Holmes DR, Reeder GS, et al: Immediate angioplasty compared with the administration of a thrombolytic agent followed by concerwative treatment for myocardial infarction. N Engl J Med 1993;328;685-691.

33. Ellis SG, van de WerfF, Ribeiro-daSilva E, Topol El: Present status of rescue coronary angioplatsty: Current polarization of opinion and randomized trials. J Am Coll Cardiol 1992;19:681-686.

34. Ellis SG, da Silva ER, Heyndrickx G, Talley JD, Steg G, Spaulding C, Nobuyoshi M, Erbel R, Vassanelli $C$ : Randomized comparison of rescue angioplasty with conservative management of parients with early failure of thrombolysis for acute anterior myocardial infarction. Circulation $1994 ; 90(5): 2280-4$.

35. Simoons ML, Arnold AER, Betritu A, et al: Thrombolysils with tissue plasminogen activator in acute myocardial infarction: no additional benefit from immediate percutaneous coronary angioplasty. Lancet 1988;1:197-203. 
36. Harzar $\mathrm{GO}$, Rutherford $\mathrm{BD}$, McConahay DR, et al: Percutanieous transtumimal coronary angioplasty with and wirhout thrombolytic therapy for treatment of acute myocardial infarction. Am Heart J 1983:106:965-973.

37. Papapietro SE, MacLean WAH, Stanley AWH Jr et al: Percuraneous rransluminal coronary angloplasty after intracoronary streptokinase in evolving acute myocardial infarction. Am J Cardiol $1985.55: 48-53$

38. Fung AY, Lai P, Topol EJ, et al: Value of percutaneous transluminal coronary angioplasty after unsuccessful intravenous streptokinase therapy in acute myocardial infarction. Am J Cardiol $1986: 58: 686-691$.

39. Abbotsmith CW, Topol EJ, George BS, et al: Fate of parients with acure myocardial infarction with patency of the infarct-related vessel achieved with successful thrombolysis versus rescue angioplasty. J Am Coll Cardiol 1990;16:770-778.

40. Ellis SG, O'Neill WWW, Bates ER, et al: Implications for patient triage from survival and left ventricular functional recovery analysis in 500 patients treared with coronary angioplasty for acute myocardial infarction. I Am Coll Cardiol 1989;13:1251-1259.

41. Gibson CM., Cannon CP, Piana RM, et al: Rescue PTCA in the TIMI 4 Trial. J Am Coll Cardiol $1994: 225 \mathrm{~A}: 755$.

42. Topol EJ, Califf RM, George BS, et al: A randomized trial of immediate versus delayed elective angioplasty after intravenous tissue plasminogen activator in acure myocardial infarction. New Eng J Med 1987;317:581-588.

43. Erbel $\mathrm{R}$, Top $\mathrm{T}$, Henrichs $\mathrm{KJ}$, et al: Percutaneous transluminal coronary angioplasty after thrombolytic therapy: a prospecrive controlled randomized trial. Am Coll Cardiol 1986;8: 485-495.

44. Stone GW, Grines CL, Browne KF, et al: Acute outcome after primary angioplasty in myocardial infarction - The Primary Angioplasty in Myocardial Infarction (PAMI) trial. J Am Coll Cardiol 1993;21:331A.

45. Ohman E. Magnus, Califf Robert M, Topol Eric J, et al: Consequences of reocclusion after successful reperfusion therapy in acute myocardial infarction. Circulation 1990;82:781-791.

46. O'Neill WW, Weintraub R, Grines CL, er all A prospectiwe, placebo-controlled, randomized trial of intravenous streptokinase and angioplasty versus lone angioplasty therapy of acure myocardial infarction. Circulintion 1992;86:1710-1717.

47. Grines $\mathrm{CL}$, Browne $\mathrm{KF}$, Vandormael $\mathrm{M}$, er al: Primary Angioplasty in Myocardial Infarcrion (PAMI) triall. Circulation 1992;86(Suppl 1):I-641.

48. Bär FW, Meyer J, Michells R, et al: T'iprostene might improwe the effect of thrombolytic treatment in acute myocardial infarction. Results of the START study. Eur Heart J 1993:14:1118-1126.

49. Topol EJ, Califf RM, George BS, Kereiakes DJ, Lee KL, for the TAMI Srudy Group: Insighrs derived form the Thrombolysis and Angioplasty in Myocardial Infarction (TAMT) Trials. I Am Coll Cardiol 1988;12:24A-31A.

50. Califf RM, Topol El, George BS, et al: Characteristics and outcome of patients in whom reperfusion with intravenous tissue-rype plasminogen activator fails: Results of the Thrombolysis and Angioplasty in Myocardial Infarction (TAMI) trial. Circulation 1988:77:1090-1099. 
51. Morgan CD, Roberts RS, Haq A, et al: Coronary parency, infarce size and left ventricular function after thrombolytic therapy for acute myocardial infarction: Results from the Tissue Plasminogen Activator: Toronto (TPAT) placebo-controlled crial. J Am Coll Cardiol 1991;17:1451-1457.

52. Braunwald $\mathrm{E}$ : Myocardial reperfusion, limitation of infaret size, reduction of left ventricular dysfunction, and improved survival: Should the paradigm be expanded? Circularion 1989:79:441-444.

53. Fortin DG, Califf RM: Long-term survival from acure myocardial infarction: Salutary effect of an open vessel. Am J Med 1990;88:1-9N-1-15N.

54. The TIMI Study Group: Comparison of invasive and conservative strategies after treatment with intravenous rissue plasminogen activator in acute myocardial infarction: results of the Thrombolysis In Myocardial Infarction (TIMD) phase II trial. N Engl J Med 1989;320:618-627.

55. Holmes DR, Gersh BJ, Bailey KR, Reeder GS, Bresnahan JF, Bresnahan DR, Vlierstra RE. Emergency "Rescue" percutaneous transluminal coronary angioplasty after failed thrombolysis with streprokinase. Circulation 1990;81(sup LIV):51-56.

56. Michels KB, Yusuf S: Does PTCA in acute myocardial infarcrion affect mortality and reinfarction rates: Circulation 1995:91:476-85.

57. Vermeer $F$, Simoons $M L$, Bär FW, et al: Which patients benefit most from early thrombolytic therapy with intracoronary streptokinase? Circulation 1986;74:1379-1389.

58. Bär FW, Vermeer $F$, de Zwaan $C$, et al: Value of admission electrocardiogram in prediccing outcome of thrombollytic therapy in acute myocardial infarction. A randomized crial conducred by The Netherlands Interuniversity Cardiology Institute. Am J Cardiol 1987:59:6-13.

59. Facilities and services in the United States. In: Hospital staristics $1992-93$ ed. Chicago: American Hospital Association, 1992:208-209.

60. Krucoff MW, Jackson YR, Burdette DL, et al: Digital real-time 12 lead ST segment trends: a bedside noninvasive monitor of infarct vessel parency. Circulation 1989;80 (suppl ID):11-354.

61. Gorgels APM, Vos MA, Letsch I, et al: Usefulness of the accelerated idioventricular rhythm as a marker for myocardial necrosis and reperfusion during thrombolytic therapy in acute myocardinl infarction. Am J Cardiol 1988;61:231-235. 
CHAPTER 4

Early referral for intentional rescue PTCA after initiation of thrombolytic therapy in patients admitted to a community hospital because of a large acute myocardial infarction

Oude Ophuis $A J^{1}$, Bär $\mathrm{FW}^{1}$, Vermeer $\mathrm{F}^{1}$, Krijne $\mathrm{R}^{2}$, Jansen $\mathrm{W}^{1}$, Swart de $\mathrm{H}^{1}$, Ommen van $V^{1}, M D$, Zwaan de $C^{1}$, Engelen $D^{1}$, Dassen W/R: Wellens $\mathrm{HIJ}^{1}$

${ }^{1}$ Department of Cardiology, Universiry Hospital Maastricht, Maastricht, the Netherlands

${ }^{2}$ Department of Cardiology, Maasland Hospital, Sittard, the Netherlands 


\section{ABSTRACT}

Introduction: If no in-house PTCA facilities are present, thrombolytic therapy is the treatment of choice in acute myocardial infarction (AMI). A few studies showed benefit from rescue PTCA (RPTCA) in patients directly admitted to centers with PTCA facilities. The obvious question anises whether patients with AMI initially admitted to a community hospital $(\mathrm{CH})$ can benefit from early transfer for intentional RPTCA.

Methods: One hundred sixty five patients were transferred early for intentional RPTCA from a $\mathrm{CH}$ at 20 miles distance. On arrival at the angioplasty center bedside markers were used to determine reperfusion. In case of obvious reperfusion no invasive procedure was done, otherwise coronary angiography and RPTCA, if necessary, was performed.

Results: During transfer 1 patient (1\%) died and 15 patients $(9 \%)$ suffered arrhythmic or haemodynamic problems. Median time delay between onset of chest pain and arrival at the community hospital and the PTCA center was 61 (range 0-413) minutes and 150 (range 28-472), respectively. In 66 patients (40\%) reperfusion was diagnosed by non-invasive reperfusion criteria on arrival at the PTCA center (group 1). Ninety-eight patients (59\%) without evident non-invasive criteria of reperfusion underwent angiography 187 median minutes after the onset of chest pain. Forty-one patients (25\%) had TIMI-3 flow and no further intervention was performed (group 2). In the remaining 57 patients (35\%). RPTCA was performed, which was successful in $96 \%$ (group 3). In-hospital mortality was lowest in group 1 compared to the other 2 groups ( $0 \%$ vs. $7 \%$ vs. 11\%; $<<0.05$ ). Re-infarction was highest in group 1 compared to the other groups (17\% vs. $5 \%$ W. $2 \% ; p<0.01$ ). No significant differences were found in CABG, stroke or bleeding complications. The one-year follow-up data showed low revascularization rates and 2 (1\%) patients died after discharge.

Conclusion: Early transfer of patients with large AMI for intentional RPTCA, can be done with acceptable safety and is feasible within therapeutically acceptable time limits and results in additional early reperfusion in $33 \%$ of patients. A large randomised multicenter trial is needed to compare efficacy of intravenous thrombolytic treatment in a $\mathrm{CH}$ versus early referral for either rescue or primary PTCA. 


\section{INTRODUCTION}

Successful reperfusion in acute myocardial infarction (AMI) by either thrombolysis, percutaneous transluminal coronary angioplasty (PTCA), or both improves dinical outcome (1-3). Early restoration of patency of the infarct related artery results in the largest benefit (4-6). Studies showing a beneficial effect of thrombolytic agents have been conducted in hospitals with and without PTCA facilities. However, trials showing the value of primary or rescue PTCA in AMI usually involve patients who are directly admitted to a PTCA center (3,7-12). However, the majority of patients with AMI, are admitted to community hospitals where angioplasty facilities are not available. The obvious question arises whether patients initially admitted to a community hospital, especially those with a large ischemic area, benefit from early transfer for rescue PTCA, when needed, after the initiation of thrombolytic therapy. Since the magnitude of the reduction in myocardial damage is strongly influenced by the rapidity of reperfusion, thrombolytic therapy should be given before transfer to accelerate the speed of reperfusion of the infarct-related artery. In case of reperfusion this may abolish the need for subsequent coronary angiography or rescue PTCA in the referral center in contrast to the strategy of transfer without thrombolytic therapy, for primary PTCA (12-13). Since many hospitals have no PTCA facilities we decided to study safety, feasibility and clinical outcome of patients with acute myocardial infarction initially treated with a thrombolytic agent in a community hospital with early referral to a PTCA center for rescue PTCA, when needed.

\section{METHODS}

One hundred sixty-five out of 1265 consecutive patients suffering from AMI, were transferred early from the community Maasland Hospital, Sittard, to the University Hospital Maastricht, Maastricht, for intentional rescue PTCA. The Maasland Hospital is a 580 bed community hospital located at 20 miles from the University Hospital Maastricht, a 720 bed tertiary care hospital with PTCA facilities and cardiac surgery. Transportation of patients from the community hospital to our center was done by the district ambulance service. The PTCA procedures were performed by 5 experienced interventional cardiologists with an individual parient load exceeding 200 cases yearly.

\section{INDICATIONS FOR TRANSFER TO THE PTCA CENTER}

In the referring community hospital, thrombolysis is the first choice reperfusion therapy for acute myocardial infarction. Predefined indications for early referral for intentional rescue PTCA were: electrocardiographic evidence of large AMI (sum of ST-segment deviation $>1.5 \mathrm{mV}$ ); Killip class 3-4 and or severe hypotension (systolic 
blood pressure $<90 \mathrm{mmHg}$ ); electrocardiographic evidence of right ventricular involvement suggested by the presence of ST-segment elevation in lead V4R (14). The attending cardiologist in the Maasland Hospital, called the University Hospital Maastricht announcing that a patient with a large acute myocardial infarction would be transferred by ambulance after initiation of thrombolytic therapy (Fig.1). Patients with the predefined indication for early intentional rescue PTCA were considered for transferral. Thrombolytic therapy given, was either intravenous streptokinase $(1,500,000$ units) or recombinant tissue-plasminogen activator (rt-PA). All patients were accepted for emergency evaluation. The ambulance was staffed with experienced paramedics and fully equipped to transfer critically ill parients, including continuous ECG monitoring, a defibrillator and equipment for mechanical ventilation. Expeditious transfer was facilitated by traffic light interrogation and a special high-way exit for the PTCA center.

During office hours, the first available room of the catheterization laboratory, (having two catheterization rooms), was used when indicated. Outside office hours, the catheterization personnel and the interventional cardiologist on duty were called. They always arrived before the patient and usually started the catheterization procedure within 1 hour after initial notification.

\section{ADMISSION PTCA CENTER}

On arrival at the University Hospital Maastricht, reperfusion status was evaluated by comparing the admission ECG of the community hospital and the ECG on arrival at the PTCA center and the severity of chest pain (15). Reperfusion was considered to be present in case of 1) a sudden decrease of chest pain and 2) a $\geq 50 \%$ resolution of ST-segment elevation (15). In the case that non-invasive signs of reperfusion were absent, or non-conclusive, the patient was immediately transported to the catheterization laboratory for coronary angiography, and rescue PTCA when needed.

\section{RESCUE PTCA}

Catheterization and coronary angioplasty were performed using standard technique (16). All patients received a bolus of 10.000 units of heparin immediately after arterial entry. This was continued as a continuous infusion at approximately 900 units/hr to maintain the activated partial thromboplastin time at 1.5 fold normal or greater than normal for 48-72 hours. Rescue PTCA of the infarct related coronary artery was attempted in all cases with no flow or impaired flow according to the Thrombolysis In acute Myocardial Infarction (TIMI) grading system (TIMI 0-2) (17). If TIMI 3 flow was present no further intervention was done. PTCA was defined as being successful in case of persistent TIMI 3 flow and a residual stenosis < $50 \%$ at the end of the procedure. Other procedures, like intra-aortic balloon counterpulsation or stent implantation, were left to the discretion of the operator. 


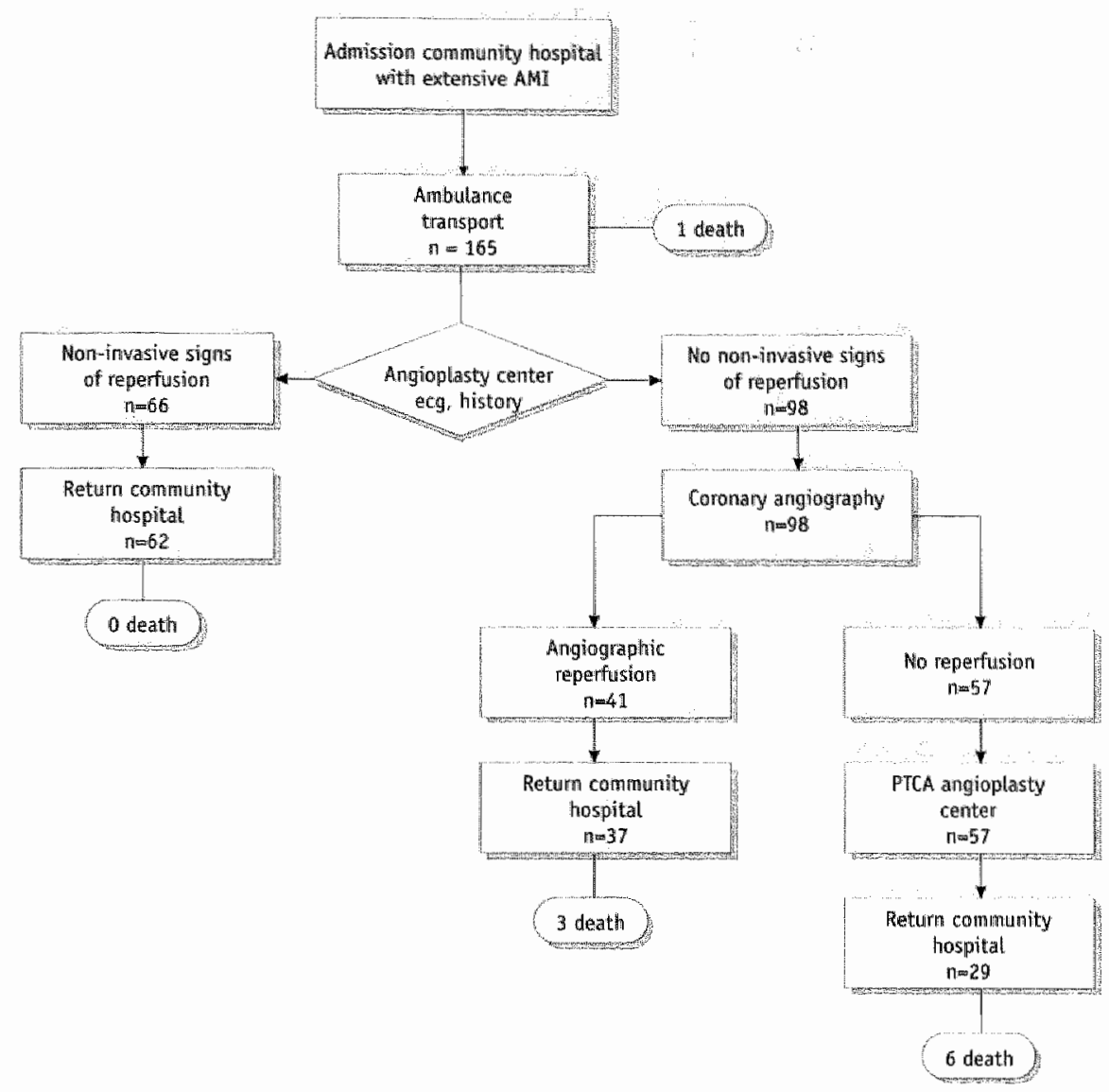

Figure 1. Flow chart

All patients received Acetyl Salicylic Acid $(80 \mathrm{mg} / \mathrm{d})$, intravenous nitrates for at least 24 hours and intravenous heparin as mentioned. The coronary angiograms were analyzed by two independent observers.

\section{RETURN TO THE REFERRING HOSPITAL}

When non-invasive signs of reperfusion were present on presentation to the PTCA center the patient returned to the referring hospital by the same ambulance when clinically stable.

After coronary angiography or rescue angioplasty, clinically stable patients returned to the Maasland Hospital, after an observation period of approximately 2 hours. Otherwise, patients were admitted to the University Hospital Maastricht until the clinical condition had sufficiently improved to ensure a safe return to the Maasland Hospital (Fig. 1). 
$4 6 \longdiv { \text { CHATTR } 4 }$

\section{BASELINE AND OUTCOME VARIABLES}

The hospital records of all patients were examined and the clinical data were collected on a standard dara acquisition form. The following outcome variables were collected: in-hospital death, recurrent AMI (chestpain with new ST-segment elevation and enzymatic evidence of myocardial necrosis (ASAT $>40 \mathrm{mmol} / \mathrm{L}$ )), recurrent anginal complaints according to the NYHA classification (18), repeat-PTCA, coronary artery bypass grafting, stroke (defined as a new neurological deficit) and bleeding complications requiring blood transfusion. One year follow-up data were also obtained from clinical and outpatient records.

The records of the district ambulance service were reviewed and information on complications during transport and time data of transfer, were collected.

The electrocardiograms were scored as to the sum of ST-segment deviation at the J-point using the 12-lead ECG, and the number of parients with a sum of $S T$-segment deviation $\geq 15 \mathrm{~mm}(1.5 \mathrm{mV})$ was determined.

\section{STATISTICAL ANALYSIS}

Data were expressed as median (range) or mean $( \pm S D)$ for continuous variables or as rates (percentage) for categorical variables. Proportions of categorical variables were compared using the chi-square test. All results with a p-value $<0.05$ were considered to be statistically significant.

\section{RESULTS}

\section{PATIENT CHARACTERISTICS}

In the three and a half-year observational period, 165 consecutive parients with large acute myocardial infarction were transferred early for intentional rescue angioplasty. This is approximately $13 \%$ of the infarct population in the community hospital.

Baseline clinical and angiographic data for the total patient group and the 3 subgroups are given in Table 1. The infarction was located anteriorly in 57\% and inferiorly in $43 \%$. Seventy-nine percent of the patients transferred early for intentional rescue PTCA had evidence of electrocardiographic extensive myocardial infarction (sum of total ST-segment deviation $>1.5 \mathrm{mV}$ ). Severe hypotension and or Killip class 3 or 4 was present in $22 \%$ of the patients. Twenty-four percent had electrocardiographic evidence of right ventricular involvement. 
Table 1. Base-line characteristics of the 165 AMI patients referted for rescue PTCA

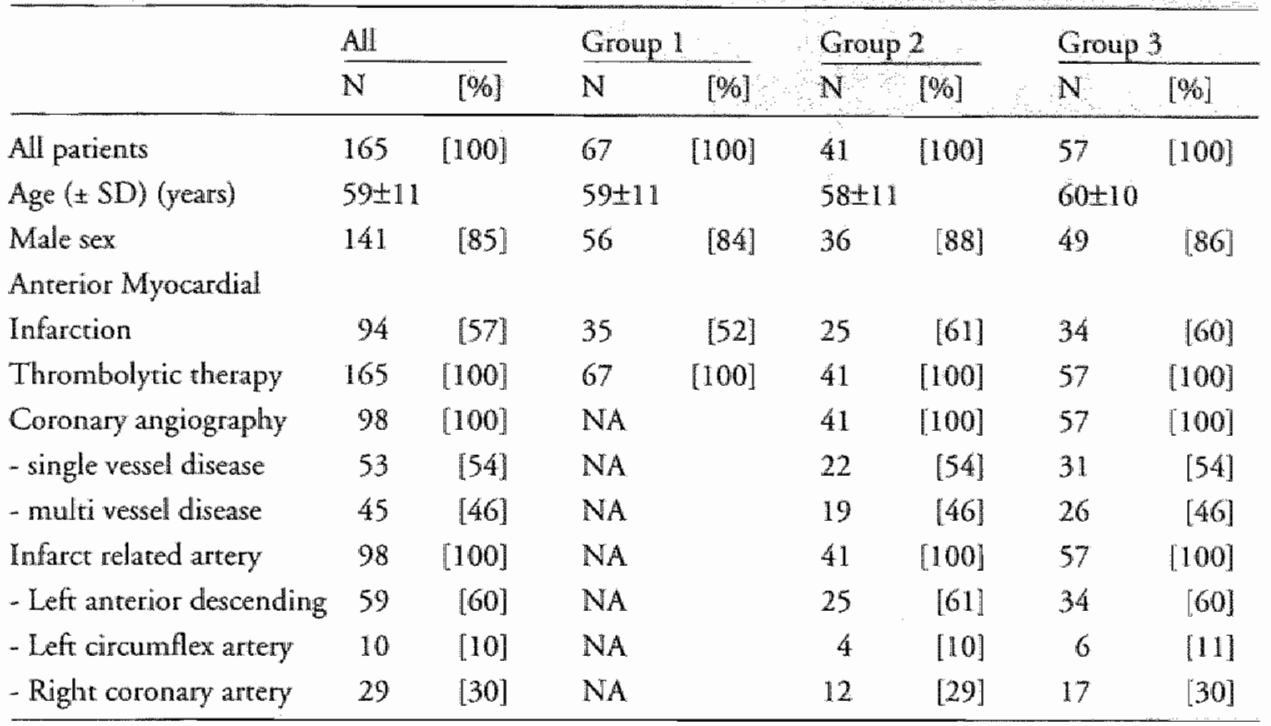

Group $1=$ Patients with noninvasive reperfusion; Group $2=$ Patients with angiographic reperfusion; Group $3=$ Patients with rescue PTCA; AMI =acute myocardial infarction; $R V I=$ right ventricular involvement; $N A=$ non- applicable.

\section{TRANSPORTATION AND TIME DELAYS}

In general, transport to the angioplasty center was rarely accompanied by severe complications. Only 1 patient, who was already in severe cardiogenic shock, died during transport. This patient suffered an extensive anterior AMI complicated by right bundle branch block and left anterior hemiblock. The patient died the moment he was put into the ambulance. Another 8 patients (5\%) had severe ventricular arrhythmia's necessitating defibrillation (which was successful in every case). Three parients ( $2 \%)$ had complete AV-block and in addition another 4 patients (2\%) required fluid expansion because of the development of severe hypotension during transport. No bleeding complications were recorded in that period. No other adverse events occurred during or as a result of transportation. During transport in the reverse direction (from Maastricht to Sittard) no complications were observed.

Median delay between onset of chest pain and arrival in Maastricht was 150 (range 28-472) minutes (Table 2). The delay decreased considerably during the study period due to a shorter time delay between admission and transfer at the community hospital. Growing familiarity with the logistics of transfer may have accounted for this reduction (Fig. 2). No statistical significant relationship between time delays and mortality could be demonstrated but there was a tendency towards increased mortality with a longer time delay (Table 3). 
$48 \mid$ CHAPTER 4

Table 2. Time delays of the 165 patients referred for rescue PTCA

\begin{tabular}{lcl}
\hline Time delay in minutes & Median & Percentile \\
\hline All parients $(\mathrm{N}=165)$ & & 25 th-75th \\
Onset chest pain-admission at $\mathrm{NPC}$ & 61 & $30-114$ \\
Admission at NPC-departure to PC & 53 & $43-82$ \\
Ambulance transport & 16 & $15-18$ \\
Onset chest pain-arrival ar $\mathrm{PC}$ & 150 & $110-210$ \\
Patients with angiography $(\mathrm{N}=98)$ & & \\
Arrival ar PC-arrival cath lab & 36 & $27-45$ \\
Onset chest pain-carh lab & 187 & $146-255$ \\
\hline
\end{tabular}

NPC=non-PTCA center; PC PTCA center; Cath lab=catheterization laboratory.

Table 3. Time delays between onset of chest pain and arrival at PTCA center in relation to mortality $(\mathrm{N}=165)$

\begin{tabular}{lllcl}
\hline Minutes & N & Mortality & {$[\%]$} & P-value \\
\hline $0-120$ & 53 & 1 & {$[2]$} & NS \\
$120-240$ & 81 & 5 & {$[6]$} & NS \\
$>240$ & 31 & 4 & {$[13]$} & NS \\
\hline
\end{tabular}

Table 4. Status of coronary reperfusion of the 164 patients on arrival at the PTCA center*

\begin{tabular}{lrl}
\hline & N & {$[\%]$} \\
\hline Non-invasive signs of reperfusion** & 66 & {$[40]$} \\
Angiographic evidence of reperfusion & 41 & {$[25]$} \\
Noninvasive or invasive signs of reperfusion & 107 & {$[65]$} \\
No angiographic evidence of reperfusion & 57 & {$[35]$} \\
\hline
\end{tabular}

*One patient died in the ambulance. ** Resolution of ST-segment elevation $\geq 50 \%$ and sudden decrease in chest pain.

\section{NON-INVASIVE CRITERIA FOR REPERFUSION}

The non-invasive reperfusion criteria, as described in the methods section, showed that 66 patients ( $40 \%$ ) (group 1) had evident signs of reperfusion (Table 4). In these patients coronary angiography was not performed. All but 4 of the 66 parients returned immediately to the community hospital, usually with the same ambulance (Fig. 1). 


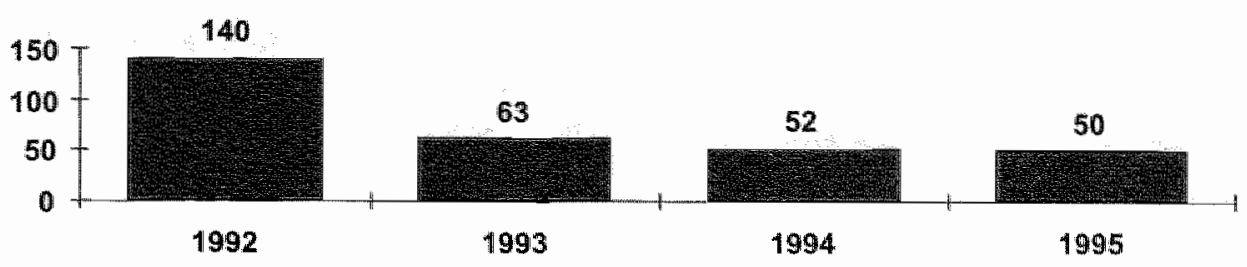

Figure 2. Time delays are given for the last 11 monchs of the year 1992, the full year 1993 and 1994 and the first 8 months of 1995. The vertical bar indicates the median delay in minutes between admission in the community hospital and arrival at the PTCA center.

\section{CORONARY ANGIOGRAPHY AND PTCA}

The 98 patients $(60 \%)$ without obvious non-invasive signs of reperfusion underwent coronary angiography, showing complete restoration of flow in 41 patients (25\%) (group 2). In the remaining 57 patients (35\%) (group 3) having no or impaired flow acute PTCA was successful in 55 patients (96\%).In 2 of these patients a stent was implanted because of recurrent occlusion. In 10 of the 98 patients $(10 \%)$ an intra-aortic counterpulsation device was inserted.

\section{CLINICAL OUTCOME}

The data were analyzed for the total patient group and subsequently for three subgroups consisting of patients with 1) non-invasively determined reperfusion (group 1),2) angiographically demonstrated TIMI 3 flow of the infarcr-related coronary artery (group 2) and 3) rescue PTCA (group 3). The in-hospital mortality of the total group of 165 patients was $6 \%$ (10 patients), including the patient who died in the ambulance. Major bleeding complications were low. These and other clinical complications are listed in Table 5. There were no in-hospital deaths in group 1 $(\mathrm{p}<0.05)$. Of the 14 patients $(8 \%)$ who suffered recurrent AMI in-hospital, 11 parients $(17 \%)$ belonged to the group of the 66 patients with non-invasive signs of reperfusion (group 1). The incidence of in-hospital. re-infarction was significantly higher in this group as compared to the other 2 groups ( $<<0.01$ ).

\section{ONE YEAR FOLLOW-UP AFTER DISCHARGE}

Of the 165 patients included in the study one patient died during transfer and 9 patients died during hospital admission. In 3 of the remaining 155 patients follow-up data were incomplete in each group 1 patient but the patients were known to be alive (Table 6). Only 2 of the 155 patients died during the first year. One patient died due to left-sided heart failure and one patient experienced sudden cardiac death. There were no significant differences between the 3 patient groups concerning recurrent AMI, PTCA and coronary artery bypass grafting. 
Table 5. If-hosptal clinical outcome of the $165^{*}$ patients referned for intentional rescue PTCA

\begin{tabular}{|c|c|c|c|c|c|c|c|c|c|}
\hline & \multicolumn{2}{|l|}{ All } & \multicolumn{2}{|c|}{ Group 1} & \multicolumn{2}{|c|}{ Group 2} & \multicolumn{2}{|c|}{ Group 3} & \multirow[t]{2}{*}{$\mathrm{P}$} \\
\hline & $N$ & {$[\%]$} & $\mathrm{N}$ & {$[\%]$} & $\mathrm{N}$ & {$[\%]$} & $\mathbb{N}$ & {$[\%]$} & \\
\hline Number of parients & \multicolumn{2}{|c|}{$165[100]$} & 66 & {$[100]$} & 41 & {$[100]$} & 57 & {$[100]$} & \\
\hline Death & 10 & {$[6]$} & 0 & {$[0]$} & 3 & {$[7]$} & 6 & [11] & $<0.05$ \\
\hline Recurrent MI & 14 & [8] & 11 & [17] & 2 & [5] & 1 & [2] & $<0.01$ \\
\hline Emergency PTCA & 12 & {$[7]$} & 9 & {$[114]$} & 2 & [5] & 1 & [2] & $<0.05$ \\
\hline Elective $T C A$ & 5 & {$[3]$} & 3 & {$[5]$} & 2 & {$[5]$} & 0 & [0] & NS \\
\hline $\mathrm{CABG}$ & 6 & 《4] & 3 & [5] & 3 & {$[7]$} & 0 & {$[0]$} & NS \\
\hline Stroke & 0 & {$[0]$} & 0 & {$[0]$} & 0 & {$[0]$} & 0 & $\lceil 0]$ & NS \\
\hline \multicolumn{10}{|l|}{ Blecding complication } \\
\hline -Transfusion & 5 & {$[3]$} & 2 & [3] & 2 & $15 \rrbracket$ & I & [2] & NS \\
\hline
\end{tabular}

Group $1,2,3=$ see Table $1 ;$ AMI = acute myocardial infarction; PTCA= percutaneous transluminal coronary angioplasty; $\mathrm{CABG}=$ coronary artery bypass graft. ${ }^{*}$ One parient died during ambulance transport.

Table 6. One year follow-up in patients who were discharged alive* $(N=155)$

\begin{tabular}{|c|c|c|c|c|c|c|c|c|}
\hline & \multicolumn{2}{|l|}{ All } & \multicolumn{2}{|c|}{ Group 1} & \multicolumn{2}{|c|}{ Group 2} & \multicolumn{2}{|c|}{ Group 3} \\
\hline & $\mathbb{N}$ & {$[\%]$} & N & {$[\%]$} & $N$ & {$[\%]$} & $\mathbb{N}$ & {$[\%]$} \\
\hline Number of parients & 152 & {$[100]$} & 65 & $\llbracket 100]$ & 37 & {$[100]$} & 50 & {$[100]$} \\
\hline Dearh & 2 & {$[1]$} & 1 & [2] & 1 & [3] & 0 & {$[0]$} \\
\hline Recurrent AMI & 7 & [5] & 3 & {$[5]$} & 2 & [5] & 2 & {$[4]$} \\
\hline PTCA & 8 & {$[5]$} & 6 & [9] & 0 & {$[0]$} & 2 & {$[4]$} \\
\hline CABG & 8 & {$[5]$} & 2 & {$[3]$} & 4 & {$[11]$} & 2 & {$[4]$} \\
\hline Anginia NYHA 24 & 40 & $\llbracket 26 \rrbracket$ & 17 & {$[26 \rrbracket$} & 10 & {$[27]$} & 13 & {$[26]$} \\
\hline
\end{tabular}

Group 1,2,3-se Table 1: AMI = acure myocardial infarcrion; P.TCA = percurancous transluminal coronary angioplasty; $C A B G=$ coronary arrery bypass graft; * In 3 patients (one in every group) follow-up data were incomplete, but the patients were known to be alive. There were no statistically significant differences between the three groups.

\section{DISCUSSION}

Most patients with acute myocardial infarction present to community hospitals where angioplasty is not available. The main purpose of this study, was to assess the feasibility, safety, and clinical outcome of early transfer of patients during the first hours of an electrocardiographic or clinically large myocardial infarction, from a 
hospital without PTCA facilities, to a PTCA center for intentional rescue PTCA after thrombolytic therapy had been initiated.

\section{PATIENT SELECTION}

Patients with clinical or electrocardiographic evidence of large acute myocardial infarction were selected by the referring cardiologist. Previous reports indicated a good correlation between the sum of ST-segment deviation and the extent of the ischaemic area in patients admitted because of an AMI (19). It has also been shown that parients with large AMI profit most from reperfusion $(19,20)$. Although, the majority of patients had anterior wall myocardial infarction, $43 \%$ of the patients had inferior AMI. The rather high contribution of inferior infarctions may have been caused by the extent of ST-segment deviation created by posterior wall ischemia.

During the study, the time interval before transfer of the patients changed. In 1993, the patients were transferred after completion of thrombolytic therapy. Later, the patients were transferred as soon as possible after initiation of thrombolytic therapy. This attitude resulted in a considerable decrease in time delays as reflected in frg. 2 .

\section{SAFETY OF TRANSPORTATION}

The present study indicates that transport of patients with a large AMI, pretreated with a thrombolytic agent, was relatively save. Safety during transport is dependent on the quality of the ambulance personnel and equipment available. The low complication rate during transport is not an unexpected finding. In trials studying pre-hospital thrombolysis in patients with AMI, similar observations have been made $(21,22)$.

The change to earlier referral did not lead to higher complication rates during ambulance transport.

As indicated by the absence of complications, also early return of patients to the referring hospital was safe. Only 36 patients (22\%) were kept in the PTCA center for some time.

\section{NON-INVASIVE REPERFUSION PARAMETERS}

Coronary angiography remains the golden standard to determine patency of the infarct-related artery ever since DeWood et al. demonstrated safety and feasibility of acute coronary angiography in AMI (23). However, this diagnostic procedure has disadvantages. Logistic problems may arise if this has to be done in every patient with AMI. Apart from the costs, acute coronary angiography may have adverse events such as bleeding at the puncture site especially after the administration of thrombolytic agents. Thus, especially after thrombolytic treatment effective 
non-invasive detection of reperfusion will diminish the need for acute coronary angiography. Sudden resolution of chest pain, one of the 2 parameters used for the non-invasive detection of coronary reperfusion in this study is a subjective finding during AMI and is dependent of the stare of ischemia and of the moment of evaluation. The correlation between sudden resolution of chest pain and coronary artery patency has been documented previously $(15,24)$. Resolution of ST-segment elevation the other non-invasive reperfusion parameter has been shown to be most valuable in determining coronary reperfusion but the predictive value $(15,24,25,26)$ is limited. The vallidity of the clinical criteria for reperfusion is still a matter of debate.

\section{DIAGNOSIS OF REPERFUSION}

By applying the electrocardiographic and clinical reperfusion criteria, approximately one third of the patients were diagnosed to have reperfusion at the time of arrival in the angioplasty center (Group 1). In these patients, no coronary angiography was performed as is advacated in previous studies $(27,28)$. They usually returned to the referring hospital by the same ambulance. Interestingly, none of these patients died in- hospital, however 11 of the 66 patients (17\%) suffered re-infarction during hospital admission ( $\mathrm{p}<0.01)$ possibly due to a high-grade residual stenosis.

Anorher one fourth showed to have TIMI-3 flow at the time of coronary angiography (group 2). Based upon the results from previous studies, no angioplasty was attempted in those patients $(27,28)$. Only $2(5 \%)$ of these 41 patients developed re-infarction and 3 patients (7\%) died in hospital. The $7 \%$ in-hospital mortality rate in patients with angiographically documented TIMI 3 flow seems high but may be explained by the small number of patients and the extent of the area at risk (57\% anterior AMI).

Clinical or angiographic reperfusion was achieved in 107 of $165(65 \%)$ parients. This is higher than expecred with thrombolytic therapy. In part this may be explained by possible overestimation of the degree of reperfusion by the use of non-invasive criteria for reperfusion. Another explanation may be the beneficial effect of the ballistics of transport on the rapidity of reperfusion.

\section{PTCA}

In most countries, angioplasty facilities are limited to tertiary centers with cardiosurgical backup. In the Netherlands, only $10 \%$ of the hospitals are licensed and equipped for coronary angioplasty. At this time their patient load varies between 500 and 1600 parients yearly. This approach has certain advantages: to perform rescue angioplasty in AMI safely, high operator skills are required. Usually, only high-volume angioplasty centers meet these requirements and can guarantee 24 hours service. 
Of the 98 patients who underwent coronary angiography, 57 patients $(58 \%)$ were found to have incomplete restoration of coronary blood flow. Successful angioplasty was performed in $96 \%$ of cases, which is similar to the success rates reported in primary angioplasty (9-12). In 10 patients an intra-aortic balloon pump was inserted prior to the angioplasty procedure because of a poor haemodynamic condition of the patient. The low number of stents used reflects the years in which these patients were studied.

\section{CLINICAL OUTCOME}

In view of the selection of patients, the short and long-term clinical outcome in the present study appear to be acceptable. However, the lack of a control group, does not allow an estimation of the true value of the approach described above.

In comparing our data to the GUSTO-IIb trial (29), in which also smaller AMI's were included, overall mortality was similar, $6.1 \%$ and $6.3 \%$, respectively. Of the 55 patients with successful rescue PTCA 4 patients died (7\%) during admission; both patients with unsuccessful rescue PTCA died. This is in line with the findings of others: the prognosis in patients with,failed rescue PTCA is poor (30-36). This might suggest that failed rescue angioplasty is in fact harmful, and is worse than no rescue attempt at all. Mckendall et al. showed a 7\% mortality rate in the no rescue group, a $12 \%$ mortality rate in the group with successful rescue PTCA, and a $33 \%$ mortality rate in the group with failed rescue PTCA (37). However, especially patients doing poorly after failed thrombolysis are subjects for rescue PTCA, indicating the higher risk if this procedure is unsuccessful.

The number of severe bleeding complications requiring blood transfusion $(3 \%)$ is low compared with other studies (38).

\section{LIMITATIONS}

Conclusions that can be drawn from this study apply especially for the subset of patients with large acute myocardial infarctions based on clinical or electrocardiographic grounds. Their value is limited, by the retrospective nature of our data and the lack of matched controls. The use of non-invasive criteria to establish presence of coronary reperfusion may have overestimated the degree of reperfusion. However we tried to create a practical approach in which we investigated the indication for coronary angioplasty in patients with early transfer for rescue PTCA, when needed. Prospective randomised studies analyzing this approach have not yet been performed but the results of this study justify a randomised study comparing thrombolytic therapy versus primary and rescue PTCA in patients with large acute myocardial infarction initially admitted to a community hospital without PTCA facilities. 


\section{CONCLUSIONS}

This study of 165 consecutive patients with the electrocardiographic or clinical suggestion of a large AMI shows that early transfer after treatment with a thrombolytic agent from a community hospital to a PTCA center for intentional rescue PTCA is feasible and safe with respect to complications during transport. It can be considered in patients presenting with a large AMI. In the Maastricht area, transfer can be done within therapeutically acceptable time limits and leads to additional successful early reperfusion in $33 \%$ of patients. The use of non-invasive reperfusion criteria as a guide to coronary angioplasty and further therapy allowed recognition of patients with a very low mortality risk and was of value to reduce the work-load in the PTCA center. Those patients, however, had an increased incidence of in-hospital reinfarction. Recurrent AMI and late PTCA were significantly less frequent in the patients treated by rescue PTCA, but in-hospital mortality was higher, especially in those patients who failed rescue PTCA. Early return of stable patients did not result in complications duting transport. The long term clinical outcome utilizing this reperfusion strategy of early transfer for intentional rescue PTCA was excellent.

In the absence of a control group, the true value of our approach cannot be evaluated. However, the outcome with regard to safety and feasibility, and a recently published study on transferring patients with AMI for primary PTCA (39), with favorable results, should be a reason to start a large scale multi-center prospective randomized trial comparing three treatment modalities in patients admitted with a large acute myocardial infarction to a non-PTCA hospital: 1) thrombolytic therapy in the admitting hospital without transport, 2) thrombolytic therapy followed by immediate transport and rescue PTCA if indicated, and 3) no pretreatment with a thrombolytic agent, immediate transport, and primary PTCA.

\section{REFERENCES}

1. Gruppo Iraliano per lo Studio della Streptochinasi nell' Infarto Miocardico (GISSI). Effectiveness of intravenous thrombolytic treatment in acute myocardial infarction. Lancet 1986;1:397-402.

2. Simoons ML, Serruys PW, Van den Brand M, Res J, Verheugt FWA, Krauss H, Remme W], Bär

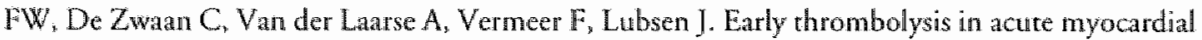
infarcrion: limitation of infarct size and improved survival. J. Am Coll Cardiol 1986;7:717-28.

3. Ellis SG, Ribeiro-da Silwa E, Heyndrickx G, Talley D, Cernighani C, Sreg G, Spaulding C, Nobuyoshi $M$, Erbel R, Vassanelli $C$, Topol EJ for the RESCUE Investigators. Randomized comparison of rescue angioplasty with conservative management of patients with early failure of thrombolysis for AMT. Circ 1994;90:2280-4.

4. Vermeer F, Simoons ML, De Zwaan C, Van Es GA, Verheugr FWA, Van der Laarse A, Van Hoogenhuyze DCA. Azar AJ, Van Dalen FL, Lubsen. J, Hugenholtz PG. Cost benefit analysis of arly thrombolyric treatment with intracoronary streptokinase: Twelve month follow up report of 
the randomised mulcicenter trial conducted by I.C.I.N. of the Netherlands. Br Heart I $1988 ; 59: 527-534$.

5. Raitt MH, Maynard C, Wagner GS, Cerqueira MD, Selvester RH, Weaver WD. Relarion between symptom duration before thrombolytic therapy and final myocardial infirct size. Circulation 1996:93:48-53.

6. Mauri F, Maggioni AP, Franzosi MG, De Vita C, Santoro E, Gianuzzi P, Tognoni G. A simple electrocardiographic predictor of the outcome of patients with acute myocardial infarction treared with thrombolyric agents. J AM Coll Cardiol 1994;24:600-607.

7. Ellis $S G$, van de Werf $F$, Ribeiro $E$ et al. Present status of rescue coronary angioplasty: Current polarization of opinion and randomized trials. I AM Coll Cardiol 1992;19:681-686.

8. Belenkie I, Traboulsi $\mathrm{M}$, Hall $\mathrm{CA}$ et al. Rescue angioplasty during myocardial infarction has a beneficial effect on mortality: attenable hypothesis. Can J Cardiol 1992;8:357-362.

9. Grines CL, Browne KF, Marco J, Rorhbaum D, Stone G, O'Keefe ], Overlie P, Donohue B, Chelliah N, Timmis GC, Vlietstra R, Strzelecki M, Puchrowice S, O'Neill W, for the Primary Angioplasty in Myocardial Infarcrion Study Group. A comparison of immediate angioplasty with thrombolytic therapy for acute myocardial infarction. N Engl J Med 1993:328:673-9.

10. Gibbons RJ, Holmes DR, Reeder GS, Bailey KR, Hopfenspirger MR, Gersh B』, Phil D, for the Mayo Coronary Care Unit and Catheterization Laboratory groups. Inmediate angioplasty compared with the administration of a thrombolytic agent followed by conservatiwe tratment for myocardial infarction. N Engl J Med 1993;328:685-91.

11. Zijlstra F, Boer de MJ. Hoontje JCA, Rieffers S, Rieber J, Suryapranata H. A comparison of immediate coronary angioplasty with intravenous streptokinase in acute myocardial infarction. $N$ Engl J Med 1993;328:680-4.

12. Every NR, Parsons LS, Hlatky M, Martin MS, Weaver WP. A comparison of thrombolyric therapy with primary coronary angioplasty for acute myocardial infarcrion. N Engl J Med 1996;335: $1253-1260$.

13. Lange RA, Hillis LD. Should thrombolysis or primary angioplasty be the rearment of choice for acute myocardial infarction? $\mathrm{N}$ Engl J Med 1996;335:1311-12.

14. Braat SH, Gorgels APM, Bär FW, er al. Value of ST-T segment in lead V4R in inferior wall acure myocardial infarction to predict the site of coronary arterial occlusion. Am J Cardiol 1988:62: 140-142.

15. Doevendans PA, Gorgels AP, Zee wd R, Partouns J, Bär FW, Wellens HJJ. Electrocardiographic diagnosis of reperfusion during thrombolytic therapy in acute myocardial infarction.Am J Cardiol $1995 ; 75: 1206-1210$.

16. Topol EJ. Textbook of interventional Cardiology. 2nd ed. Philadelphia:Saunders, 1994.

17. The TIMI Study Group: Comparison of invasive and conservative strategies after treatment with intravenous tissue plasminogen activator in acute myocardial infarction: results of the Thrombolysis In Myocardial Infarction (TTMD) phase II rrial. N Engl J med 1989;320:618-627.

18. The criteria committee of the New York Heart Association. Nomenclature and criteriz of discases of the heart and great wessels, 9th edition. Boston:Little Brown and Company, 1994.

19. Simoons ML Arnold AE. Taillored Thrombolytic Therapy a perspective. Circulation $1993 ; 88: 2556-2564$ 
20. Bar FW, for the SESAM study group. Early parency and reocclusion in acute myocardial infarction. A comparison between thrombolytic agents saruplase and alteplase. Results of the SESAM trial. I AM Coll Cardioll 1994;405A:954-43.

21. The European Myocatdial Infarction Project Group. Prehospital thrombolytic therapy in parients wirh suspected acure myocardial infarction. N Engl J Med 1993;329:383-9.

22. Great group. Feasibiliry, safety and efficacy of domiciliary thrombolysis by general practitioners: Grampian regtion early anistreplase trial. BMJ 1992;305:548-53.

23. DeWood MA, Spores J. Notske Rer al. Prevalence of total coronary occlusion during the early hours of transmual myocardial infarction. N Engl J Med 1980;303:897-902.

24. Kircher BI, "lopol EJ, O'Neill WW, Pitc B. Predicrion of infarce coronary artery recanalization after intrawenous thrombolytic therapy. Am J Cardiol 1987:59:513-5115.

25. Clemmensen I", Ohman ME, Sevilla DC, Peck S, Wagner NB, Quigley PS, Grande P, Lee KL, Wagner GS. Changes in standand Electrocardiographic ST-segment elewation predictive of successful reperfusion in acure myocatdial infarction. Am J Cardiol 1990;66:14071411.

26. Califf RM, ONeill W, Stack RS, et al. Failure of simple dinical measurements to predict reperfusion stans after intravenous thrombolysis. Ann Intern Med 1988;108:658-662.

27. The European Cooperarive Study Group For rTPA. Thrombolysis with rissue plasminogen activator in acute myocardial infarction: No additional benefit from immediate percutancous coronary angioplasty. Lancet 1988;1:197-202.

28. The TIMI Research Group. Immediate vs delayed cathererizarion and angioplasty following thrombolytic therapy for acute myocardial infarction. TTMI IIA results. JAMA 1988;260: $2849-2858$.

29. Gusto IIb study group. A dinical trial comparing primary coronary angioplasty with tissue plasminogen activator for acute myocardial infarction. N Engl J Med 1997;336:1621-1628.

30. Hartzler GO, Rutherford BD, McConahay DR, et al. Percutaneous transluminal coronary angioplasry with and withour thrombolytic therapy for treatment of acute myocardial infarcrion. An Hearr J 1983;106:965.973.

31. Papapiero SE, Madean WAH, Stanley AWH jr. er al. Percutaneous transluminal coronary angioplasty after intracoronary streptokinase in evolving acure myocardial infarction. Am $\int$ Cardiol 1985,55:48-53.

32. Fung AY, Lai P, Topol ED, et at. Value of percutaneous ransluminal angioplasty after unsuccessful intravenous streptokinase therapy in acute myocardial infarction. Am J Cardiol 1986;58:686-69 1.

33. Abbotsmita CW, Topol EJ, George BS, et al. Fate of patients with acure myocardial infarction with patency of the infarctrelated vessel achiewed with successful thrombolysis versus rescue angioplasty. J Am Coll Cardiol 1990; 16:770-778.

34. Ellis SG, ONeill WW, Bates ER, et al. Implications for patient triage from survival and left ventricular functional recovery analysis in 500 parients rreared with coronary angioplasty for acure myocardial infarcrion. I An Coll Cardiol 1989;13:1251-1259.

35. Gibson CM, Cannon CP, Piana RM, er al. Rescue PTCA in the TIMI 4 trial. I Am Coll Cardiol $1994: 225 \mathrm{~A} ; 755$. 
36. Bär FW, Oude Ophuis AJM, Frederiks ), Ommen van V, Swart de H, Zwaan C, Wellens HIJ. Rescue PTCA following falled thrombolysis and primary PTCA. J Thrombosis and Thrombolyis 1997:4:281-288.

37. Mckendall GR, Forman S, Sopko G, for the Thrombolysis in Myocardial Infarcrion Investigators. Value of rescue percutaneous transluminal coronary angioplasty following unsuccessful thrombolytic therapy in patients with acuce myocardial infarction. Circulation 1994;90:2280-2284.

38. Guerci $A D$, Gerstenblith $G$, Brinker JA, Chandra NC, Gotrlier SO. A randomized trial of intravenous tissue plasminogen activator for acute myocardial infarction with subsequent randomizarion to elective coronary angioplasty. N Engl I Med 1987:317:1613-1618.

39. Zijlstra F, Hof van het AW, Liem AY, Hoorntje JC, Suryapranata $\mathrm{H}_{3}$ Boer de MJ. Transferring parients for primary angioplasty: a retrospecrive analysis of 104 selected high risk patients with acute myocardial infarction. Heart 1997:78:333-336. 
CHAPTER 5

\section{Angiographic assessment of prospectively determined non-invasive reperfusion parameters in acute myocardial infarction}

Can the number of acute coronary angiography and subsequent angioplasty be reduced?

Oude Ophuis AJ, Bär FW, Vermeer F, Janssen W, Doevendans PA, Haest RJ,

Dassen WR, Wellens H]J

Department of Cardiology, University Hospital Maastricht, Maastricht, the Netherlands 
60

\section{ABSTRACT}

Objective: Patients with acute myocardial infarction can benefit from coronary angiography and subsequent coronary angioplasty in case of no or insufficient reperfusion. The present study in 230 patients investigates the value of 7 non-invasive reperfusion parameters with respect to Thrombolysis in Myocardial (TIMI) flow, by avoiding the possible need for acute coronary angiography and subsequent angioplasty.

Desigr: In a prospective angiographic study, the value of 7 potential electrocardiographic ar clinical markers of reperfusion was analysed in 230 patients with AMI. In all patients two 12-lead ECG's were used: the ECG on admission and the ECG immediately before coronary angiography. Non-invasive markers of reperfusion determined just before coronary angiography were prospectively correlated to TIMI flow. Data analysis was conducted correlating these non-invasive parameters to coronary flow (analysis A: TIMI 2-3 versus TIMI 0-1 flow; analysis B: TIMI 3 wersus TIMI 0-2 flow).

Results: Sudden decrease in chest pain was the most common sign of reperfusion (36\%), followed by resolution of ST-segment elevation $\geq 50 \%$ in $30 \%$, and the development of a terminal negative T-wave (20\%) in the lead with highest ST-segment elevation. Resolution of ST-segment elevation $\geq 50 \%$ and appearance of an accelerated idioventricular thythm (AIVR) had the highest positive predictive value (PPV) for reperfusion. For analysis A and B the PPV was $85 \%$ and $66 \%$ for resolution of $5 T$-segment elevation, and $94 \%$ and $59 \%$ for AIVR, respectively. The presence of 3 or more non-invasive markers of reperfusion predicted TIMI 3 flow accurately in $80 \%$ of cases.

Conclusions: The prospective use of non-invasive parameters of reperfusion is simple, practical, and can be of value to assess coronary patency in patients admitted with AMI. Using these parameters, discrimination between TIMI 0-1 and TIMI 2-3 flow can be done with good accuracy. However, IIMI 3 flow cannot reliably be determined. Depending on the goal of reperfusion the non-invasive parameters of reperfusion can be used accordingly. 
Abbreviations and Acronyms

AMI $=$ acute myocardial infarction
ECG $=$ electrocardiogram
AIVR = accelerared idioventricular rhythm
PTCA = percutaneous transluminal coronary angioplasty
CAG = coronary angiography
SD $=$ scandard deviation
PPV = positive predictive value
NPV = negative predictive value

\section{INTRODUCTION}

Several studies have shown the value of non-invasive reperfusion parameters in acute myocardial infarction (AMI) (1)(2)(3)(4). A number of non-invasive parameters were useful to determine coronary reperfusion like resolurion of ST-segment elevation, change in chest pain and the occurrence of certain arrhythmia's. Most of these studies were done in a small number of patients and the interval berween the non-invasive evaluation and the angiographic validation of reperfusion was variable. Many of these studies were retrospective. The prospective value of non-invasive parameters of reperfusion is still not clear.

Determination of the presence of coronary reperfusion through simple non-invasive tools is of obvious value to establish successful thrombolysis and to identify spontaneous reperfusion in patients referred for percutaneous transluminal coronary angioplasty (PTCA). Acute intervention in the presence of reperfusion has not shown to improve clinical outcome and coronary angiography should be withheld in case non-invasive markers of reperfusion are of sufficient predictive value. (5)(6) When coronary blood flow has not been restored, emergency PTCA is likely to be helpful (7)(8)(9)(10). The value of intracoronary intervention in patients with Thrombolysis in Myocardial Infarction (TIMI) 2 flow is still a matter of debate. Anderson et al showed a better prognosis in patients with TIMI 3 flow in comparison to TIMI 2 flow (11). Other investigators could not confirm these results. (12)(13) In case the findings of Anderson et al are correct it would be of importance to discriminate non-invasively between patients with TIMI $0-2$ and patients with TIMI 3 flow of the infarct-related artery. Otherwise, only differentiation is needed between TIMI $0-1$ and TIMI 2-3 flow of the infarct-related artery. The aim of this angiographically controlled study was to determine the prospective value of sewen reperfusion parameters. If non-invasive reperfusion parameters can reliably predict adequate restoration of flow, the costly, possible hazardous and oftentimes logistically difficult acute coronary angiography can be avoided. 
62 CHATER 5

\section{METHODS}

\section{STUDY PATIENTS}

Two-hundred thirty consecutive patients with acute coronary angiography were entolled in this study. All patients were admitted within the first 6 hours of AMI. Entry in the study required chest pain for at least 30 minutes not responding to nitroglycerin, associated with more than $0.1 \mathrm{mV}(1 \mathrm{~mm})$ ST-segment elevation in two or more limb leads and at least $0.2 \mathrm{mV}$ in two or more contiguous precordial leads according to normal standards for thrombolytic treatment. Thrombolytic therapy (streptokinase, saruplase, alteplase) was administered in-hospital, usually at the emergency department. The reasons for acute coronary angiography were: primary PTCA, coronary angiography after thrombolytic therapy in the setring of a study protocol, and possible rescue PTCA.

\section{HISTORY}

Careful attention was paid to chest pain evolution. Before coronary angiography, each patient was asked to rate the severity of chest pain to indicate whether sudden changes in chest pain had occurred. Chest pain was then classified as unchanged or as a sudden decrease or a sudden increase between admission and start of coronary angiography.

\section{ELECTROCARDIOGRAPHY}

A 12-lead electrocardiogram recording was made on admission and just prior to coronary angiography (Figure 1). These two ECG's were compared and used for the presence of reperfusion parameters. The criteria for reperfusion as listed in Table 1 were checked by the angiographer just prior to the angiographic procedure and documented in the patient record form. Using these criteria, the angiographer additionally predicted presence or absence of patency of the infarct related artery before the start of coronary angiography.

\section{CORONARY ANGIOGRAPHY}

All patients underwent coronary angiography in the acute phase of the AMI usually within 73 median minutes after admission at the Academic Hospital of Maastricht (Table 2). Coronary angiography was performed using the Seldinger technique. The first intracoronary injection was used to determine coronary flow. Reperfusion of the infarct-related artery was determined according to the TIMI criteria (6). In case of infero-posterior infarction combined with multi-vessel disease, right precordial leads and the aspect on coronary angiography were used to differentiate between circumflex and right coronary artery as the infarct related artery (14). 
A

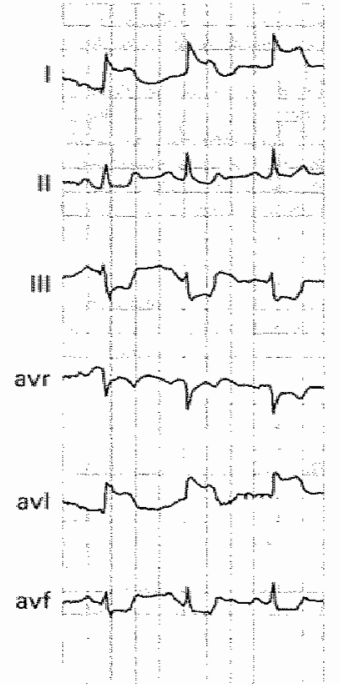

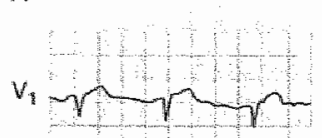
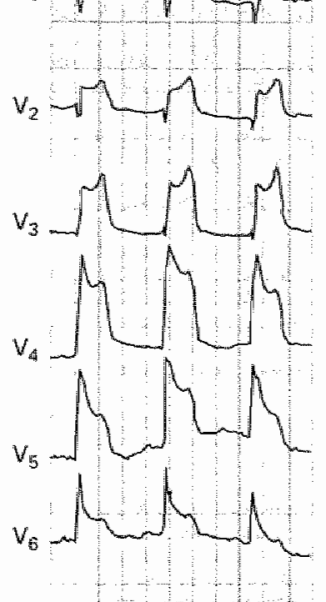

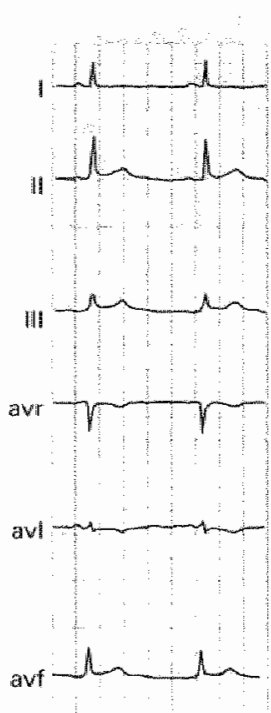

B

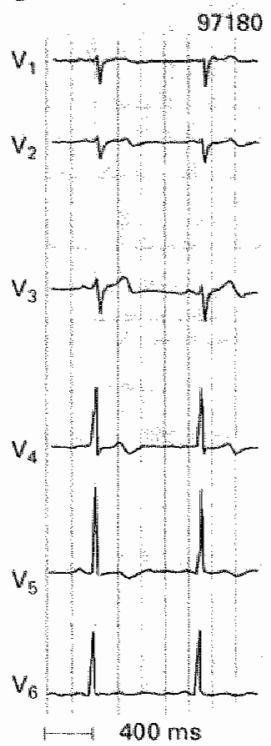

Figure 1. Example of the resolution of ST-segment elevation and development of terminal negarive T-waves as a sign of reperfusion. Patient with extensive anterior wall myocardial infarction treated with a thrombolytic agent.

Panel A: Admission ECG showing ST-segment elevation in anterior leads (most prominent in lead V4).

Panel B: ECG just prior to first intracoronary contrast injection showing TIMI 3 flow. Resolution of ST-segment elevation $\geq 50 \%$ and development of rerminal negative $T$-wave in lead $V 4$. "This patient also had a sudden decrease of chest pain.

\section{STATISTICAL ANALYSIS}

The data were stored in a compurer and analysed by SPSS/7.0. Data were expressed as mean $\pm S D$ for continuous variables or as rates for categorical variables. For categorical variables the Chi-square test, or when applicable, Fisher's exact test was used. A p(robability) value $<0.05$ was considered statistically significant.

\section{RESULTS}

The characteristics of the 230 patients are listed in Table 2 . One hundred sixty-five patients $(72 \%)$ had received thrombolytic therapy. Coronary angiography data are shown in Table 3. Fifry-seven percent of the parients had TIMI 0 or 1 and $29 \%$ showed TIMI 3 coronary flow at the first intracoronary injection. One-year mortality was lowest in the patients with TIMI 3 flow at first injection (Table 3). The frequency of the individual non-invasive reperfusion parameters is shown in 
Table 1. Definitions of the paramerers of reperfusion

\begin{tabular}{|c|c|}
\hline ST-segment resolution $250 \%$ & $\begin{array}{l}\text { Reduction of } \geq 50 \% \text { of } S T \text {-segment elevation in the } \\
\text { infarct-lead showing the highest } S T \text {-segment elevation } \\
\text { measured from the J-point between admission ECG and } \\
\text { ECG just prior to coronary angiography (CAG). }\end{array}$ \\
\hline Sudden decrease chest pain: & $\begin{array}{l}\text { Sudder decrease of chest discomfort in the period berween } \\
\text { admission ECG and CAG as indicated by the parient. }\end{array}$ \\
\hline Sudden increase chest patin: & $\begin{array}{l}\text { Sudden increase of chest discomfort in the period between } \\
\text { admission ECG and CAG as indicated by the patient. }\end{array}$ \\
\hline Accelerated Idio-Ventricular Rhythm: & $\begin{array}{l}\text { Run of }>4 \text { consecutive non-premature ventricular complexes } \\
\text { ar a rate between } 80-125 \text { beats/min present at ECG in the } \\
\text { period berween admission ECG and CAG. }\end{array}$ \\
\hline Ventricular fibrillarion: & $\begin{array}{l}\text { Episode of ventricular fibrillation requiring defibrillation } \\
\text { berween admission ECG and } C A G \text {. }\end{array}$ \\
\hline Ventricular ectopy: & $\begin{array}{l}\text { Premature ventricular complexes present on admission } \mathrm{ECG} \\
\text { or } \mathrm{ECG} \text { just prior to } \mathrm{CAG} \text {. }\end{array}$ \\
\hline Terminal negative $T$-wave: & $\begin{array}{l}\text { The development of terminal negative } T \text {-wave } \geq 0.1 \mathrm{mV}(\geq 1 \\
\mathrm{mm} \text { ) in the infarct lead with highest } S \mathrm{~T} \text {-segment elevation on } \\
\text { the } \mathrm{ECG} \text { just prior to } \mathrm{CAG} \text {. }\end{array}$ \\
\hline
\end{tabular}

Table 2. Patient characteristics of the 230 patients

\begin{tabular}{lll}
\hline & $N$ & {$[\%]$} \\
\hline All patients & 230 & {$[100]$} \\
Age (mean \pm SD in years) & $59 \pm 11$ & \\
Male & 176 & {$[77]$} \\
Previous infarction & 29 & {$[13]$} \\
Patients with anterior infarction & 119 & {$[52]$} \\
Thrombolytic therapy & 165 & {$[72]$} \\
Referred for primary PTCA & 65 & {$[28]$} \\
Hospital admission-CAG (min) median** & 73 & {$[34 ; 102]$} \\
Maximal ASAT" (U/L) median* & 241 & {$[132 ; 340]$} \\
\hline
\end{tabular}

* Range 25 th percentile; 75 th percentile]. 
Table 3. Angiographic dara of the 230 parients

\begin{tabular}{|c|c|c|c|c|}
\hline & \multirow[b]{2}{*}{$N$} & \multirow[b]{2}{*}[\%]{} & \multicolumn{2}{|c|}{ 1-y mortaliry* } \\
\hline & & & $\mathrm{N}$ & {$[\%]$} \\
\hline All patients & 230 & {$[100]$} & 15 & {$[6.5]$} \\
\hline \multicolumn{5}{|c|}{ Wriforet related artery } \\
\hline LAD & 119 & {$[51.7]$} & 9 & {$[7.5]$} \\
\hline$c x$ & 14 & {$[6.1]$} & 0 & $\llbracket 0 \rrbracket$ \\
\hline RCA & 96 & {$[41.8]$} & 6 & [6.2] \\
\hline Graft & 1 & 0.4 & 0 & {$[0]$} \\
\hline \multicolumn{5}{|c|}{ THMI flow forst injecton } \\
\hline TIMI 0 & 106 & {$[46.1]$} & 8 & [7.5] \\
\hline TIMI 1 & 25 & {$[10.9]$} & 3 & {$[12]$} \\
\hline TIMI 2 & 32 & {$[13.9]$} & 2 & {$[6.2]$} \\
\hline TIMI 3 & 67 & {$[29.1]$} & 2 & {$[3.0]$} \\
\hline \multicolumn{5}{|l|}{ Vessel disease } \\
\hline -One & 134 & {$[58.3]$} & 8 & {$[5.9]$} \\
\hline -Two & 45 & {$[19.5]$} & 1 & {$[2.2]$} \\
\hline Three & 51 & {$[22.2]$} & 6 & {$[11.7]$} \\
\hline PTCA & 143 & {$[62.2]$} & 8 & {$[5.5]$} \\
\hline
\end{tabular}

*3 patients were lost to follow-up.

Table 4. The frequencies of non-inwasive parameters of reperfusion were not significantly different between the patients with or without thrombolytic therapy (Table 4). A sudden decrease in chest pain had the highest incidence (36\%), followed by resoJution of ST-segment elevation (30\%). The average degree of ST-segment elevation in the most prominent infarct lead on the admission ECG was $4.7 \mathrm{~mm} \pm 3.4 \mathrm{~mm}$ (range $1-23 \mathrm{~mm}$ ). Jus prior to coronary angiography mean ST-segment elevation in the same lead was $4.1 \mathrm{~mm} \pm 3.6 \mathrm{~mm}$ (range $0-30 \mathrm{~mm}$ ). Thirteen patients $(6 \%)$ had a sudden increase of chest pain after admission but prior to coronary angiography. The non-invasive reperfusion parameters were correlated to the TIMI flow at the first angiographic view of the infarct-related artery: analysis A: TIMI 2-3 versus TIMI 0-1 flow (Table 5); analysis B: TIMI 3 versus TIMI 0-2 flow (Table 6). Except for the sudden increase in chest pain and ventricular fibrillarion, all parameters correlated well with TIMI flow. Table 7 shows the specificity, sensitivity and positive- and negative predictive value of the number of reperfusion parameters required to be present to determine TIMI 2-3 or TIMI 3 flow of the infarct-related artery. The presence of more than three parameters of reperfusion is highly specific for the presence of TIMI 3 flow of the infarct-related artery (99\%). 
$66 \mid$ Chaph 5

Table 4. Freguency of non-invasive parameters of reperfusion in the 230 patients

\begin{tabular}{|c|c|c|c|c|c|c|c|}
\hline & \multicolumn{2}{|c|}{ All $(n=230)$} & \multicolumn{2}{|c|}{$\begin{array}{l}\text { Thrombolysis: } \\
(n=165)\end{array}$} & \multicolumn{2}{|c|}{$\begin{array}{l}\text { No Thrombolysis } \\
(\mathrm{n}=65)\end{array}$} & \multirow[t]{2}{*}{ P-value } \\
\hline & $\mathbb{N}$ & {$[\%]$} & $N$ & {$[\%]$} & $\mathbf{N}$ & {$[\%]$} & \\
\hline \multicolumn{8}{|l|}{ Chest pain } \\
\hline Sudden decrease. & 83 & {$[36]$} & 65 & [39] & 18 & {$[28]$} & 0.070 \\
\hline Sudden increase & 13 & {$[6]$} & 7 & [4] & 6 & [9] & 0.257 \\
\hline Resolution $S \mathrm{~T}$-segment elevation $\geq 50 \%$ & 68 & {$[30]$} & 51 & [31] & 17 & {$[26]$} & 0.657 \\
\hline AlvR & 17 & {$[7]$} & 15 & {$[9]$} & 2 & [3] & 0.194 \\
\hline Ventricular fibrillation & 13 & {$[6]$} & 10 & {$[6]$} & 3 & $\llbracket 5 \rrbracket$ & 0.904 \\
\hline Ventricular ectopy & 33 & {$[14]$} & 23 & {$[14]$} & 10 & $\llbracket 15 \rrbracket$ & 0.956 \\
\hline Development terminal negative $T$-wave & 46 & {$[20]$} & 34 & {$[21]$} & 12 & [18] & 0.880 \\
\hline
\end{tabular}

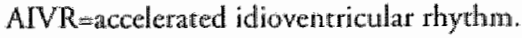

Table 5. Correlation non-invasive reperfusion paramerers and TIMI 2-3 flow in the 230 patients

\begin{tabular}{|c|c|c|c|c|c|c|c|}
\hline \multirow{2}{*}{ 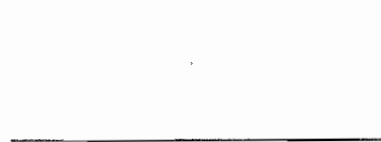 } & \multicolumn{2}{|c|}{ TIMI 0-1 } & \multicolumn{2}{|c|}{ TIMI 2-3 } & \multirow{2}{*}{$\begin{array}{l}\text { PPV } \\
\%\end{array}$} & \multirow{2}{*}{$\begin{array}{l}\text { NPV } \\
\%\end{array}$} & \multirow[t]{2}{*}{ P-value } \\
\hline & $\mathrm{N}$ & {$[\%]$} & $N$ & {$[\%]$} & & & \\
\hline All patients & 131 & {$[100]$} & 99 & {$[100$} & & & \\
\hline$S \mathrm{~T}$-segment resolution $\geq 50 \%$ & 10 & {$[7.6]$} & 58 & {$[58.6]$} & 85 & 75 & 0.001 \\
\hline Sudden decrease chest pain & 8 & {$[6.1]$} & 65 & {$[65.7]$} & 89 & 78 & 0.001 \\
\hline Sudden increase chest pain & 7 & [5.3] & 6 & {$[6.1]$} & 46 & 57 & 0.83 \\
\hline AIVR & 1 & {$[0.8]$} & 16 & {$[16.2]$} & 94 & 61 & 0.001 \\
\hline Ventricular fibrillation & 5 & {$[3.8]$} & 8 & {$[8.1]$} & 62 & 58 & 0.17 \\
\hline Ventricular ectopy & 9 & {$[6.9]$} & 24 & {$[24.2]$} & 73 & 62 & 0.001 \\
\hline Negative T-wave & 11 & {$[8.4]$} & 35 & {$[35.4]$} & 76 & 65 & 0.001 \\
\hline
\end{tabular}

PPV=positive predictive value $(\%)$ NPV=negative predictive value $(\%)$; AIVR=accelerated idioventricular rhythm.

Before the start of the procedure the invasive cardiologist predicted reperfusion: TIMI 2-3 flow of the infarct-related artery was accurarely predicted in $88 \%$. However, TIMI 3 coronary flow prediction could only be made in $67 \%$ of cases. In case of prediction of improved flow by the invasive cardiologist the clinical outcome with respect to one-year mortality appeared to be excellent ( $0 \%)$. 
Table 6. Correlation non-inwasive reperfusion parameters and TIM1 3 flow in the 230 patients

\begin{tabular}{|c|c|c|c|c|c|c|c|}
\hline & \multicolumn{2}{|c|}{ TIMI $0-2$} & \multicolumn{2}{|c|}{ TIMI 3} & \multirow{2}{*}{$\begin{array}{l}\text { PPV } \\
\%\end{array}$} & \multirow{2}{*}{$\begin{array}{l}\text { NPV } \\
\%\end{array}$} & \multirow[t]{2}{*}{ P-value } \\
\hline & $\mathrm{N}$ & {$[\%]$} & $\mathbb{N}$ & {$[\%]$} & & & \\
\hline All parients & 163 & $\lfloor 100 \rrbracket$ & 67 & {$[100]$} & & & \\
\hline$S T$-segment resolution $\geq 50 \%$ & 23 & [14..1] & 45 & {$[67.2]$} & 66 & 86 & 0.001 \\
\hline Sudden decrease chest pain & 36 & {$[22.1]$} & 47 & {$[70.1]$} & 57 & 86 & 0.001 \\
\hline Sudden increase chest pain & 9 & {$[5.5]$} & 4 & {$[6.0]$} & 31 & 71 & 0.92 \\
\hline AIVR & 7 & {$[4.3]$} & 10 & [14.9] & 59 & 73 & 0.005 \\
\hline Ventricular fibrillarion & 7 & {$[4.3]$} & 6 & {$[9.0]$} & 46 & 72 & 0.17 \\
\hline Ventricular ectopy & 18 & {$[11.0]$} & 15 & {$[22.4]$} & 45 & 74 & 0.03 \\
\hline Negative Twave & 18 & {$[11.7]$} & 28 & [41.8] & 61 & 79 & 0.001 \\
\hline
\end{tabular}

PPV=positive predictive value (\%); NPV=negative predictive value $(\%)$; AIVR=accelerated idioventricular rhythm.

Table 7 . The value of the total number of non-invasive parameters of reperfusion present in predicting either TIMI 2-3 or TIMI 3 flow of the infarct relared artery

\begin{tabular}{lcccc}
\hline No. of parameters & Sens & Spec & PPV & NPV \\
\hline TIMI 2-3 & & & & \\
$>0$ & 85 & 71 & 69 & 86 \\
$>1$ & 72 & 87 & 81 & 80 \\
$>2$ & 46 & 95 & 88 & 70 \\
$>3$ & 10 & 100 & 100 & 60 \\
& & & & \\
TIMI 3 & & & & \\
$>0$ & 88 & 61 & 48 & 93 \\
$>1$ & 78 & 78 & 59 & 89 \\
$>2$ & 54 & 90 & 69 & 83 \\
$>3$ & 12 & 99 & 80 & 73 \\
\hline
\end{tabular}

$P P V=$ positive predictive value $(\%) ; N P V=$ negatiwe predictive value $(\%)$; Sens. = sensitivity; Spec.= specificity. 


\section{DISCUSSION}

The treatment of AMI is directed towards limitation of infarct size, to reduce complications and to prolong longevity $(15)(16)$. Patients promptly treated after the onset of symptoms by restoring patency of the infarct-related artery will have the largest benefit. Patients with complete reperfusion of the infarct related artery will have a better prognosis than patients with no or incomplete restoration of flow (11). The one-year mortality is $5 \%$ in patients with TIMI 3 as compared to $27 \%$ in parierits with TIMIO/1 flow (17)(18). Therefore, the value of (non-invasive) detection of adequate reperfusion is of great importance. In case non-invasive reperfusion parameters point towards insufficient coronary flow, acute coronary angiography followed by PTCA if indicated, may alter the prognosis in a positive way.

\section{STUDY POPULATION}

The reason to perform acute coronary angiography in this group of 230 parients varied, as described in the methods section with $72 \%$ having received thrombolytic therapy. TIMI 0-1 flow was present in 57\% (Table 3) which is rather high. It is in part explained by the contribution of patients referred for primary PTCA.

\section{TIMI FLOW}

Coronary angiography remains the golden standard to determine patency of the infarct related artery ever since DeWood et al demonstrated safery and feasibility of acute coronary angiography in AMI (19). However, this diagnostic procedure has disadvantages. Logistic problems may arise if this has to be done in every patient with AMI. Apart from the costs, acute coronary angiography may have adverse effects such as bleeding at the puncture site especially after the administration of thrombolytic agents. Thus, especially after thrombolytic treatment effective non-invasive detection of reperfusion will diminish the need for acute coronary angiography. The present prospective study documents the value of the 7 non-invasive parameters of reperfusion as a predictor for coronary reperfusion enabling differentiation between TIMI 0-1 and TIM $12-3$ flow of the infarct-related artery. The obvious advantage of the use of these non-invasive parameters of reperfusion is that they are simple, cheap and parient-friendly.

WHAT IS THE GOAL OF REPERFUSION: TIMI 2 FLOW OR TIMI 3 FLOW?

As stated earlier, the discussion on pursuing either TIMI 2 flow or TIMI 3 flow of the infarct-related artery is still ongoing but favours achievement of TIMI 3 flow. The non-invasive discrimination between TIMI 0-2 flow and TIMI 3 flow is important if the outcome of patients with TIMI 3 flow of the infarct-related artery is 
considered to be superior to TIMI 2 flow. If TIMI 2 flow is considered to be more or less equal to TIMI 3 flow with respect to clinical outcome it is more important to discriminate between TIMI $0-1$ and TIMI 2-3 flow. Limitations in budget, manpower, access to coronary angioplasty and the distance of travel to an angioplasty facilicy may intervene with the goal of reperfusion and definitions of treatment goals will depend on local and personal circumstances.

The issue of TIMI 3 flow or TIMI 2-3 flow may in fact be important in community hospitals without PTCA facilities who consider transfer of patients with AMI for emergency PTCA. This scenario is frequently the case in many European countries where angioplasty facilities are limited and the distance to tertiary PTCA centers is considerable. We recently published a study showing that early referral for intentional rescue angioplasty can be beneficial. In that study it was shown that patients with noninvasive signs of reperfusion in whom acute coronary angiography was refrained had a very good prognosis $(20)$.

\section{INCIDENCE AND VALUE OF THE DIFFERENT NON-INVASIVE PARAMETERS}

ST-segment resolution $\geq 50 \%$ had an incidence of $30 \%$ in this study population with good positive and negative predictive value to identify patients with reperfusion. In $85 \%$ of patients TIMI $2-3$ flow was correctly predicted. However the positive predictive value of this non-invasive reperfusion parameter drops to $66 \%$ when it is used to predict TIMI 3 flow. Thus, using this non-invasive parameter only, it would lead to $15 \%$ of patients being falsely identified as having TIMI 2-3 flow and $34 \%$ of patients incorrectly considered to have TIMI 3 flow.

The weak prediction of complete restoration of flow (TIMI 3 flow) questions the value of this single reperfusion parameter. It is clear that there is considerable overlap in ST-segment behaviour in the patients with TIMI 2 or TIMI 3 flow of the infarct-related artery. Our findings are comparable to those of Kircher et al who found qualitative ST-segment improvement in $33 \%$ of patients with AMI associated with $88 \%$ probability of reperfusion (21). Clemmensen et al indicated that a decrease of $20 \%$ of the sum of ST-segment elevation was an useful non-invasive predictor of TIMI 2-3 flow of the infarct related artery (PPV 88\%; NPV 80\%) (22). In a small test population, Hogg and co-workers using the lead with maximal ST-segment deviation on the standard 12 -lead ECG found that a $50 \%$ reduction in ST-elevarion was $67 \%$ specific and $93 \%$ sensitive, however perfusion criteria were not given (23). Many orher studies have been reported using a different percentage of ST-segment resolution usually in small patient groups and with a wide variety in time between the ECG recording and the determination of the state of reperfusion. The strength of our study lies in its prospective nature, in the simplicity of using only the ECG lead with the highest ST-segment elevation, the immediare coronary angiography after the second ECG giving the correct perfusion stacus, and the rather large parient population with a $43 \%$ coronary artery patency. 


\section{SUDDEN CHANGE IN CHESTPAIN}

Increase or relief of chest pain is a subjecrive finding during AMI, and dependent on the state of ischemia and the moment of evaluation. Kircher et al showed the relation between suddlen resolution of chest pain and coronary artery patency (21). However, extensive and long lasting myonecrosis can be accompanied by a gradual decrease in symptoms (the natural course of myocardial infarction). The duration between onset of pain and assessment of severity of complaints was rather short ( $<7.5$ hours) in our study. During this time interval symproms usually are still present. Pain-relieving medication and the administration of anti-ischemic agents can contribute to a decrease in symptoms and may partially have influenced assessment of chest pain (24)(25). Also cyclic changes of coronary perfusion and coronary tonus can contribute to changes in chest pain. Finally, an increase in chest pain can be experienced just after reperfusion of the infarct-related artery and could be caused by wash out of toxic metabolites. Like in other studies, the predictive value of sudden decrease or increase of chest pain had only limited predictive value (3) (26).

\section{ARRHYTHMOGENECITY OF REPERFUSION}

Due to the washout phenomenon during reperfusion of the infarct related artery, a sudden change in electrolytes, free radicals, fatty acids and other factors, can result in electrical instability and tissue heterogeneity of the reperfused myocardium. This is considered to be the ideal substrate for the occurrence of arrhythmias such as accelerated idioventricular rhythm (AIVR), increased ventricular ectopy, and ventricular fibrillation (27). Gressin et al have previously shown that AIVR and other ventricular arrhythmias can be observed in patients with an occluded artery but more than 5 hours after the onset of AMI (28). These ventricular rhythm disturbances will be observed during the first hour after reperfusion and fits well within our timing of coronary angingraphy. As shown in Table 4, AIVR has a high (94\%) positive predictive value to discriminate between TIMI $0-1$ and TIMI 2-3 flow of the infarct related attery, but the incidence of AIVR is low. It's positive predictive value drops to $59 \%$ if TIMI 3 flow has to be discriminated from TIMI $0-2$ flow. It seems likely that the arrhythmia's are the result of reperfusion of the infarct related artery and not of the intensity of flow. Similar observations have been done with respect to ventricular fibrillation and the occurrence of ventricular ectopy during this study.

\section{DEVELOPMENT OF TERMINAL NEGATIVE T-WAVE}

Myocardial ischemia is a clinical condition associated with primary $\mathrm{T}$-wave changes (3) (29). In the present study the early occurrence of a terminal negative $T$-wave more than $0.1 \mathrm{mV}(1 \mathrm{~mm})$ in the most outspoken infarct lead, showed to be a sign of coronary reperfusion $(\mathrm{p}<0.001)$. Although the positive predictive value of this 
parameter in determining TIMI 2-3 flow is reasonably good, it drops to poor values in predicting TIMI 3 flow. It must be stated that for this parameter as for the other parameters considerable overlap in presentation exists:

\section{PROSPECTIVE PREDICTION OF REPERFUSION BY THE INVASIVE CARDIOLOGIST}

Prior to the start of the procedure, the invasive cardiologist was asked to write down his prediction about reperfusion. As previously mentioned, the invasive cardiologist was free to use the reperfusion parameters at his own discretion. He was able to predict reperfusion defined by TIMI 2-3 flow correctly in $88 \%$ of the patients and reperfusion defined as TIMI 3 flow in $66 \%$. Prediction of complete restoration of flow by the invasive cardiologist correlated with excellent clinical outcome with respect to one-year mortality.

\section{STUDY LIMITATIONS}

The conclusions that can be derived from this study have to be placed against the rather heterogeneous group of patients referred for coronary angiography because of research protocols, possible rescue P'TCA or primary PTCA. Because also patients were referred for primary PTCA, the overall patency rate at the first intracoronary injection was only $43 \%$. We believe, however, that the patients used in the study population reflect all-day cardiology. The use of only the infarct- lead with highest ST-segment elevation to determine $\geq 50 \%$ resolution and development of T-wave negativity were chosen to increase simplicity. The fact that only two moments of ECG evaluation have been used, does not take into account that ST-segment elevation frequently and significantly can fluctuate in the acute setting of AMI. However, the decision to perform acute coronary angiography has to be made promptly and cannot await long lasting analysis.

The evaluation of chest pain is a subjective measurement, but in our experience sudden changes in chest pain are well recognised by the patients. Complete avoidance of anti-ischemic agents might allow a more accurate determination of reperfusion with respect to chest pain, however it does not seem ethical not to give medication that potentially can limit infarct-size.

\section{CONCLUSIONS}

Using acute coronary angiography as the gold standard for the perfusion grade of the infarct related artery in 230 patients with acute myocardial infarction we confirmed that non-invasive parameters (especially the ST-segment) are of value in discriminating between TIMI 0-1 and TIMI 2-3 flow of the infarct related artery. The inability of non-invasive parameters of reperfusion to differentiate berween patients 
with TIMI 3 How and TIMI 2 flow with great accuracy is a limitation because TIMI 3 flow of the infarct-related attery might be associated with better prognosis than TIMI 2 flow with respect to mortality and wentricular function. In case it is believed that TIMI 2 flow will have a poor prognosis, acute coronary angiography should be recommended to facilitate further treatment. The ability to do so will depend on the belief in that only TIMI 3 flow should be accepted and on the local circumstances. Especially in the European countries were access to angioplasty facilities is limited, and the manpower and healthcare budget is restricted, choices with respect to the (optimal) goal of treatment will have to be made. From the present data it becomes clear that a perfectly correct non-invasive confirmation of re-established infarcr related coronary artery blood flow within therapeutically acceptable time limits, is nor available at this moment.

\section{REFERENCES}

1. Krucoff MW, Croll MA, Pope JE,Pieper K, Kanani PM et al. Continuously updated 12-lead ST-segment recowery analysis for myocardial infarct artery patency assessment and its correlarion with multiple simultaneous early angiographic obserwations. Am / Cardiol 1993; 1:145-151.

2. Klootwijk P, Langer A, Meij S, Green C, Veldkamp RF Ross AM et al. Non-invasive prediction of reperfusion and coronary artery patency by continuous ST-segment monitoring in the GUSTO-1 trial., Eur Heart 1996;17:689-698.

3. Doevendans PA, Gorgels AP, Van der Zee R, Partouns J, Bär FW, Wellens HIJ. Electrocardiographic diagnosis of reperfusion during thrombolytic therapy in acute myocardial infarction. Am $I$ Cardiol 1995;75:1206-1210.

4. Califf RM, O'Neill W, Stack RS, et al. Faillure of simple clinical measurements to predicr reperfusion starus after intravenous thrombolysis. Ann Intern Med 1988:108:658-62.

5. Simoons ML, Anold AER, Betriu A et al for the European Cooperative Study Group for recombinant rissue-type plasminogen activator (rTPA). Thrombolysis with rissue plasminogen activator in acute myocardial infarction: no additional benefit from immediate percutancous coronary angioplascy. Lancet 198:;1:197-203.

6. TTMI research group. Immediare ws delayed catheterization and angioplasty following rhrombolycic therapy for acute myocardial infarction. TIMI 2A results. JAMA 1988;260: $2849-2858$.

7. Ellis SG, Da Silwa ER, Heyndrickx Gr at. Randomized comparison of rescue angioplasty with conservative mangement of patients with early failure of thrombolysis for acure myocardial infurction. Circ 1994,90:2280-2284.

8. Zijlstra F, de Boer MJ, Hoorntje ICA. Reiffers S, Reiber JHC, Suryapranara H. A comparison of immediate coronary angioplasty with intravenous streptokinase in acure myocardial infarcion. $\mathrm{N}$ Engl J Med 1993;328:680-684. 
9. Grines $\mathrm{CL}$, Browne KF, Marco J, et all for the primary angioplasty in myocardial infarction study group: A comparison of immediate angioplasty with thrombolytic therapy for acute myocardialt infarction. N Engl J Med 1993;328:680-684.

10. Gibbons RJ, Holmes DR, Reeder GS, er al. Immediate angioplasty compared with the administration of a thrombolytic agent followed by conservative treatment for myocatial infarction. N Engl J Med 1993:328:685-91.

11. Anderson JL, Karagounis LA, Becker LC, Sorensen SG, Menlove RL. TIMI perfusion grade 3 but not grade 2 results in improved outcome after thrombolysis for myocardial infarction. Ventriculographic, enzymatic and electrocardiographic evidence of the TEAM-3 study. Citc 1993;87:1,829-1839.

12. Bär FW. Meyer J, Vermeer F et al. Comparison of saruplase and alteplase in acure myocardial infarction. Am J Cardiol 1997:79:727-732.

13. Bär FW, Meyer J, Boland J et al. Bolusadministration of saruplase in Europe (BASE), a pilorstudy in patients with acute myocardial infarction. J Thrombosis and Thrombolysis 1998;6:147-53.

14. Braat $S$, Gorgels $A$, Bär $F$ et al Value of the ST-T segment in lead $V_{4} R$ in inferior wall acute myocardial infarction to predict the sire of coronary anterial occlusion. Am J Cardiol $1988 ; 62: 140-142$.

15. Raitt MH, Maynard C, Wagner GS, Cerqueira MD, Selvester RH, Weaver WD. Relation benween symptom duration before thrombolytic therapy and final infarct size. Circ 1996;93:48-53.

16. Maliri F, Maggioni AP, Franzosi MG, deVita C, Sanrono L, Gianuzzi P, Tognoni G. A simple electrocardiographic predictor of the outcome of patients with acute myocardial infarction treated with a thrombolytic agent. I AM Coll Cardiol 1994:24:600-607.

17. Kennedy JW, Ritchie JL, Dawis $\mathrm{KB}$, Iiritz JK. Westem Washington randomized trial of incracoronary streptokinase in acute myocardial infarction. N Engl J Med 1983;309:1477-1482.

18. Moreno FL, Karagounis L, Marshall H, Menlove RL, Ipsen S, Anderson JL. "Thrombolysis-relared. carly parency reduces ECG late potentials after acute nyocardial infarction. Am Heart ] $1992 ; 124: 557-564$

19. DeWood MA, Spores J, Notske R, Mouser LT, Burroughs R, Golden MS, Lang HT. Prexalence of total coronary occlusion during the early hours of transmural myocardial infarction. N Engl I Med $1980 ; 303: 897-902$.

20. Oude Ophuis AJ, Bär FW, Vermeer F, Kuijne R, Janssen W], Swart H, Ommen VG, Zwan C, Engelen D, Dassen W, Wellens HI. Early referral for intentional rescue PTCA after intiation of thrombolytic therapy in parients adnirted to a community hospital because of a large acute myocandial infarction. Am Heart J 1999:137:846-854.

21. Kircher BJ, Topol E), ONeill WW, Pir B. Prediction of infarct coronary artery recaualization after intravenous thrombolytic therapy. An J Cardiol 1987,59:513.51.5.

22. Clemmensen P, Ohman ME, Sevilla DC, Peck $S_{*}$ Wagner NB, Quigley PS, Grande P, Lee KL, Wagner GS. Changes in standard electrocardiographic ST-segment elevation predictive of successful reperfusion in acute myocardial infarction. Am J Cardiol 1990;66:1407-11.

23. Hogg KJ. Hornung RS, Howie CA, Hocking N, Dunn FG, Hillis W. Elecrocardiographic prediction of coronary artery patency after thrombolytic tratment in acute myocardial infarction: use of the ST-segment as a non-invasive marker. Br Heart J 1988:60:275-280. 
24. Gold HK, Leinbach RC, Harper RW. Usefulness of intravenous propanolol in predicting left anterior descending blood flow during anterior myocardial infarction. Am J Cardiol 1984;54: $264-258$.

25. Herliz J, Ruchter A, Hjalmarson A, Holmberg $\$$. Variabiliny of chest pain in suspected acure myocardial infarction according ro subjective assessment and requirement of narcoric analgesics. Int J Cardiol $1986 ; 13: 9-11$.

26. Shah PK, Cercek B, Lew AS, Ganz W. Angiographic validarion of bedside markers of reperfusion. J Arn Coll Cardiol 1993:21:55-61.

27. Gorgels AP, Vos MA, Letsch IS, Verschuuren EA, Bär FW, Janssen JH, Wellens HJJ. Usefulness of the acclerated idiowentricular thythm as a marker for myocardial necrosis and reperfusion during thrombolytic therapy in acute myocardial infarction. Am J Cardiol 1988;61:231-235.

28. Gressin $V$, Louvard $Y$, Pezzano $M$, Lardoux $H$. Holter recording of ventricular arrhythmias during intravenous thrombolysis for acute myocardial infarction. Arn I Cardiol; 1992:69:152-159.

29. De Zwaan C, Bär FW, Janssen JHA, Cheriex EC, Dassen WRM, Brugada P, Penn OCKM, Wellens HJI. Angiographic and clitical characteristics of parients with unstable angina showing an ECG pattern indicating critical narrowing of the proximal LAD coronary artery. Am Hearr J $1989 ; 117: 657-665$. 
CHAPTER 6

\title{
Background and protocol of the Limburg myocardial infarction (LIMI) study
}

\author{
Participating centers: \\ Hospital Brunssum \\ Hospital Heerlen \\ Hospital Kerkrade \\ Hospital Roermond \\ Hospital Sittard \\ University Hospital Maastricht
}




\section{INTRODUCTION}

In recent years it has become clear that re-opening of the occluded coronary artery in acute myocardial infarction is the key factor determining clinical outcome (1). Because thrombosis is the most common cause for the obstruction, thrombolysis has become the therapy of choice in most institutions. This type of treatment has shown to be effective: patency of the culprit vessel can be achieved in 50-90\% at 90 minutes after the start of therapy, but drawbacks of thrombolytic therapy are severe bleeding complications like intracranial hemorrhage (2-22). Therefore, primary PTCA (i.e. percutaneous transluminal coronary angioplasty, or balloon dilatation performed without previous administration of thrombolytic therapy) was advocated as a safe, fast, and also as a more successful alternative (19). After primary PTCA, patency rares above $90 \%$ and a low incidence of complications were reported (23-29). Recently, several studies have been published indicating that also in randomised trials primary PTCA is more effective than thrombolytic therapy (30-32). However, none of the these studies had a treatment arm in which rescue PTCA (i.e PTCA performed after administration of thrombolytic therapy that did not result in reperfusion of the infarct related vessel) was offered systematically to patients after failed thrombolysis. The RESCUE study, as commented in an editorial review, shows the controversies on rescue PTCA after failed thrombolysis (33). "The question, therefore, remains if the efficacy and safety of the combined therapy of thrombolysis and rescue PTCA when needed, is different from that of primary PTCA. To study safery and efficacy of rescue PTCA after failed thrombolysis, a retrospective analysis was performed of patients with acute myocardial infarction. Patients with rescue PTCA were compared to patients in whom thrombolytic therapy was withheld and primary PTCA offered. In total 176 consecurive acute myocardial infarction patients admitred to the Academic Hospital Maastriche between 1986 and 1992 were reviewed: 100 parients had rescue PTCA after failed thrombolysis and 76 patients had primary PTCA (34). Procedural complications were compared and showed to be identical. This contrasts to orher data which were published on the angiographic outcome of rescue PTCA after failed thrombolysis when compared to primary PTCA (19,30,33,35-55). In addition, in our study no significant differences were seen in the clinical outcome during admission and the outcome during the first year after the event.

Data of a consecutive subgroup of parients in which thrombolysis was successful, indicates that such patients also had an excellent prognosis. However, these findings were retrieved from a retrospective analysis in which the patient groups were not completely comparable. A retrospective study in 165 patients who were referrred from a community hospital to a PTCA center for intentional PTCA showed that transport was safe and feasible within therapeutically acceptable time limits. So far, no prospective study has been published on the outcome of a three-armed strategy study of parients randomised to either thrombolysis only, to thrombolysis and rescue 
PTCA if indicated, or to primary PTCA. The outcome of earlier trials however, makes it probably unethical to conduct such a study in patients directly admitted to a PTCA center. Reason is that the group of patients having thrombolysis only without further intervention has proven to have a worse outcome than the other two treatment modalities, if they are admitted in such centers. However, it is unclear wherher thrombolytic treatment in patients admitted in non-PTCA centers is also inferior to the other two treatment forms. Negative effects of transport and time delays might be so important that the final outcome of "thrombolysis only" is identical to or even better than one of the two other regimes. Therefore, a study has been designed comparing 3 groups of myocardial infarction patients admitted in non-PTCA centers: Group 1: treated locally with thrombolytic therapy. Group 2: thrombolytic therapy and immediate transport to a PTCA center and rescue PTCA in case of persistent occlusion of the culprit artery. Group 3: Immediate transport to a PTCA center without thrombolytic therapy and primary PTCA in case of an occluded culprit artery. Inclusion in the trial will be limited to patients with large infarcts. The minimal requirements in ST segment elevation will lead to inclusion of the majority of parients with anterior myocardial infarction, but will limit the inclusion of patients with inferior myocardial infarction to those with extensive ischemia and a large area at risk. Clinical and angiographic follow-up will be done. Furchermore, a cost effectiveness analysis will be performed. All patients admitted to the cardiology department of non-PTCA centers in Limburg will enter the study in case they meet the inclusion criteria.

Feasibility: In the last three years more than 150 patients with acute myocardial infarction were sent to our institution for acute intervention, either rescue PTCA or primary P'TCA.

Possible consequences: The outcome of the study might have important consequences for the treatment of acute myocardial infarction for patients who are admitted in non-PTCA centers and might influence the policies of the "Dutch Health Care" system.

\section{REFERENCES AT THE END OF THE CHAPTER}

\section{OBJECTIVES}

The aim of this trial is to evaluate three therapeuric regimens in the treatment of acute myocardial infarction: thrombolytic therapy, thrombolytic therapy followed by acute angiography and (if indicated) rescue PTCA, and primary PTCA. All patients are admirted to centers that do not have facilities for PTCA. All parients allocated to thrombolytic therapy followed by acure angiography and all parients allocated to primary PTCA have to be transported by ambulance to the University 
Hospital Maastricht in the acute phase of the myocardial infarction. The patients allocated to thrombolytic therapy will stay in the hospital where they have been admitred. After the second angiogram (24 to 36 hours after the start of the study medication) the patient will be transferred back to the local hospital.

Primary endpoint of the study: Death and recurrent myocardial infarction during the first 42 days.

Secundary endpoints:

- One year mortality.

- NYHA functional class at one year.

- Reinfarction during the first 42 days.

- CABG.

- (Re)PTCA.

- ECG infarct score.

- Bleeding complications.

- Adverse events.

- Coronary patency at acute angiography.

- Complications due to the transport to and from Maastricht.

- Differences in delay to the start of therapy, especially delay related to the transport to and from Maastricht.

- Relation treatment delay and clinical parameters.

Technical:

- Estimation of enzymatic infarce size by cumulative enzyme release. The "Unsatisfactory Outcome Endpoint Score" according to Braunwald (56, see appendix).

- Echocardiographic assessments, assessing the development of left ventricular function and remodeling by serial echocardiography.

- Angiography analysis, assessing coronary patency and left ventricular function, at the acute stage (group 2 and 3 only) and after six months.

- Risk effectiveness analysis and cost effectiveness analysis; assessing the risks and costs involved with the different strategies in the various treatment arms, with special attention to the risks and costs involved with the transport by ambulance to and from Maastricht.

- Stratification of baseline risk, using a risk stratification score.

\section{DESIGN}

The study is an open randomised trial with three groups.

Group 1: Patients allocated to thrombolytic therapy without transport to Maastricht. Group 2: Patients allocated to thrombolytic therapy followed by acute angiography (in Maastricht).

Group 3. Patients allocated to primary PTCA (in Maastricht). 
From all eligible patients a fax of the ECG of the patient with the patient's initials and date of birth is sent to the CCU in Maastricht. After receipt of the fax the patient will be allocated to one of the treatment groups. The fax directly sent from Maastricht back to the local center with the allocated treatment number is considered to be the irrevocable entry in the study. Patients allocated to group $2 \operatorname{nad} 3$ will be transported to the University Hospital Maastricht in the acure phase. After the second angiogram ( 24 to 36 hours after inclusion in the study) transport back to the local center will be scheduled.

\section{STEERING COMMITTEE AND POLICY ADVISORY BOARD}

The steering committee will consist of the principal investigators of the participating centers, the study coordinators and the study monitors. A policy advisory board will be formed and will consist of three members not involved in the trial. The policy advisory board will be informed about the progress of the study, and the overall incidence of adverse events. The policy advisory board will (upon request) have access to the unblinded data at any time.

\section{INFORMED CONSENT AND ETHICAL COMMITTEES}

The nature and purpose of this study, including effects and possible side-effects of the treatment will be explained to each subject by the investigator according to the declaration of Helsinki and according to local requirements. Informed consent will be obtained from all patients, in the form of oral consent obtained in the presence of a witness. This protocol will be presented for approval to the ethical committee of the University Hospital Maastricht, and to the ethical commirtees of the trial centers. All patients will receive written information about the nature of the study (the day) after the acute phase of the study.

\section{PATIENTS}

\section{Inclusion criteria:}

- Age less than 80 years.

- First or recurrent myocardial infarction.

- Chest pain lasting for at least 30 minutes, not responding to nitrates.

- Onset of chest pain less than six hours before start of treatment.

- ST segment deviation (elevation in at least one lead + depression) of at least $15 \mathrm{~mm}$ $(1.5 \mathrm{mV}$ ) or ST-segement deviation $>10 \mathrm{~mm}$ but $<15 \mathrm{~mm}$ and at least 2 of the 3 following criteria. 
- Previous MI or

- Anterior wall Ml or

- Signs of hemodynamic instability $(H \mathbb{R}>100 / \mathrm{min}$, ot systolic bloodpressure $<100$ $\mathrm{mmHg}$ ).

Exclusion criteria:

- Severe hypertension unresponsive to nitrate therapy, remaining despite treatment > $180 / 110 \mathrm{mmHg}$.

- Known bleeding disorder or enhanced risk of bleeding.

- Active internal bleeding.

- Previous stroke in the last 12 months.

- Overt cardiogenic shock.

- Severe concomittant disease affecting life expectancy.

- A priori known logistic problems inevitable for transport or cath lab facilities (e.g. transport to Maastricht must be feasible within approximately 60 minutes after allocation)

- No informed consent.

- Incomplete follow-up anticipated (e.g. patients living abroad).

\section{MEDICATION}

\section{Study medication:}

- Group 1: alteplase.

- Group 2: alteplase.

- Group 3: no thrombolytic therapy.

\section{Co-medication:}

Heparin: heparin is to be given as a bolus of $5000 \mathrm{U}$ i.w. before the administration of the thrombolytic agent (group 1 and 2) or as a bolus of $10.000 \mathrm{U}$ iv for patients allocated to primary PTCA. A second bolus of $5000 \mathrm{U}$ of heparin is given at the start of the acute angiogram (group 2 and 3 ), and a third bolus of 5000 U of heparin is given after completion of the PTCA procedure (if applicable). After the infusion of the thrombolytic agent (group 1), or after the acute angiography (group 2 and 3), a heparin infusion is to be started with the dosage titrated against aPTT $(2-2.5 \mathrm{X}$ normal value for at least 24 hours.

Aspirin: Acetylsalicylic acid is to be given before the administration of the thrombolytic agent, either intravenously (dosage $300 \mathrm{mg}$ ) or orally (minimum dosage 160 $\mathrm{mg}$, followed by a minimum dosage of $80 \mathrm{mg}$ of aspirin daily, unless contraindicated. Note that other thrombotic agents should not be given unless the clinical situation requires such therapy.

Nitrates: If not contraindicated, a nitrate infusion (starting with $0,1 \mathrm{ug} / \mathrm{kg} / \mathrm{min}$ and titrated against the blood pressure will be given on admission and will be continued for approximately 24 hours.

Other medication: All orher medication is given on indication. 


\section{GENERAL GUIDELINES FOR ANGIOGRAPHY AND PTCA}

- Start with angiography of the non-ischemic vessel to evaluate severity of coronary artery disease and presence of collaterals. At least 3 views of the left system and 2 views of the right system have to be made.

- An attempt of PTCA should be performed of the culprit lesion only.

- Do not undersize the angiography balloon.

- In all cases of TIMT0/1 flow PTCA should be attempted unless the angiographic findings favour acute $C A B G$.

- A final stenosis grade of $<50 \%$ and TIMI 3 flow should be reached. Local haziness after PTCA is a normal finding and should be accepted.

- In case of TIMI 2 flow the decision to perform PTCA will be made by the angiographer.

- In case of TIMT 3 flow PTCA should not be performed unless the clinical situation of the parient requires such procedure.

- In case of recurrent occluding dissection other technics than PTCA can be done.

\section{ASSESSMENTS}

The following assessments are scheduled:

Baselinelacute phase:

- Medical history.

- Physical examination.

- ECG.

- Delay (and reasons for delay) of transport by ambulance to and from Maastricht (group 2 and 3).

- Complications during or related to the transport to and from Maastricht (group 2 and 3).

- Angiography at 90 minutes followed by PTCA (in case of an occluded infarct related artery; group 2 and 3 ).

- Second coronary angiography at 24 to 36 hours (group 2 and 3).

In hospital phase:

- Adverse events.

- Follow-up ECG's.

- Cumulative enzyme release.

- Laboratory investigations (local routine).

- Echocardiogram (day 2 to 6 ; locally).

- Exercise test (day 5 to 10 ; locally).

- Coronary angiography (on clinical indication only).

Follow-up:

- Assessment at day 30 to 50 (including ECG and echo; locally). 
- Assessment at 6 months (including ECG, echo, exercise rest, coronary angiography and LV angiography; locally).

- Assessment afrer one year (including ECG; locally).

\section{NUMBER OF PATIENTS}

A total of 225 patients will be included in the trial (approximately 75 patients per treatment group). Pacient recruitment is expected to be completed within two years after the start of the trial.

\section{DATA ANALYSIS}

The primary analysis will be on "intention to treat" basis. All patients allocated to one of the three treatment regimens in response to the fax received at the department of cardiology of the University Hospital Maastricht, will be included in the analysis. The mortality and reinfarction $<42$ days will be used as the primary endpoint to assess the differences in safery and efficacy of the three treatment regimens. The differences in costs between the three treatment regimens will also be evaluated, especially the additional costs related to the acute transport to and from Maastricht. From the observed differences in efficacy, in safery, and in costs, a risk/effectiveness ratio, and a cost/effectiveness ratio will be computed.

\section{SPECIAL ANALYSES}

\section{ESTIMATION OF ENZYMATIC INFARCT SIZE BY CUMULATIVE ENZYME RELEASE}

Cumularive enzyme release is calculated from the total release of $\mathrm{LDH}$ in the first days after the onset of the myocardial infarction. $\mathrm{LDH}$ is measured twice daily during the first three days, and once daily during day 4 and 5 . From the enzyme levels cumulative enzyme release is computed using the two compartment model (58).

\section{ECHOCARDIOGRAPHIC ASSESSMENTS}

Echocardiography is performed after 2 to 6 days, at the follow-up visit at day 30 to 50 , and after six months. The echocardiograns will be made locally. The echocardiography analysis will be performed centrally. From the echocardiograms left ventricular function will be assessed, especially global and regional wall motion, the wall motion score, and the development of left ventricular volumes over time 
(remodeling). Differences in diastolic function over time will also be analysed, as well as the development of mitral incompetence. The results of the echocardiography analysis will be compared to the results of the assessment of left ventricular function obtained by angiography.

\section{ANGIOGRAPHY ANALYSIS}

Coronary patency will be assessed at acute angiography and at the angiography performed after 24 to 36 hours for the patients in group 2 and 3 , and angiography is performed in patients of all three groups after six months. At the angiogram performed after six months the status of the coronary anatomy is assessed, and global and regional wall motion is analysed. For the patients in group 2 and 3 these data can be compared to the data of the acute phase (angiography performed at the acute phase and after 24 to 36 hours). The data of the left ventricular wall motion will be compared with the echocardiographic data.

\section{RISK EFFECTIVENESS AND COST EFFECTIVENESS ANALYSIS}

A risk effectiveness analysis will be performed, as well as a cost effectiveness analysis. The effectiveness of the three different strategies is expressed as the outcome of the "Unsatisfactory Outcome Endpoint Score". The risks of the acute procedure, especially the acute transport (death, cardiopulmonary resuscitation, or artificial respiration during or related to the acute transport to Maastricht), will be weighted against the effectiveness of strategies in group 2 and 3 . With regard to cosss the following costs will be taken into account (if applicable):

- administration of the thrombolytic agent.

- transport by ambulance to and from Maastricht.

coronary angiographies (acute phase, after 24 to 36 hours, after six months.

- acure PTCA (either primary PTCA or rescue PTCA).

- late interventions (additional angiographies, late PTCA or CABG).

- length of stay on CCU (in days).

- length of hospital stay (in days).

- costs involved with readmissions during follow-up.

From these data a cost effectiveness ratio will be computed. The costs per year of life gained will be calculated.

\section{RISK STRATIFICATION}

Baseline risk will be assessed for each patient. The baseline risk assessment will take into account the location of the infarct, the extent of the ischemic area (based on the total amount of ST segment elevation on the baseline ECG), the delay from onset of therapy to randomisation and to start of therapy, the age of the patient, the presence 
of a previous myocardial infarction, and the presence of signs of heart failure (59). The baseline risk assessment score will be used as a predictor of the "Unsatisfactory Outcome Endpoint Score" in order the define the subsets of patients that benefit most of one of thee trearment strategies as defined in this protocol.

Appendix. Unsatisfactory Outcome Endpoint Score

\begin{tabular}{lc}
\hline Event & Score \\
\hline Death & 100 \\
Stroke with permanent deficit & 100 \\
LV punp failure (NYHA clas III) & 80 \\
LVEF $40 \%$ or infarct size $>20 \%$ & 60 \\
Stroke without permanenet deficir & 40 \\
Reocclusion or teinfarction & 40 \\
Major "spontaneous" blecding & 30 \\
No reperfusion of IRA & 20 \\
Major "catheter sire" bleeding & 10 \\
None of the above & 0 \\
\hline
\end{tabular}

\section{REFERENCES}

1. Lincoff AM, Topol EJ: Illusion of teperfusion. Does anyone achieve oprimal reperfusion during acure myocardial infarction? Circulation 1993;87:1792-1805.

2. Kennedy JW, Ritchie JL, Davis KB, Fritz JK: Western Washington randomized trial of intracoronary streptokinase in acute myocardial infarction.. N Eng J Med 1983;309:1477-82.

3. Simoons ML, Serruys PW, van den Brand M, et al: Eatly thrombolysis in acute myocardial infarction: limitation of infarct size and improved survival. I Am Coll Cardiol 1986;7:717-28.

4. Schroder R, Neuhaus K-L, Leizorovicz A, Linderer T, Tebbe U: A prospective placebo-controlled double-blind multicenter trial of intravenons streprokinase in acute myocardial infarction (ISAM): Long-term mortality and morbidity, I Am Coll Cardiol 1987;9:197-203.

5. Gruppo Iraliano per lo Studio della Streprochinasi nell'infarto Miocardico (GISSI): Effectiveness of intravenous thrombolytic treatment in acure myocardial infarction. Lancet 1986;1:397-402.

6. Wilcox $R G$, von der Lippe $G$, Olsson $\mathrm{CG}_{*}$ et al: Trial of tissue plasminogen activator for mortality reduction in acute myocardial infarction. Anglo-Scandinavian Study of Early Thrombolysis (ASSET). Lancer 1988;2:525-30.

7. IS1S-2 (Second International Study of Infarcr Servival). Collaborative Group: Randomized trial of intravenous streptokinase, oral aspirin, both, or neither among 17,187 ases of suspected acure myocatial infarction: ISIS-2. Lancet 1988;2:349-60.

8. AIMS Trial Study Group: Effect of intravenous APSAC on mortally after acute myocardial infarction: Prelimininary report of a placebo-controlled dinical trial. Lancer 1.988;1:545-9. 
9. Topol EJ, Califf RM, George BS, et al: A randonized trial of immediate versus clelayed clective angioplasty after intrawenous tissue plasminogen activator in acute myocardial infarction. N Engl I Med 1987;317:581-8.

10. TIMI Study Group: Thrombolysis In Myocardial Infarction (TMM) trial. N Engl I Med $1985 ; 312: 932-6$.

11. Neuhaus K-L, Tebbe U, Gottwik M, et al: Intravenous recombinant tissue plasminogen activator (rt-PA) and urokinase in acute myocardial infarction: results of the German Acrivator Urokinase Study (GAUS). J Am Coll Cardial 1988; 12:58:1-7.

12. Hogg KJ, Gemmill JD, Burns JM, et al: Angiographic parency study of anistreplase versus streptokinase in acute myocardial infarction. Lancet 1990;335:254-8.

13. Verstraere $M$, Bernard $R$, Bory $M$, et al: Randomised trial of intravenous recombinant tissue-type plasminogen activator versus intravenous streptokinase in acute myocardial infarction: report from the European Cooperative Study Group for Recombinant Tissue-type Plasminogen Activator. Lancet $1985 ; 1: 842-7$.

14. Topol EJ, Califf RM, George BS, et al, and the TAMI Study Group: Coronary arterial thrombolysis with combined infusion of recombinant tissue-type plasminogen activator and urokinase in patients with acute myocardial infarction. Circulation 198:8;7:1100-7.

15. Neuhaus $K-L$, Feuerer W, Jeep-Tebbe $S$, et al: Improved thrombolysis with a modified dose regimes of recombinant tissue-type plasminogen activator. J Am Coll Cardiol 1989;14:1566-9.

16. PRIMI trial study group: Randomized double-blind trial of recombinant pro-urokinase against streprokinase in acute myocardial infarction. Lancet 1989;1:863-8.

17. Bär FW, for the SESAM study group: Early parency and reocelusion in acute myocardial infarction. A comparison between thrombolytic agents saruplase and alteplase. Results of the SESAM-Trial. I Am Coll Cardiol 1994,405A.

18. The GUSTO Angiographic Investigators: The effects of tissue plasminogen activator, streptokinase, or both on coronary-artery patency, ventricular function, and survival after acure myocardial infarcrion. N Engl J Med 1993;329:673-82.

19. Califf RM, Topol EJ, Stack RS, et al: Evaluation of combination thrombolytic therapy and timing of cardiac catheterization in acute myocardial infarction: results of thrombolysis and angioplasty in myocardial infarction - phase 5 randomized trial. Circulation 1991;83:1543-56.

20. Topol EJ, Morris DC, Smalling RW, et al: A multicenter, randomized, placebo-controlled trial of a new form of intravenous recombinant tissue-type plasminogen activator (Activase) in myocardial infarcrion. I Am Coll Cardiol 1987; 9: 1205-13.

21. Chesebro JH, Knatterud G, Roberts R, et al: Thrombollysis In Myocardial Infarcrion (TIMI) triat, phase I: a comparison berween intravenous tissue plasminogen activator and intrawenous streptokinase. Circulation 1987; 76: 142-54.

22. The GUSTO Investigators: An interventional randomized trial comparing four thrombolytic strategies for acute myocardial infarction. N Engl J Med 1993;329:673-82.

23. O'Keefe JH Jr, Rutherford BD, McConahay, et al: Early and late results of coronary angioplasty without antecedent thrombolyric therapy for acute myocardial infarction. Am J Cardiol $1989 ; 64: 12211-30$. 
24. Rothbatum DA, Linnemeier T], Landin RJ, er all: Emergency percutancous transluminal coronary angiophasty in acute myocardial infarction: a 3 year experience. I Am Coll Cardiol 1987;10:264-72.

25. Miller PF; Brodie BR, Weincraub RA, er al: Emergency coronary angioplasty for acute myocardial infarction: results from a community hospital. Arch Intern Med 1987:147:1565-70.

26. Perrigo ES, Leguizamon $\mathrm{E}$ : Managenent of acute myocardial infarction (AMI) using immediate percutaneous transluminal angioplasty (1-PTCA). Med Sci Sports Exer 1989;21:S-55 A.

27. ONelll WW, Brodic BR, Knopf W, et al. Initial report of the Primary Angioplasty Revascularization (PAR) Multicenter Registry. Circulation 1991;84:Suppl II:II-536 A.

28. Kahn JK, Rutherford BD, McConahay DR, et all: Catheterization laboratory events and hospital ouccome with direct angioplasty for acute myocardial infarcrion. Circularion 1990;82:1910-5.

29. Meier B: Balloon angioplasty for acute myocardial infarcrion: was it buried alive? Circulation $1990 ; 82: 2243-5$.

30. Grines CL, Browne KF, Marco J, et al, for the Primary Angioplasty in myocardial Infarccion Study Group: A comparison of immediate angio- plasty with thrombolytic therapy for acure myocardial infarction. N Engl J Med 1993;328:673-9.

31. Zijlstra F, de Boer MJ, Hoornije JCA, et al: A comparison of inmmediate corronary angioplasty with intravenous streptokimase in acute myocardial infarcrion. N Engl J Med 1993;328:680-4.

32. Gibbons RI, Holmes DR, Reeder GS, et al: Immediate angioplasty compared with the administration of a thrombolytic agent followed by concervative treatment for myocardial infarction. N Engl J Med 1993:328;685-91.

33. Ellis SG, van de Werf $F_{*}$ Ribeiro-daSilva E, Topol EJ: Present status of rescue coronary angioplasty: Current polarization of opinion and randomized trials. J Am Coll Cardiol 1992;19:681-6.

34. Bär FW, Frederiks I, de Swart $\mathrm{H}$, et al: Comparison berween acute PTCA after failed thrombolysis and immediate PTCA without thrombolysis in acute myocardial infarction. J Am Coll Cardiol 1994; 1.:484 A

35. The TIMI Study Group: Comparison of invasive and conservative strategies afrer tteatment with intravenous tissue plasminogen acrivator in acute myocardiall infarction: results of the Thrombolysis In Myocardial Infarcrion (TIMI) phase II trial. N Engl J Med 1989;320:61 8-27.

36. Harter GO, Rurherford BD, McConahay DR, et al: Percutaneous translumimal coronary angioplasty with and without thrombolytic therapy for treament of acute myocardial infarction. Am Heard J 1983; 106:965-73.

37. Papapietro SE, Maclean WAH, Stanley AWH Jr, et al: Percutaneous transhuminal coronary angioplasty after intracoronary streptokinase in evolving acure myocardial infarction. Am ] Cardiol 1985;55:48-53.

38. Fung AY, Lai P. Topol E), et al: Value of percutaneous transluminal coronary angioplasty after unstnccessful intravenous streptokinase therapy in acute myocardial infarction. Am I Cardiol 1986;58:686-91.

39. Abbottsmith CW, Topol EJ, George BS, et al: Fate of patients with acute myocardial infarction with parency of the infarcr-relared vessel achieved with successful thrombolysis versus rescue angioplasty. J Am Coll Cardiol 1990;16:770-8. 
40. Ellis SG, O'Neill WW, Bates ER, et al: Implicarions for patient triage from surwwal and left ventricular functional recovery analysis in 500 patients reated with coronary angioplasty for acute myocardial infarction. J Am Coll Cardiol 1989;13:1251-9.

41. Gibson CM, Cannon CP, Piana RM, et al: Rescue PTCA in the TIMI 4 Trial. J Am Coll Cardiol $1994 ; 225$ A:755-2 A.

42. Topol EJ, Califf RM, George BS, et al: A randomized trial of immediate versus delayed elective angioplasty after intravenous tissue plasminogen activator in acute myocardial infarction. New Eng J Med 1987,317:581-8.

43. Erbel R, Top T, Henrichs $\mathrm{KJ}$, et al: Percutaneous transluminal coronary angioplasty after thrombolytic therapy: a prospective controlled randomized trial. Am Coll Cardiol 1986"8; 485-95.

44. Stone GW, Grines CL, Browne KF, et al: Acute outcome after primary angioplasty in myocardial infarcrion - The Primary Angioplasty in Myocardial Infarction (PAMD trial. J Am Coll Cardiol $1993 ; 21: 331$ A.

45. Ohman $\mathbb{E}$. Magnus, Califf Roberr $M$, Topol Eric J, er al: Consequences of reocclusion after successful reperfusion therapy in acute myocardial infarction. Circulation 1990;82:781-91.

46. O'Neill WW, Weintraub R, Grines $\mathrm{CL}$, et al: A prospective, placebo-controlled, randomized trial of intravenous streptokinase and angioplasty versus lone angioplasty therapy of acure myocardial infarction. Circulation 1992;86:1710-7.

47. Grimes CL, Browne KF, Vandormael M, et al: Primary Angioplasty in Myocardial Infarction (PAMD) trial. Circulation 1992;86 (Suppl I):I-641. A.

48. Bär FW, Meyer J, Michels R, et al: Taprostene might improve the effect of thrombolytic treatment in acute myocardial infarction. Results of the START study. Eur Heart J 1993;14:1118-26.

49. Topol EJ, Califf RM, George BS, Kereiakes DJ, Lee KL, for the TAMI Study Group: Insights derived form the Thrombolysis and Angioplasty in Myocardial Infarction (TAMI) Trials. J Am Coll Cardiol 1988;12:24A-31A.

50. Califf RM, Topol EJ, George BS, et al: Characteristics and outcome of parients in whom reperfusion wirh intravenous tissue-type plasmainagen activator fails: Results of the Thrombolysis and Angioplasty in Myocardial Infarction ("TMMI) trial. Circulacion 1988777:1090-9.

51. Morgan CD, Roberts RS, Waq A, et al: Coronary patency, infarce size and left ventricular function after thrombolytic therapy for acute myocardial infarction: Results from the Tissue Plasminogen Activator: Toronto (TPAT) placebo-controlled trial. J Am Coll Cardiol 1991;17:1451-7

52. Brannwald E: Myocardial reperfusion, limitation of infarct size, reduccion of left ventricular dysfunction, and improved surwival: Should the paradign be expanded? Circulation $1989: 79: 441 \times 4$

53. Fortin DG, Califf RM: Long-term survival from acute myocardial infarction: Salutary effecr of an open vessel. Am J Med 1990;88; 1-9N-1-15N.

54. Siu SC, Nidorf SM, Gallambos GS, Weyman AE, Picard MH: The effect of late patency of infarct-retated coronary artery on left ventricular morphology and regional function after thrombolysis. Am Heart ] 1992;124:265-72. 
55. Simoons $M L$, Arnold $A E R$, Betriu $A$, et al: Thrombolysis with rissue plasminogen acrivator in acute myocandial infarction: no additional benefit from immediate percutaneous coronary angioplasty. Lancet 1988:1:197-203.

56. Braunwald E, Cannon CP, McCabe $\mathrm{C}$ : Use of composite endpoints in thrombolysis trials of acute myocardial infarction. Am I Card 1993:72:3G-12G.

57. OBrien PC and Fleraing TR: A multiple testing procedure for clinical trials. Biometrics $1979,35,549-556$

58. Laarse A wan der, Vermeer F Hermens WT, et al: Effects of early intracoronary streptokinase on infarce size estimated from cumulative enzyme release and on enzyme release rate: A randomized thial of 533 patients with acute myocardial infartion. Am Heart J 1986;112:672-681.

59. Vermeer F, Simoons ML, Bär FW。 et al: Which parients benefit most from early thrombolytic therapy with intracoronary streptokinase? Circulation 1986;74:1379-1389. 
CHAPTER 7

\title{
Prospective randomised comparison between
} thrombolysis, rescue PTCA and primary PTCA in patients with extensive myocardial infarction admitted to a hospital without PTCA facilities

The LIMI study, a safety and feasibility study

\author{
Vermeer $F^{1}$, Oude Ophuis $A J^{\prime}$, Berg vd $\mathrm{EJ}^{2}$, Brunninkhuis $\mathrm{LC}^{3}$, Werter $\mathrm{Cf}^{4}$, \\ Boehmer $\mathrm{AG}^{5}$, Lousberg $\mathrm{AH}{ }^{1}$, Dassen WR ${ }^{1}$, Bär FW' \\ 'Department of Cardiology, University Hospiral Maastricht, Maastricht, the Netherlands \\ ${ }^{2}$ Department of Cardiology, Atrium Hospital, Heerlen, the Netherlands \\ ${ }^{3}$ Department of Cardliology, Maasland Hospital, Sittard, the Netherlands \\ ${ }^{4}$ Deparment of Cardiology, Laurentius Hospital, Roermond, the Netherlands \\ ${ }^{5}$ Department of Cardiology, Atrium Hospital, Kerkrade, the Nerherlands
}




\begin{abstract}
Objective: To assess the safety and feasibility of acute transport followed by rescue PTCA or primary PTCA in patients with acute myocardial infarction initially admitted to a hospital without PTCA facilities.

Design: In a multicenter randomised open trial, three regimens of treatment of acute large myocardial infarction were compared for patients admitted to hospitats without angioplasty facilities: thrombolytic therapy with alteplase (75 patients), alteplase followed by transfer to the PTCA center and (if indicated) rescue PTCA (74 patients), or transfer for primary PTCA (75 patients). Results: Between 1995 and 1997224 patients were included. Baseline characteristics were distributed evenly. Transport to the PTCA center was without severe complications in all patients. Mean delay from onset of symptoms to randomisation was $130 \pm 75$ minutes and from randomisation to angiography $90 \pm 25$ minutes. Clinical outcome: death or recurrent infarction within 42 days occurred respectively in 12 patients (thrombolysis group), 10 patients (rescue PTCA group), and 6 patients (primary PTCA group). These differences were statistically not significant.

Conclusions: Acute transfer for rescue PTCA or primary PTCA in patients with extensive myocardial infarction is feasible and safe. Efficacy of rescue PTCA or primary PTCA in this setting will have to be tested in larger series before this approach can be implemented as "routine therapy" for patients with extensive myocardial infarction..
\end{abstract}




\section{INTRODUCTION}

\section{THE THROMBOLYTIC ERA}

In the last decade it has become clear that reopening of the occluded coronary artery in acute myocardial infarction is the key factor determining clinical outcome (1). Because thrombosis is the most common cause for the obstruction, thrombolysis has become the therapy of choice. This treatment has shown to be reasonably effective: patency of the culprit vessel (TIMI 2 or 3 flow) can be achieved in $50-90 \%$ at 90 minutes after start of therapy. However, side effects of thrombolytic therapy are severe bleeding complications like intracranial haemorrhage (2-5).

\section{PRIMARY PTCA}

Primary PTCA (acute PTCA without previous administration of thrombolytic therapy) has shown to be a safe and successful alternative for thrombolytic therapy. After primary PTCA patency rates above $90 \%$ with لow incidence of complications were reported (6-9). Recently, several randomised studies reported thar primary PTCA is more effective than thrombolytic therapy (10-13). However, none of these studies included a treatment arm in which rescue PTCA (PTCA after failed thrombolysis) was part of the protocol.

\section{RESCUE PTCA}

So far, the published results of rescue PTCA (acute PTCA after failed thrombolysis) have been equivocal. A high complication rate was described in several retrospective studies (14-17). The RESCUE study prospectively evaluated rescue PTCA in patients with anterior infarcrion (18). The findings of the RESCUE study and several other studies support the suggestion that an invasive strategy in patients wirh acute myocardial infarction might contribute to an improved clinical outcome (19-21).

\section{TRANSFER OF PATIENTS TO PTCA CENTER}

The conclusions concerning PTCA as mentioned above are limited to the group of parients directly admitted to a hospital with PTCA facilities. The optimal strategy for patients initially admitted to a hospital withour PTCA facilities remains unclear. The relative safety of transferring patients with acute myocardial infarction to a PTCA center for primary PTCA or for rescue PTCA has been described in retrospective studies $(22,23)$, but prospective studies are lacking. The present study is the first study that compares prospectively the outcome of thrombolysis, primary PTCA, and thrombolysis followed by rescue PTCA (if indicated) for patients with 
extensive myocardial infarction initially admitted to a hospital without PTCA faciliries.

The present study was designed as a pilot study with as main objective to test the safery and feasibility of acure transport to the nearest PTCA center for patients with acute myocardial infarction. For this reason the outcome of the patients who underwent or were allocated to immediate transport was compared to the outcome of the patients allocated to receive thrombolytic therapy without transport to the PTCA. center.

\section{METHODS}

\section{DESIGN}

In this open randomised trial three therapeutic regimens in the treatment of acute myocardial infarction were compared: thrombolytic therapy, primary PTCA, and thrombolytic therapy followed by acure angiography and rescue PTCA (if indicated). All participaring centers to which the patients were initially admitted had no PTCA facilities. Patients with extensive acute myocardial infarction were candidates for the study if they had no contraindications for thrombolytic therapy. From all eligible patients who gave informed consent a fax of the ECG with the patient's initials and date of birth was sent to the CCU of the PTCA center. Randomisation was done by computer. The fax from the PTCA center back to the referring center with the treatment allocation was considered to be the irrevocable entry in the study. Patients allocated to thrombolytic therapy received alteplase and stayed in the hospital where they were initially admitted. Patients allocated to primary or rescue PTCA underwent immediate transport to the PTCA center. The transport was operated by the ambulance services by well trained paramedic staff in ambulances equipped to transfer critically ill patients. A twenty-four hours service was available in the PTCA center for acute angiography with two catheterisation rooms. Patients were transferred back to the referring center the next day. If no bed was available, patients were transferred back after angiography as soon as their clinical situation had stabilised. Patient recruitment was completed within two years.

\section{ENDPOINTS}

The primary endpoint of this pilot study was to test the safery and feasibility of acute transport to a PTCA center for patients with acute myocardial infarction. The combined incidence of death and recurrent myocardial infarction within the first 42 
days was considered to be a secondary endpoint and was used to compute the required sample size for a study to test the efficacy of these treatment strategies. Other endpoints were: mortality, recurrent infarction, thromboembolic and haemorrhagic stroke, recurrent interventions as PTCA or CABG, and recurrent ischemia during one year follow-up; coronary patency, bleeding complications, complications due to the transport to and from the PTCA center and differences in delay to start of therapy, especially delay related to the transport to the PTCA center. Recurrent infarction was defined as a new episode of chest pain occurring ar least 48 hours after the initial infarction, accompanied by ECG changes and by a new rise in serum enzymes. The diagnosis of stroke was confirmed by the neurologist, the origin of the stroke was CT scan confirmed. Recurrent ischemia was defined as a new episode of chest pain at least 48 hours after the initial infarction with transient ECG changes and without enzyme rise.

\section{PARTICIPATING CENTERS}

Seven centers in Limburg, a province in the south of The Netherlands, participated in the study. The distance between the referring centers and the PTCA center (Maastricht) varied from $25 \mathrm{~km}$ (Sittard) to $50 \mathrm{~km}$ (Roermond).

\section{PATIENT SELECTION}

Inclusion criteria were: age less than 80 years, first or recurrent myocardial infarction, chest pain lasting for at least 30 minutes not responding to nitrates, and onset of chest pain less than six hours before randomisation. The following ECG criteria had to be fulfilled: ST segment deviation (elevation in at least one lead + depression) of at least $1.5 \mathrm{mV}(=15 \mathrm{~mm})$. Exclusion criteria were: severe hypertension unresponsive to acute therapy, enhanced risk of bleeding, previous stroke in the last 12 months, cardiogenic shock, severe concomitant disease affecting life expectancy, a priori known logistic problems for transport or angiography (transport to the PTCA center should be feasible within one hour after randomisation), no informed consent, incomplete follow-up anticipated.

\section{MEDICATION}

Alteplase (accelerated regimen) was given as thrombolytic agent. Alteplase was given immediately after randomisation. For the parients allocared to rescue PTCA the alteplase bolus was given and the alteplase infusion started prior to the ambulance transport. The alteplase infusion was continued during transport and upon arrival in the PTCA center. In the majority of cases the alteplase infusion was completed (at 90 minutes) before start of angiography. Heparin was given as bolus of $5000 \mathrm{U}$ iv. before the administration of alteplase or as bolus of $10.000 \mathrm{U} \mathrm{i.w.} \mathrm{for} \mathrm{patient} \mathrm{allo-}$ 
cated to primary PTCA. A second bolus of $5000 \mathrm{U}$ was given at the start of the acute coronary angiogram, and a third bolus of $5000 \mathrm{U}$ was given after completion of the PTCA procedure (if applicable). After infusion of the thrombolytic agent or after acure coronary angiography a heparin infusion was started with the dosage titrated against the partial thromboplastin time (aPTT, prolongation 2 to 3 times) for 24 hours. Acetylsalicylic acid (300 mg intravenously or $160 \mathrm{mg}$ orally) was administered before initiation of thrombolytic therapy, followed by $80 \mathrm{mg}$ of oral aspirin daily unless contraindicated. A nitrate infusion titrated against blood pressure was started and continued for 24 hours. The patients were not treated with abciximab. All orher medication was left at the discretion of the investigator.

\section{PRIMARY PTCA}

PTCA was performed of the culprit lesion only. In all cases of TIMI 0/1 flow PTCA was attempted unless the angiographic findings favoured acute $C A B G$. In case of TIMI 2 flow the decision to perform PTCA was made by the angiographer. In case of TIMI 3 How PTCA was not performed unless the clinical condition of the patient required such procedure. In case of a severe dissection or incomplete result of the PTCA a coronary stent was implanted. Successful. PTCA was defined as TIMI 3 flow and stenosis $<50 \%$ at the end of the procedure.

\section{RESCUE PTCA}

In the patients allocated to rescue PTCA the same procedure was followed in the catheterisation laboratory as for the patients allocated to primary PTCA. The angiographer was not blinded to the treatment allocation. Rescue PTCA was defined as acure PTCA performed in patients with TIMI 0 or 1 flow at the angiogram performed ( 60 to appr. 120 minutes) after intravenous administration of the thrombolytic agent.

\section{DATA ANALYSIS}

The primary analysis was on intention to treat basis. All patients allocated to one of the three treatment regimens in response to the fax received in the PTCA center, were included in the analysis. If applicable, Fisher's exact test was used; two sided p values are reported. 


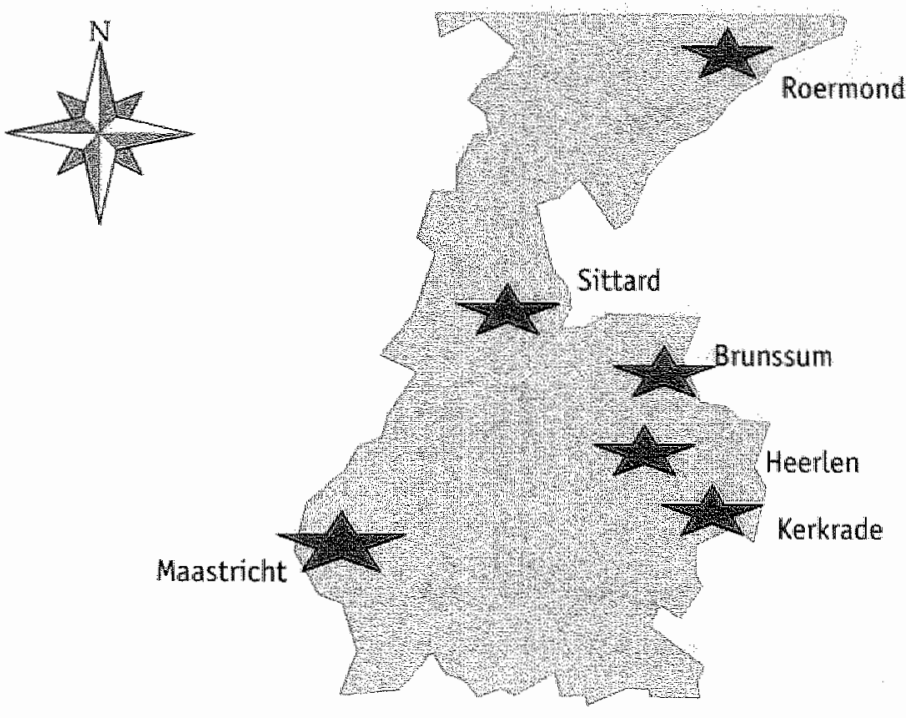

Figure 1. Location of the participating hospitals. All participating centers are located in the province Limburg in The Netherlands, with on the west and south side the border with Belgium and on the east sidde the border with Germany.

\section{RESULTS}

\section{BASELINE CHARACTERISTICS}

Between Seprember 1995 and August 1997 a total of 224 patients with acute myocardial infarction. were included in the study; 75 patients were allocated to thrombolytic therapy, 74 patients to thrombolysis and rescue PTCA (if indicated), and 75 patients to primary PTCA. Inclusion was limited to the hospitals in the sourhern part of the province Limburg in The Netherlands (figure 1). Only patients with extensive ischemia (total ST segment elevation and depression at least $1.5 \mathrm{mV}$ or $15 \mathrm{~mm}$ ) were included. This resulted in a relatively large proportion of parients wirh anterior infarction. All baseline characteristics were distributed evenly over the three treatment groups (table 1).

\section{TREATMENT DELAY}

Mean interval from onset of symptoms to randomisation varied between $125 \pm 80$ minutes in the thrombolysis group to $140 \pm 70$ minutes in the rescue PTCA group. Mean interval between randomisation and start of angiography in the PTCA center was $85 \pm 25$ minutes in the primary PTCA group, and was slightly longer namely 
Table 1. Baseline Characteristics

\begin{tabular}{llll}
\hline & Thrombolysis & $\begin{array}{l}\text { Thrombolysis } \\
\text { + rescue PTCA }\end{array}$ & $\begin{array}{l}\text { Prinary } \\
\text { PTCA }\end{array}$ \\
\hline Number of patients & 75 & 74 & 75 \\
Age (mean + sd: years) & $59 \pm 11$ & $59 \pm 12$ & $58 \pm 11$ \\
Male gender & 56 & 57 & 54 \\
Female gender & 19 & 17 & 21 \\
Aviterior mi & 36 & 37 & 34 \\
Inferior mi & 39 & 37 & 41 \\
Previous mi & 13 & 15 & 9 \\
Previous PTCAVCABG & 3 & 2 & 1 \\
Previous angina & 2 & 6 & 4 \\
\hline
\end{tabular}

$\mathrm{MI}=$ myocardial infarction; $\mathrm{PTCA}=$ percutaneous transluminal coronary angioplasty; $\mathrm{CABG}=$ coronary antery bypass graft.

$100 \pm 30$ minutes in the rescue PTCA group (figure 2). On average PTCA was started 15 minutes after start of coronary angiography. Patency of the infarct related coronary artery was in the majority of parients obtained within four hours after onset of symptoms. Hospital admission was on average 90 minutes after the onset of chest pain. In the thrombolysis group and in the rescue PTCA group the thrombolytic therapy was initiated on average 10 minutes after randomisation, i.e. on average 45 minutes after hospital admission. There were no significant differences in the rreatment delays between the three treatment groups.

\section{COMPLICATIONS DURING TRANSPORT}

Inmediately after randomisation, patients allocated to the primary PTCA or the rescue PTCA group were transferred to the PTCA center, located at a distance of 25 to $50 \mathrm{~km}$ from the referring hospital (figure 1), usually by the same ambulance that had taken care of the transfer of the patient to the hospital. Prior to the transfer all patients received aspirin, a heparin bolus, an infusion of nirroglycerin, and patients allocated to the rescue PTCA group also received a bollus and infusion of alteplase. Travel time in the ambulance lasted on average 20 minutes and did not exceed 30 minutes. There were no severe complications during transport. In the ambulance no patients died, two patients had to be cardioverted because of ventricular arrhythmias, two patients received atropine because of bradycardia, and the dosage of the nitroglycerin infusion had to be decreased in six patients because of hypotension. Acute transport was withheld in three patients. In one patient (rescue PTCA group) an echocardiogram was made because of suspicion of aortic dissection. 


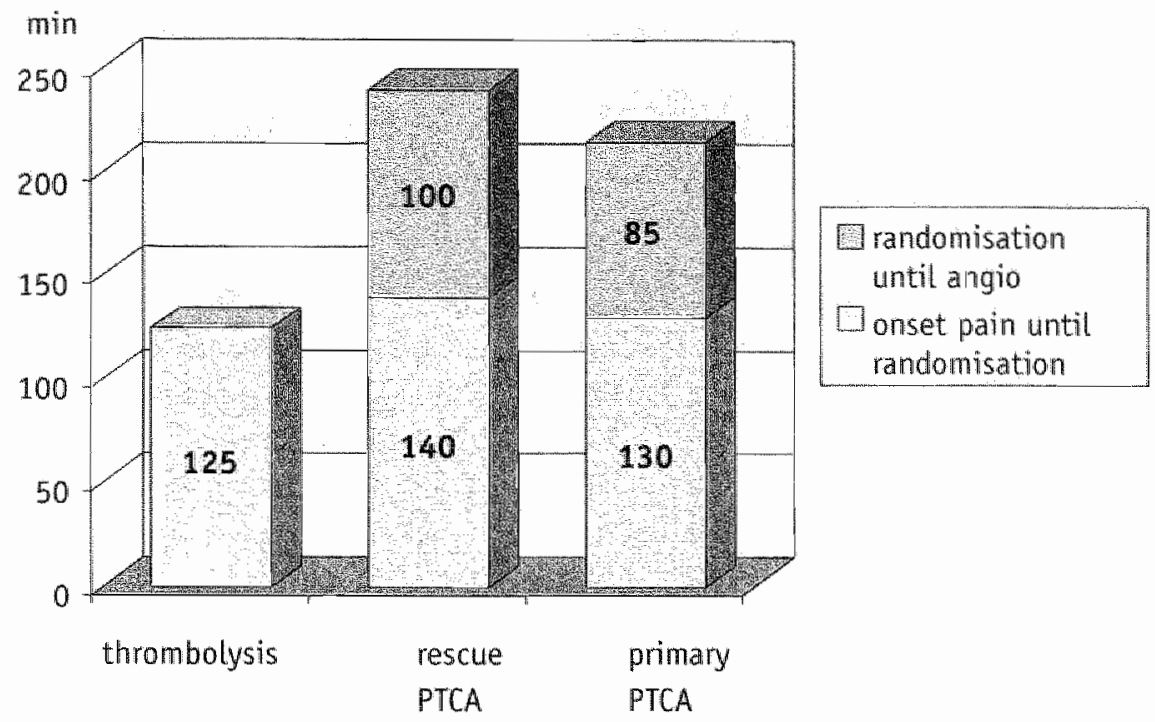

Figure 2. Treatment delays. Mean treatment delay in minutes from onset of chest pain to randomisation (lower part), and from randomisation to start of angiography for the rescue PTCA and the primary PTCA group (upper part).

At the end of the echocardiography (there were no signs of aortic dissection) the patient showed signs of reperfusion on the ECG. Because of the long delay and the ECG signs of reperfusion it was decided that acute transport was no longer indicated. In two patients allocated to primary PTCA the hermodynamic situation of the patient impeded acute transport, and thrombolytic therapy was given by the referring cardiologist. From the 146 patients who came to Maastricht, 1.43 underwent angiography. In 128 patients angiography took place withour delay, in 15 patients there was a delay of 60 minutes or more from arrival at Maastricht till start of angiography (with a mean of 83 minutes), because at the time the patient arrived the catheterisation room was not immediately available. In three patients immediate angiography was not possible, and at the rime the catheterisation laboratory was ready, immediate angiography was no longer considered indicated because of the rime delay and the presence of non-invasive signs of reperfusion. The majority of patients was transferred back to the referring center the next day. Because of shortage of hospital beds in Maastricht, 33 patients had to be rransferred back after coronary angiography as soon as their clinical situation had stabilised. The transport from the PTCA center back to the referring center was without complications in all cases. 
Acute angiography was performed in 143 patients. In the rescue PTCA group TIMI 3 flow was seen at the first angiogram in 41 patients (57\%), TIMI 2 flow was present in 10 patients $(14 \%)$. This means that patency of the infarct related coronary artery (TIMI 2 or 3 flow) was obtained by alteplase in 51 patients (71\%) at 90 minutes after initiation of the thrombolytic therapy. Rescue PTCA was performed in 14 of the 20 patients with TIMI 0 or 1 flow, and acute PTCA was performed in 5 of the 10 patients with TIMI 2 flow and in one patient with TIM 3 flow. In the remaining seven patients with TIMI 0 or 1 flow PTCA was not performed for technical reasons, usually because of the small diameter of the infarct related vessel. Acute PTCA was successful in $18 / 20$ patients $(90 \%)$ with a stent implanted in three patients. Ar the end of the procedure TIMI 3 flow was obtained in 58 patients and TIMI 2 flow in 6 parients (figure 3). In the primary PTCA group the infarct related coronary artery appeared to be occluded (TIMI 0 or 1 flow) in 55 patients, and TIMI 2 flow was present in 8 patients. Primary PTCA was performed in 52 out of 55 patients with TIMI 0 or 1 flow, and in all patients with TIMI 2 flow. TIMI 3 flow was present from the beginning of the angiography in 9 parients, and PTCA was performed in two patients. PTCA was successful in 60/63 patients (95\%) with a stent in 13 parients. At the end of the procedure TIMI 3 flow was obtained in 66 patients and TIMI 2 flow in 3 patients. Second angiography, scheduled 24 to 36 hours after inclusion, was done in 112 patients, with high patency rate in all groups (figure 3). Second angiography was not performed in 31 patients. The reasons not to perform second angiography were: patients transferred back immediately after the first angiogram (12 patients), no consent for second angiography ( 7 patients), sheath already removed ( 2 patients), angiography nor possible or considered not indicated on clinical grounds ( 10 patients).

\section{CLINICAL COURSE}

There were no significant differences in the clinical course during the first 42 days between the three treatment groups (table 2). The clinical endpoint of the study (death or recurrent MI within 42 days) was reached in 12 patients $(16 \%)$ in the thrombolysis group, in 10 patients (14\%) in the rescue PTCA group, and in 6 patients $(8 \%)$ in the primary PTCA group. A total of 7 parients suffered from stroke within 42 days, of which the stroke was of hemorrhagic origin in 3 patients. The incidence of recurrent ischemia and of late PTCA and CABG was the highest in the thrombolysis group, lower in the rescue PTCA group and lowest in the primary PTCA group (table 2). Severe bleeding complications were not observed, the incidence of minor bleeding complications was somewhat higher in the rescue PTCA group (21\%), than in the orher two groups (11\%). Clinical course was uncomplicated in the majority of patients. Transient severe hypotension ( 4 patients) and signs 


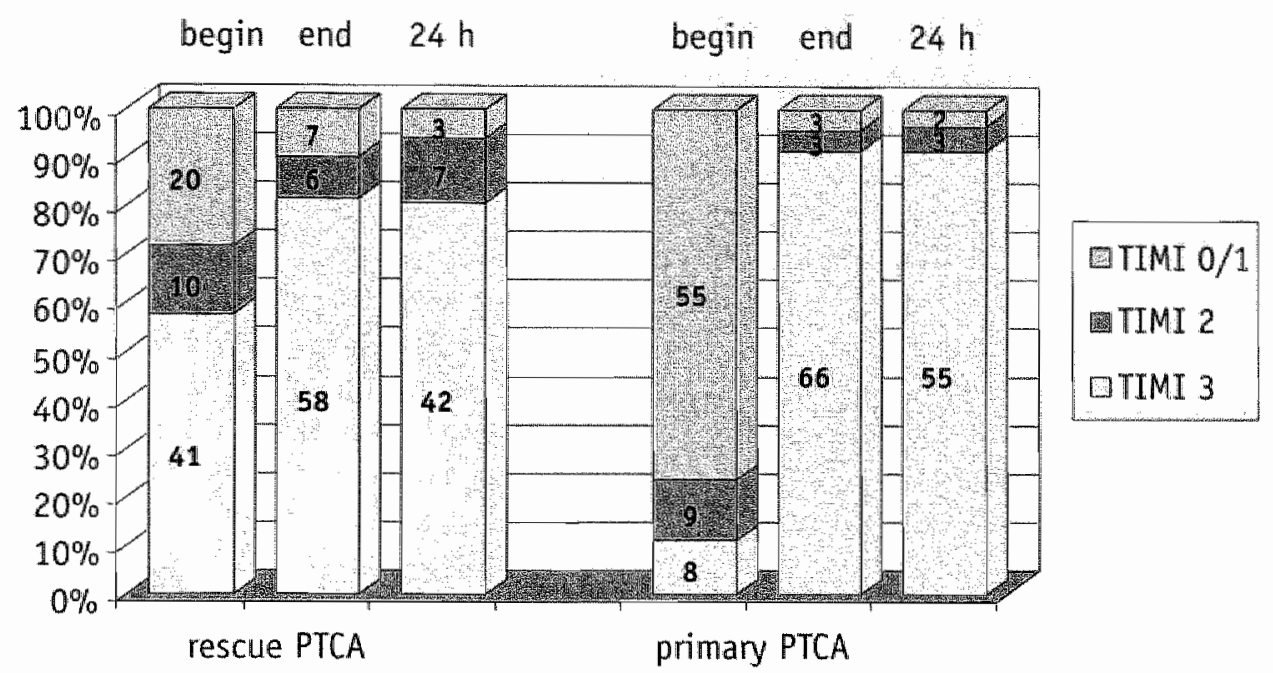

Figure 3. Angiography. TIMI flow at the begin of the acute angiography, at the end of the acute angiography, and at the second angiogram afrer 24 to 36 hours for parients allocated to rescue PTCA (left bars) and to primary PTCA (right bars).

of severe heart failure ( 8 patients) were observed only in a minority of the patients. The incidence of ventricular arrhythmia's was not different between the treatment groups, and of a magnitude as could be expected from a group of patients with extensive myocardial infarction.

\section{ONE YEAR FOLLOW-UP}

Results of one year follow-up are presented in table 2. Clinical course from 42 days up to one year follow-up was uneventful in the majority of patients. In the thrombolysis group any event (mortality, stroke, recurrent infarct, PTCA, CABG or recurrent ischemia) between 42 days and one year was observed in 15 patients, versus in 6 patients in the rescue PTCA group and in 11 patients in the primary PTCA group (differences not significant). In general, one-year mortality and morbidity was relatively low in these groups of patients who were admitted with extensive ischemia and suffered from large myocardial infarctions.

\section{PATIENT LOG}

A parient $\log$ was recorded in all participating hospirals. A total of 1267 patients with acute myocardial infarction were admitred at the participating centers during the period of patient recruitment. Reasons not to include patients were: no indication for thrombolytic therapy due to patient delay or absence of ECG abnormalities, 
Table 2. Clinical course during one year follow-up.

\begin{tabular}{|c|c|c|c|}
\hline & Thrombolysis & $\begin{array}{l}\text { Thrombolysis } \\
\text { + rescue PTCA } \\
\mathbb{N}\end{array}$ & $\begin{array}{l}\text { Primary } \\
\text { PTCA } \\
\mathbb{N}\end{array}$ \\
\hline Number of parients: & 75 & 74 & 75 \\
\hline Deceased & {$[5]$} & $7 \quad[6]$ & {$[5]$} \\
\hline Thrombolic stroke & $\mathbb{1} \quad[1]$ & $2 \quad[1]$ & $2 \quad[2]$ \\
\hline Hacmornhagic stroke & {$[1]$} & $2 \quad\left[\begin{array}{ll}2 \\
2\end{array}\right]$ & $0 \quad[0]$ \\
\hline Recurrent infarction & {$[7]$} & $5 \quad[4]$ & [1] \\
\hline Late $\mathrm{PTCA} / \mathrm{CABG}$ & $29 \quad[23]$ & $24\lfloor 17\rfloor$ & $10 \quad[6]$ \\
\hline Recurrent ischemia only" & $10 \quad[6]$ & $\left.\begin{array}{ll}9 & 15\end{array}\right]$ & $10 \quad[6]$ \\
\hline None of the above & $33 \quad[48]$ & $38 \quad[44]$ & $47 \quad[58]$ \\
\hline
\end{tabular}

Data are of one year follow-up. Between brackes data concerning 42 days follow-up. *Recurrent ischemia withour infarction and not followed by intervenrion (PTCA/CABG).

contraindications for thrombolytic therapy, or absence of signs of extensive ischemia with total ST segment deviation not reaching $1.5 \mathrm{mV}$ or $15 \mathrm{~mm}$. In this latter group the patients were treated with thrombolytic therapy, if indicated, but acute transport to the PTCA center was not undertaken unless the clinical situation required such an action.

\section{DISCUSSION}

\section{TREATMENT DELAY}

Mean delay from onset of symptoms to hospiral admission was somewhat on ayerage 90 minutes, a delay that correlates well with results of other trials in patients with acute myocardial infarction in Europe (24,25), and compares favourably to the delay observed in GUSTO (13). This is of importance because the efficacy of reperfusion strategies is strongly dependent on total ischemia time. Mean delay from randomisation to start of angiography was 85 minures in the primary PTCA group. On average, primary PTCA could be started 215 minutes after onset of symptoms, a finding similar to several primary PTCA studies in which the parient was directly admitted to the PTCA center (11-13). Delay from randomisation to start of angiography was slightly longer in the rescue PTCA group (on average 100 minutes). This was in part due to the time needed for the preparation of the bolus and infusion of the thrombolytic agent, but the fact that this was an open study might also have played a role. This bias could be avoided by giving a placebo instead 
of the thrombolytic agent to the patients allocated to primary PTCA prior to the transport to the PTCA center.

\section{LOCATION AND DISTANCE}

The geographical location of the PTCA center in Maastricht limited the number of centers that could participare (see figure 1). In order to avoid excessive treatment delay participation of referral centers was limited to centers who were in the neighbourhood of the PTCA center and who were used to send unstable patients to Maastricht. In another study in The Netherlands, a retrospective study concerning acute transport for primary PTCA, transport was foreseen for distances up to 100 $\mathrm{km}$ with inevitably long treatment delay (22). This probably will influence the outcome of the patients, who undergo primary PTCA after a long treatment delay.

\section{COMPLICATIONS DURING TRANSPORT}

From the results of this trial it can be concluded that transfer of a patient with acute myocardial infarction to a PTCA center is probably feasible and safe. The incidence of complications during transport was low, and these complications could be handled well by the experienced ambulance personnel. These results are in accordance with the results of the retrospective studies, which were done in the same region in The Netherlands (23), and in a different region in The Netherlands (22).

\section{ANGIOGRAPHY AND CLINICAL COURSE}

The results of the angiograms and clinical course during follow-up show a similar pattern as reported from primary PTCA studies in which the patients were directly admitted to the PTCA center $(11,21)$. In the rescue PTCA group $57 \%$ of the patients had TIMI 3 flow, and as a consequence acure PTCA was not necessary. This means that the costs and the workload were lower in the rescue P'TCA group than in the primary PTCA group. With regard to clinical endpoints, there were no signifcant differences between the three treatment groups. However, a trend was visible towards a lower rate of recurrent infarction in the PTCA groups. The fact that after thrombolytic therapy a significant residual stenosis remains present in the majority of cases, might be the explanation for this finding. Total mortality and morbidicy was low in this group of patients, moreover when it is taken into account that this was a parient group with extensive ischemia on the admission ECG, which reflects a large area at risk. 


\section{FUTURE STUDTES}

This pilot study was designed as a safety and feasibility study, so conclusions abour the efficacy of the three regimens are not possible, due to the low number of parients included. All centers in this region of The Netherlands (Limburg) participated in this study. This resulted in inclusion of 224 patients in two years. From the results of this study can be computed that a minimum of 600 patients per treatment group will be needed to discover relevant differences between thrombolytic therapy allone versus primary PTCA or rescue PTCA in this setting. In The Netherlands such a study is only feasible when done at a nation-wide level. Presently, a nation-wide study is planned. However, future developments might influence the outcome of these treatment strategies in all three treatment groups. Newer thrombolytic agents with high patency rates will soon be available $(24,25)$. Thrombin inhibitors or glycoprotein IIb/IIIa receptor antagonists might either replace heparin or be added to heparin leading to higher parency and lower reocclusion rates $(26,27)$. This will probably improve the ourcome of patients treated with thrombolytic therapy, which will decrease the need for rescue PTCA. On the other hand, implementation of the new generation of stents will probably have a positive effect on the long term success rate of both primary and rescue PT'CA $(28,29)$. The net effect of these amelioration's will have to be awaited.

\section{CONCLUSIONS}

Acute transport for rescue PTCA or primary PTCA in patients with extensive myocardial infarction is feasible and safe. Efficacy of rescue PTCA or primary PTCA in this setting will have to be tested in larger series. The results of these trials will have to be awaited before transfer of patients in the acute phase to a PTCA center can be implemented as "routine therapy" for patients with extensive myocardial infarction.

\section{PARTICIPATING CENTERS}

- University Hospiral, Maastricht (PTCA center): FW Bär, SH Braat, EC Cheriex, JM van Dantzig, WR Dassen, PA Doevendans, K den Dulk, H Frank, AH Lousberg, ED de Muinck, GVA van Ommen, AJM Oude Ophuis, J Smeets, J Stappers, JB de Swart, F Vermeer, MA Vos, C de Zwaan.

- Hospital De Wever \& Gregorius, Brunssum/Heerlen: E vd Berg, J Lunde, HA Kragten, J Tjan, J Vermaat, C Vincent.

- St. Jozef Hospital, Kerkrade: AG Boehmer.

- Laurentiuszickenhuis Roermond: CJ Werter, A Mattart, E van Nes, E Göbel.

- Maasland Hospital, Sirtard/Geleen: LG Brunninkhuis, R Krijne, G de Weerd. 


\section{ACKNOWLEDGEMENT}

This study would not have been possible without the collaboration of the ambulance personnel in the region Limburg, of the personnel of the catheterisation laboratory, and of the staff and the nurses of all participating centers.

\section{REFERENCES}

1. Lincoff AM, Topol EJ. Nllission of reperfusion. Does anyone achieve oprimal reperfusion during acure myocardial infarction? Circulation 1993;87:1792-805.

2. Simoons ML, Serruys PW, van den Brand M, et al. Early thrombolysis in acure myocardial infarcrion: limitacion of infarct size and improved survival. I Am Coll Cardiol 1986;7:717-28.

3. Fibrinolytic therapy trialists collaborative group. Indications for thrombolycic therapy in suspected acute myocardial infarction: collaborarive overview of early mortality and major morbidity results from all randomised trials of more than 1000 patiencs. Lancet 1994:311-22.

4. De Jacgere PP, Arnold. AA, Balk AH, Simoons ML. Intracranial hemorrhage in association with thrombolytic therapy: incidence and dinical predicrive factors. J Am Coll Cardiol 1992;2:289-94.

5. The GUSTO Angiographic Imwestigators. The effects of tissue plasminogen activator, streptokinase, or both on coronary-artery patency, ventricular funcrion, and survival after acute myocardial infarcrion. N Engl J Med 1993;329:673-82.

6. Califf RM, Topol EJ, Stack RS, er all. Evaluation of combination thrombolytic therapy and timing of cardiac carheterization in acure myocardial infarction: results of thrombolysis and angioplasty in myocardial infarction - phase 5 randomized trial. Circulation 1991:83:1543-56.

7. O'Keefe JH Jr, Rutherford BD, McConahay, et al. Early and late results of coronary angioplasty without antecedent thrombolytic therapy for acute myocardial infarction. Am I Card $1989 ; 64: 1221-30$.

8. Rothbaum DA, Linnemeier TJ, Landin RJ, et al. Emergency percutaneous transluminal coronary angioplasty in acute myocardial infarcion: a 3 year experience. I Am Coll Cardiol 1987:10:264-72.

9. Kahn JK, Rutherford BD, McConahay DR, et al. Catheterization laboratory events and hospital outcome with direct angioplasty for acute myocardial infarction. Circulation 1990;82:1910-5.

10. Grines CL, Browne KF, Marco J, et al, for the Primary Angioplasty in myocardial Intarction Study Group. A comparison of immediate angio- plasty with thrombolytic therapy for acute riyocardial infarction. N Engl J Med 1993:328:673-9.

11. Zijlstra F, de Boer M], Hoontje JCA, et al. A comparison of inmediate coronary angioplasty with incravenous streptokinase in acute myocardial infarction. N Engl J Med 1993:328:680-4.

12. Gibbons RJ, Holmes DR, Reder GS, et al. Immediate angioplasry compared with the administration of a thrombolytic agent followed by conservative treatment for myocardial infarction. N Engl J Med 1993;328;685-91.

13. The Global Use of Strategies to open ocd uded coronaty arteries in acure coronary syndromes (Gusto 11b) angioplasty substudy investigators. A clinical trial comparing primary coronary angioplasty wirh tissue plasminogen activator for acute myocardial infarcrion. N Eng J Med 1997;336:1621-8. 
14. The TIM Study Group. Companison of invasive and conservative sraregies after treatment with intravenous rissue plasminogen activator in acure myocardial infarction: results of the Thrombolysis In Myocardial Infarction (TMI) phase II trial. N Engl J Med 1989;320:618-27.

15. Hartaler GO, Rutherford BD, McConahay DR, et al. Percutaneous transluraimal coronary anguplasty with and wichout thrombolyric therapy for treatment of acure myocardial infarction. Aw Heart J $1983 ; 106: 965-73$.

16. Abbotsmith CW, Topol EJ, George BS, et al. Fate of patients with acute nyocardial infarcion with parency of the infarctrelated vessel achieved with successful thrombolysis versus rescue angioplasty. I Am Coll Cardiol 1990;16:770-8.

17. O’Neill WW, Weinmaub R, Grines CL, er al. A prospective, placebo-controlled, randomized trial. of intravenous streprokinase and angioplasty versus lone angioplasty therapy of acure myocardial infarction. Circ 1992;86:1710-7.

18. Ellis SG, Ribeiro da Silva E, Heyndricks et ail. for the RESCUE investigators. Randomized comparison of rescue angioplasty with conservative management of patients with earty failure of thrombolysis for acute anterior myocardial infarcrion. Circ 1994:90:2280-4.

19. Holmes DR, Gersh B], Bailtey KR et al. Emergency "Rescue" percuraneous transluminal cotronary angioplasty after failed thrombolysis with streptokinase. Circ 1990;81:51-6.

20. Califf RM, Topol EJ, George BS, et al. Characteristics and outcome of patients in whom reperfusion with intravenous tissue-type plasminogen acrivator fails:" Results of the Thrombolysis and Angioplasty in Myocardial Infarcrion (TAMI) trial. Circ 1988;77:1090-9.

21. Bä FW, Oude Ophuis A.JM, Frederiks J, et al. Rescue PTCA following failed thrombolysis and primary PTCA: A retrospective study of angiographic and clinical outcome. I Thromb and Thrombolysis 1997;4:281-8.

22. Zijlstra F, van 't Hof AWJ, Leem AL Hoomtje JCA, Suryapranata $H$, de Boer MJ. Transferring parients for primary angioplasty" a retrospecrive analysis of 104 selected high risk patients with acure myocardial infarcion. Heart 1997;78:333-6.

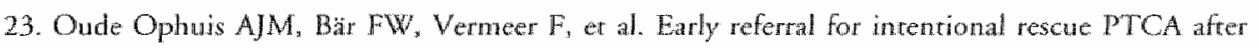
iniriation of thrombolytic therapy in patients admitted to a communiry hospital because of a large acure myocsudial infarcrion. Am Heart $\int 1999 ; 137: 846-854$.

24. Bar FW, Meyer J, Vermed F, et al. Comparison of sareplase and alreplase in acure myocardial infarction. Am ICardiol 1997,79:727-32.

25. Den Hejer P, Verneer F: Ambrosini, er al. Evaluation of a wight-adjusted single-bolus plasminogen acrivator in patients with myocardial infarction. A double blind randomized. angiographic trial of lanoteplase versus alreplase. Cinc1 1998;98:2117-25.

26. Topol EJ for the GUSTO investigators. A comparison of recombinant hirudin with heparin for the treatment of acute coronary syndromes. N Engl J Med 1996:335:775-82.

27. The EPIC inwesrigators. Use of a monodonal antibody directed against the platelet glycoprotein IIb/llia receptor in high risk coronary angioplsty. N Eng J Med 1993;330:956-61.

28. Suryapranata H. Hoorntje JCA, Boer MJ de, Zijlstra F. Randomized comparison of primary stenting with primary balloon angioplasty in acute myocardial infarcrion. Circ 1997;96,8:1-327.

29. Gibson M, Rizzo MJ, McLean C, et al. Adjuncrive stenting following thrombolysis in TMMI 10A \& B. Circ 1997;96,8:1-328. 


\title{
Cost-effectiveness analysis of the LIMI protocol
}

\begin{abstract}
A prospective comparison between thrombolysis, rescue PTCA, and primary PTCA in patients with acute myocardial infarction initially admitted to a hospital without PTCA facilities
\end{abstract}

\footnotetext{
Oude Ophuis AJ ${ }^{1}$, Vermeer $\mathrm{F}^{2}$, Van Hour $\mathrm{BA}^{3}$, Lousberg $\mathrm{A}^{2}$, Berg vd EI

Brumninkhuis $L G^{5}$, Werter $C^{6}{ }^{6}$, Boehmer $A G^{7}$, Dassen WR ${ }^{2}$, Wellens $H J J^{2}$, Bär FW ${ }^{2}$

"Department of Cardiology, Canisius Wilhelmina Hospital, Nijmegen, the Netherlands

${ }^{2}$ Department of Cardiology, Uniwersity Hospital Maastricht, Maastricht, the Netherlands

${ }^{3}$ IMTA, Erasmus University, Rotterdam, the Netherlands

${ }^{4}$ Deparment of Cardiology, Atrium Hospital, Heerlen, the Netherlands

${ }^{5}$ Deparment of Cardiology, Maasland Hospital, Sitrard, the Netherlands

${ }^{6}$ Department of Cardiology, Laurentus Hospital, Roermond, the Netherlands

${ }^{7}$ Department of Cardiology, Arrium Hospiral, Kerkrade, the Netherlands
} 


\section{ABSTRACT}

Introduction: The Limburg Myocardial Infarction study (LIMI), a multicenter open randomized trial for patients admitted to hospitals without angioplasty facilities was designed to evaluate three strategies of reperfusion in the treatment of extensive acute myocardial infarction; 1) thrombolytic therapy with alteplase $(T), 2)$ alteplase followed by immediate transfer to a PTCA center for acute coronary angiography and rescue PTCA, if indicated (RP) and 3 ) immediate transfer for primary PTCA (PP). Previously has been published, that acute transfer of patients for either rescue PTCA or primary PTCA was safe and feasible. Cost-effectiveness of the three strategies are assessed in this study.

Methods: Costs are limited to the direct medical costs and are calculated per patient after one year by multiplying volumes of resource utilization with estimates of unit costs. Effectiveness is expressed in terms of survival free of death, myocardial infarction (MI) and/or stroke; survival free of death, MI/Stroke and revascularisations. (MACE-free survival), and in terms of the distribution of patients by functional class. The balance between costs and effects was addressed by cost effectiveness ratio's and by probability ellipses indicating the distribution of both costs and effects.

Results: 224 patients were randomised: 75 to thrombolytic therapy, 74 to rescue PTCA and 75 to primary PTCA. The percentage of patients with survival free of death, MI and or stroke after one year follow up was estimated at respectively $81 \%(\mathrm{~T}), 81 \%(\mathrm{RP})$ and $84 \%$ (PP). One-yearMACE-free survival was estimated at respectively 55\% (thrombolysis) $58 \%$ (rescue PTCA) and $76 \%$ (primary PTCA) p 00.021 . Costs per patiënt after 1 year were estimated at EUR 8,704 (thrombolysis); EUR 11,524 (rescue PTCA); and EUR 11,661 (primary PTCA). The additional costs per additional MACE free survivor in comparison to treatment with thrombolysis was EUR 81,928 for rescue PTCA and EUR 13,862 for primary PTCA.

Conclusion: Transferring patients to a PTCA center may improve clinical outcome but at significant costs. Moreover, the data raise serious doubts about whether transferring patients to a PTCA center is a cost efficient way to further improve health care, suggesting that thrombolytic therapy may be the best approach in the management of acute myocardial infarction for patients admitted to a hospital without angioplasty facilities in an enwironment of limited resources. 


\section{INTRODUCTION}

Over the past decade, several reperfusion strategies in acute myocardial infarction (AMI) have been developed. The administration of thrombolytic therapy has reduced early mortality by $20-30 \%(1-2)$. Until now this treatment remains the most common mode of reperfusion in patients admitted with acute myocardial infarction. Previous randomized studies indicate that primary PTCA (angioplasty not preceded by the administration of thrombolytic therapy) is a safe and effective alternative for thrombolytic therapy (3-7). Also when patients are referred from another hospital the place of rescue PTCA (angioplasty after failed thrombolysis) has been less clear (8-12). The RESCUE study, a prospective study to evaluate rescue PTCA in parients with anterior myocardial infarction suggested that invasive treatment can improve clinical outcome (13). A recent analysis by Bär et al. suggested that the angiographic and clinical outcome of rescue PTCA and primary PTCA is similar in case rescue PTCA is performed early after failed thrombolysis (14). However, the conclusions concerning rescue PTCA or primary PTCA, as mentioned above, are mostly from patients directly admitted to a PTCA center.

The optimal strategy for parients admitred to a hospital without angioplasty facilities remains unclear and requires further clarification. The question can be asked whether certain patients with acute myocardial infarction admitted to a non-interventional hospital should be transported to a nearby PTCA center for rescue or primary PTCA with its inherent risks, costs and time delays. Transfer of selected patients may be appropriate if the benefits of rescue or primary PTCA ourweigh the risk of inter-hospital patient transport, costs and the porentially negative effects of the additional time delay.

Vermeer et al. reported a prospective randomized multi-center study in patients with acute myocardial infarction who were initially admitred to a hospital without angioplasty facilities. In this LImburg Myocardial Infarction (LIMI) pilot study three strategies were compared 1) thrombolytic therapy without transfer, 2) thrombolytic therapy, immediate transport and early rescue PTCA, in case of failed thrombolysis and 3 ) transfer and primary PTCA (15). If referred angioplasty would be more effective than thrombolysis alone, valid reasons may exist to adopt either the strategy of immediate transfer to an angioplasty center with or without pretreatment with a thrombolytic agent, and to increase the number of hospitals with angioplasty facilities. Such an approach should however be also evaluated for additional (side)-effects and the costs. 


\section{METHODS}

\section{THE LIMI STUDY}

Britly the primary aim of this open randomized multi-center study was to evaluate the safety and feasibility of transfer of patients with extensive acute myocardial infarction for acute intervention (15). All patients were admitted to five noninterventional hospitals in the mid and southern region of Limburg, a province in the southern part of the Nerherlands with approximately 550.000 inhabitants. Patients allocated to thromolytic therapy only remained at the referring hospital. Patients allocated to primary or rescue PTCA had immediate transport to the PTCA center. Interventions wete performed in the Academic Hospital of Mastricht. In general, parients were transferred back to the referring hospital after a 24-hour stay at the PTCA center. Time of discharge from the referring hospital was left to the discretion of the referring cardiologist and was dependent on the clinical condition of the patient.

\section{PATIENT SELECTION}

Inclusion criteria were: age less than 80 years, first or recurrent myocardial infarction, chest pain lasting for at least 30 minutes, not responsive to nitrates and onset of chest pain less than six hours before randomization. The following ECG criterium had to be fulfilled; ST-segment deviation (ST segment elevation in at least one lead + ST segment depression) of at least $1.5 \mathrm{mV}(15 \mathrm{~mm})$.

Exclusion criteria were contraindications for thrombolytic therapy like: severe hypertension unresponsive to acute therapy, enhanced risk of bleeding, previous stroke in the last 12 months. Patients were also excluded in case of overt cardiogenic shock, severe concomitant disease, logistical problems already known before randomization, no informed consent and incomplete follow-up to be expected.

\section{THROMBOLYSIS AND ACUTE PTCA}

Patients allocated to the thrombolysis regimen were treated with alteplase (accelerated dose) after a bolus of 5,000 $U$ of heparin and a heparin infusion, and acerylsalisylic acid.

Patients allocated to rescue PTCA had the same treatment but were immediately thereafter transferred to the PTCA center by ambulance. Patients allocated to primary PTCA were immediately transferred to the PTCA center after receiving a bolus of $10,000 \mathrm{U}$ of heparin intravenously and 300 milligram of acetylsalisylic acid.

In all cases of TIMI 0-1 flow, PTCA was attempted unless the angiographic findings favored acute CABG. In case of TIMI 2 flow the decision to perform PTCA was left to the discretion of the operator. In case of TIMI 3 How, PTCA was not 
performed. A stent was placed in case of a flow limiting dissection. PTCA was performed of the culprit lesion only.

FOLLOW-UP

All parients were followed at the ourparient clinic for at least one year.

The following data were recorded:

- Functional class for angina at 42 days, 6 months and 12 months, according to the criteria of the New York Heart association (16).

- All hospital admissions, including length of admission and reason for admission.

- Date and cause of dearh.

- Recurrent myocardial infarction or cerebrovascular accident.

- All coronary interventions such as coronary angiography (CAG), PTCA or coronary artery bypass grafting (CABG).

- Drug therapy at 42 days, 6 months and 12 months.

\section{costs}

Costs were calculated per patient by multiplying volumes of resources with unit costs. The resources included length of hospital stay (distinguishing between ICUCCU- and ward days), all major interventions (CAG, PTCA, CABG), cost of medication and costs associated with the transfer of the patients to and from the PTCA-center.

With respect to the cost of PTCA procedures a distinction was made between the costs of elective PTCA and those associated with rescue and primary PTCA. The latter being more expensive because of the unplanned character. All other unit costs were derived from previous analyses, calculated on the basis of hospiral administration data (17).

\section{EFFECTIVENESS}

Effectiveness was measured in terms of the percentage of paticnts free of death, MI or stroke after 1 year (MI/Stroke free survival) and in terms of the percentage of parients free of death, myocardial infarction, stroke or any revascularisation (MACE-free survival). Addirionally, effectiveness was measured by categorizing the patients according to their funcrional class at 1 -year follow up.

\section{COST EFFECTIUENESS}

The balance between costs and effects is addressed by calcularing the probabilities that transfer to a PTCA center is a) more effective and cost saving; b) more elfective and more expensive; c) less effective and more expensive and d) less effective and cost 
saving: Additionally, incremental cost effectiveness ratio's are calculated addressing 1) the additional costs per additional patient free of death, MI or stroke and 2) the additional costs per additional patient free of death, MI, stroke or revascularisation.

\section{STATISTICAL ANALYSIS}

All endpoints were analyzed according to the 'intention to treat' principle. Continuous variables are expressed as mean \pm standard deviation (SD) or as median (range) depending on their distribution. If applicable Fisher's exact test was used; two sided p-values are reported. A p-value $<0.05$ was considered to be statistically significant. Uncertainties surrounding the estimates of the incremental CE ratios are expressed by probability ellipses using the methodology reported by van Hout et al (18), realizing that additional uncertainties surrounding the estimates of cost per event are neglected in calculating these estimates.

\section{RESULTS}

\section{PATIENT CHARACTERISTICS}

Between September 1995 and August 1997 a total of 224 patients with acure myocardial infarction were included in the study; 75 patients were allocated to thrombolytic therapy, 74 patients to thrombolysis and rescue PTCA (if indicated) and 75 patients to primary PTCA (Table 1). Only patients with extensive ischemia were included. This resulted in a relative large contribution of patients with anterior myocardial infarction. The difference in time of 15 minutes from randomization to the start of coronary angiography between rescue PTCA and primary PTCA can be explained by the time needed to administer the thrombolytic agent and the 10 minute longer delay between onset of complaints and admission.

Table 2 depicts the clinical course during one-year follow-up.

\section{EVENTS}

The first three columns of table 3 show the number of procedures as well as data concerning length of hospital stay in either group during index hospitalization, and during one-year followup. In the parients allocated to thrombolytic therapy without early transport for angioplasty, ambulance transport to the PTCA center was needed 17 times at later stage during the same admission. Coronary bypass surgery or PTCA after the initial treatment was performed for reasons of recurrent ischemia at rest or during exercise. 
Table 1. Baseline characteristics of 224 patients of the LIMI study stratified by reperfusion modalicy

\begin{tabular}{|c|c|c|c|c|c|c|}
\hline & \multicolumn{2}{|c|}{$\begin{array}{l}\text { Thrombolysis } \\
\text { PTCA }\end{array}$} & \multicolumn{2}{|c|}{$\begin{array}{l}\text { Rescue } \\
\text { PTCA }\end{array}$} & \multicolumn{2}{|c|}{$\begin{array}{l}\text { Primary } \\
\text { PTCA }\end{array}$} \\
\hline & $\mathrm{N}$ & {$[\%]$} & $\mathrm{N}$ & {$[\%]$} & $\mathrm{N}$ & {$[\%]$} \\
\hline Number of patients & 75 & $100]$ & 74 & {$[100]$} & 75 & {$[100]$} \\
\hline Age (yr) mean $\pm S D$ & 59 & \pm 11 & 59 & \pm 11 & 58 & \pm 11 \\
\hline Anterior myocardial infarction & 36 & {$[48]$} & 37 & {$[50]$} & 34 & {$[45]$} \\
\hline Inferior myocardial infarction & 39 & {$[52]$} & 37 & {$[50]$} & 41 & {$[55]$} \\
\hline Men & 56 & {$[75]$} & 57 & {$[77]$} & 54 & $172]$ \\
\hline Women & 19 & {$[25]$} & 17 & {$[23]$} & 21 & {$[28]$} \\
\hline Previous myocardial infarction & 13 & {$[17]$} & 15 & {$[20]$} & 9 & {$[12]$} \\
\hline Previous heart failure & 0 & {$[0]$} & 1 & {$[1]$} & 0 & {$[0]$} \\
\hline Previous PTCA/CABG & 3 & {$[4]$} & 2 & {$[3]$} & 1. & {$[1]$} \\
\hline Time pain-randomisation Mean min (SD) & 125 & \pm 85 & 140 & $\$ 70$ & 130 & \pm 5 \\
\hline Onset pain-Angiography Mean min (SD) & - & & 240 & \pm 80 & 215 & $\$ 80$ \\
\hline
\end{tabular}

Table 2. Clinical course during one year follow up stratified by reperfusion modality

\begin{tabular}{|c|c|c|c|c|c|c|}
\hline & \multicolumn{2}{|c|}{$\begin{array}{l}\text { Thrombolysis } \\
\text { PTCA }\end{array}$} & \multicolumn{2}{|c|}{$\begin{array}{l}\text { Rescue } \\
\text { PTCA }\end{array}$} & \multicolumn{2}{|c|}{$\begin{array}{l}\text { Primary } \\
\text { PTCA }\end{array}$} \\
\hline & $\mathrm{N}$ & {$[\%]$} & $\mathrm{N}$ & {$[\%]$} & $N$ & {$[\%]$} \\
\hline Number of parients & 75 & {$[100]$} & 74 & {$[100]$} & 75 & {$[100]$} \\
\hline Deceased & 6 & {$[8]$} & 7 & {$[9]$} & 9 & {$[12]$} \\
\hline Srroke & 2 & {$[3]$} & 4 & {$[5]$} & 2 & {$[3]$} \\
\hline Recurrent AMI & 9 & {$[12]$} & 5 & {$[7]$} & 4 & $\mid 5$ \\
\hline "Thrombolysis & 7 & {$[9]$} & 1 & [1] & 2 & 3 \\
\hline Late PTCA/CABG & 29 & [39] & 24 & {$[32]$} & 10 & $\llbracket 13 \rrbracket$ \\
\hline
\end{tabular}


$112 \mid$ CHArren 8

Table 3. Mcan costs per pariest affer one year follow-ap stratifed by reperfuston modaliny in EURO

\begin{tabular}{|c|c|c|c|c|c|c|}
\hline & Thrombotysis & $\begin{array}{l}\text { Mescolle } \\
\text { PTCHe }\end{array}$ & $\begin{array}{l}\text { Pramary } \\
P J L^{4}\end{array}$ & Unit Costs Thrombolysis & $\begin{array}{l}\text { Resclye } \\
\text { PTCA }\end{array}$ & $\begin{array}{l}\text { Primary } \\
\text { Prod }\end{array}$ \\
\hline$N$ & 75 & 74 & 75 & & & \\
\hline
\end{tabular}

\section{Ininal treatherat}

Thromblysus 75

74

$$
2
$$

900

900

900

24

Ambulance to PTC

center

7

73

450

0

$444 \quad 438$

Ga

71

72

700

672

672

$P T C A$

20

63

4000

$108 \mathrm{~d}$

3360

Arrbulane to non

PTCA center

68

66

450

414

396

\section{Later meatwent}

Ambulartec ro $1 \mathrm{TCH}$ center

CAC:

Additional PICA

$\mathrm{CABG}$

5

Thrombolysis

1

\section{Adwinssiont}

ICU (days)

CCu (days)

9

Ward $(d y y s)$

241

614

10

$$
320
$$

4

1150

138

2249

155

61

627

455

225

1,842

3027

3211

1906

1365

Total cosus index bospitalisation

6330

$9540 \quad 9855$

Oneyera follow $U_{p}$

ICU (days) 13

CCU (days)

Watd (daps)

122

$\mathrm{CAC}$

13

PTCA

$\mathrm{CABC}$

Thrombolysis

7

Mentarion

G

Follow up conts

8
16
160
15
4
4
0

8
16
131
14
1
4
1

1150
700
225
700
3000
7000
900

199

124

$151 \quad 149$

$486 \quad 393$

1420131

16240

$378 \quad 373$

$0 \quad 12$

$540 \quad 585$

2374

$1984 \quad 1806$

Toralcosts 
Table 4 . Effectiveness and cost effectiveness strarified by reperfuston modality in EURO

\begin{tabular}{lccc} 
& Thrombolysis & Rescue PTCA & Prinary PTCA \\
\hline AP functional class 1 & $79.0 \%$ & $76.0 \%$ & $76.0 \%$ \\
AP functional class 2 & $9.0 \%$ & $14.0 \%$ & $12.0 \%$ \\
AP functional class 3-4 & $4.0 \%$ & $0.0 \%$ & $0.0 \%$ \\
Alive at 12 months & $92.0 \%$ & $90.5 \%$ & $88.0 \%$ \\
No infarcrion & $89.3 \%$ & $93.2 \%$ & $94.7 \%$ \\
No Stroke & $97.3 \%$ & $94.6 \%$ & $97.3 \%$ \\
No CABG/PTCA & $65.3 \%$ & $70.3 \%$ & $86.7 \%$ \\
& & & \\
Surviwal free of MI/Stroke & $81.3 \%$ & $81.1 \%$ & $84.0 \%$ \\
Survival free of MI/Stroke/revascularisations & $54.7 \%$ & $58.1 \%$ & $76.0 \%$ \\
& & & 110.897 \\
Costs per MI/Stroke free surviwor & & $-1,1.7 .736$ & 13.862 \\
Costs per MI/Stroke/Revascularisation free & & 81,928 & \\
survivor & & & \\
\hline
\end{tabular}

In contrast to the protocol, acute transfer of patients to the PTCA center was withheld in 3 patients ( 1 rescue PTCA, 2 primary PTCA). In all but three patients transferred to the PTCA center acute coronary angiography was performed according to the protacol. In three patients ( 2 rescue PTCA, 1 primary PTCA), immediate angiography was logistically not possible, and at the time the catheterisation laboratory was ready, angiography was no longer considered useful because of the time delay and or signs of reperfusion using non-invasive reperfusion criteria. Of the 74 patients assigned to the rescue P'TCA group, an acute intervention was performed in 20 patients (27\%). During the index hospitalisation another 11 patients (15\%) in the rescue PTCA group underwent their angioplasty as a "second-step procedure".

Of the patients assigned to primary PTCA acute intervention was performed in 63 patients $(84 \%)$. Due to the acure angioplasty, the amount of late revascularisation procedures during admission ( 3 parients $(4 \%)$ ) was significantly lower in the patient group randomized to primary PTCA compared to the other two strategies $(p=0.041)$. The length of hospital stay was shortest for the patients allocated to primary PTCA.

\section{COSTS}

The results in terms of mean costs per patient are presented in the last three columns of table 3. The middle column presents the estimates of the unit costs in ELR currency. The costs are highest in both PTCA groups. These are related to the costs of the transport, the costs of thrombolysis, angiography and coronary angioplasty in 
$114 \|^{C H A F T H} 8$

the rescue PTCA group and the costs of the inirial coronary angiography and angioplasty in the primary PTCA group. The costs of the "thrombolysis only" strategy was significantly lower than the costs of the other two straregies $(p<0.001)$. However, during hospitalisarion and during follow-up, part of the initial high costs of the primary PTCA group were compensated by a lower need for late revascularizations when compared to the other strategies.

\section{EFFECTIVENESS}

Table 4 presents the distribution of patients according to funcrional class at one year as well as survival, MI/Stroke free survival, and MACE-free survival. After one-year follow-up, there were no differences between thrombolysis and rescue PTCA in terms of MI/Stroke free survival; in both groups there were 15 patients with such an event. When revascularisations were included in the effectiveness measure there was a slight advantage of $4 \%$ for rescue PTCA, however this difference did not reach statistical significane.

When comparing primary PTCA with thrombolysis, a small non-significant advantage is found for primary PTCA in MV/stroke-free-survival and a significant advantage is found in terms of MACE-free-survival $(p=0.021)$. In terms of functional classes, again somewhat more favorable results are found for primary and rescue PTCA, the differences however not reaching statistically significance.

\section{COST-EFFECTIVENESS RATIO AT ONE-YEAR FOLLOW-UP}

Figure $1-4$ show the results concerning the balance between costs and effects using two dimensional probability ellipses. In figure 1 and 2 the costs and effects are compared berween rescue PTCA and thrombolysis, and in figure 3 and 4 between primary PTCA and thrombolysis. All results indicate that both rescue PTCA and primary PTCA are significantly more expensive than thrombolysis as all ellipses lie above the horizontal axis (of no difference in cosis). The results with respect to MI/Stroke-free survival illustrate the lack of significant differences in effectiveness, both probability ellipses lie well over the vertical axes (of no difference in effects). A similar lack of statistical difference is seen when addressing the difference in MACE free survival between rescue PTCA and thrombolysis. Here, the central cost efectiveness ratio is estimated at EUR 81,928. Only when comparing primary PTCA with thrombolysis an ellipse is found that is completely in the upper right quarter of the CE-plane. Here the central estimate of the additional costs per additional MACE free survivor is EUR 13,862 with an upper 95\% limit of EUR 27,716. 
Fugure 1 to 4. Bivariate nomal distribution of costs and effects using two dimensional probability ellipses. Differences in effects are depicted on the X-axis. Differences in costs are presented on the Y-axis. The C/E ratio is presented in the four separate figures. Outer ellipses define smallest area containing borth costs and effects with $95 \%$ probability, middle ellipses define same area with $50 \%$ probability, inner ellipses with $5 \%$ probability.

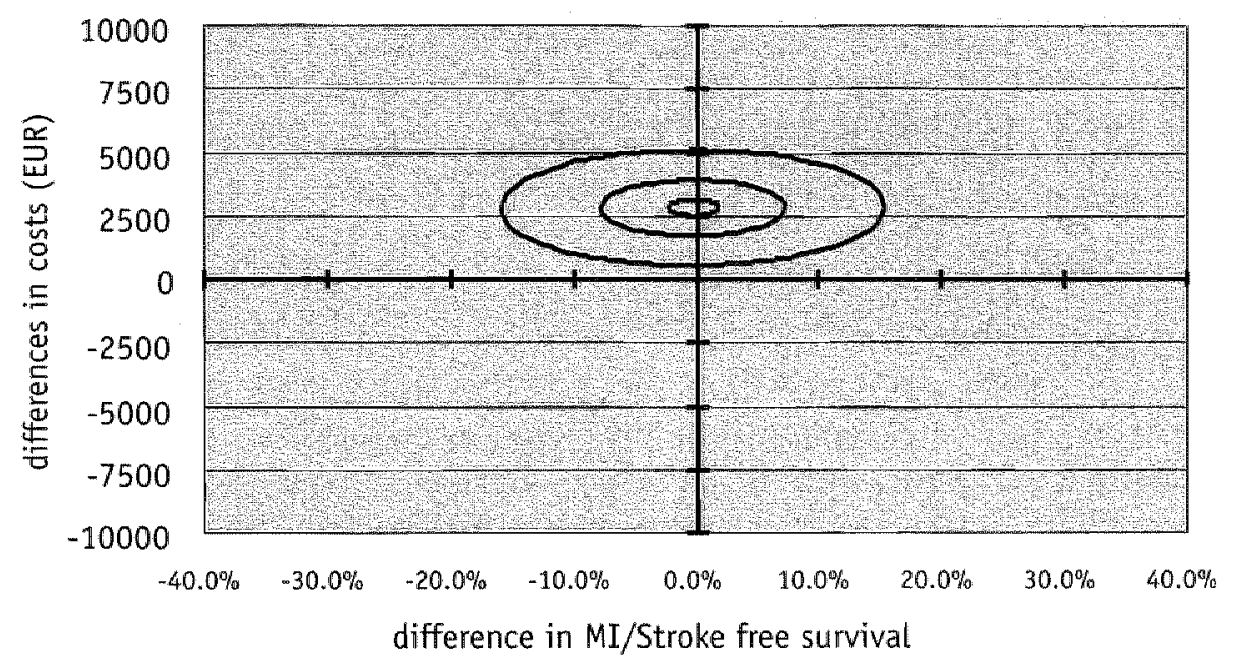

Figure 1. compares the cost and effects berween rescue PTCA and thrombolysis with respect to MI/Stroke free survival.

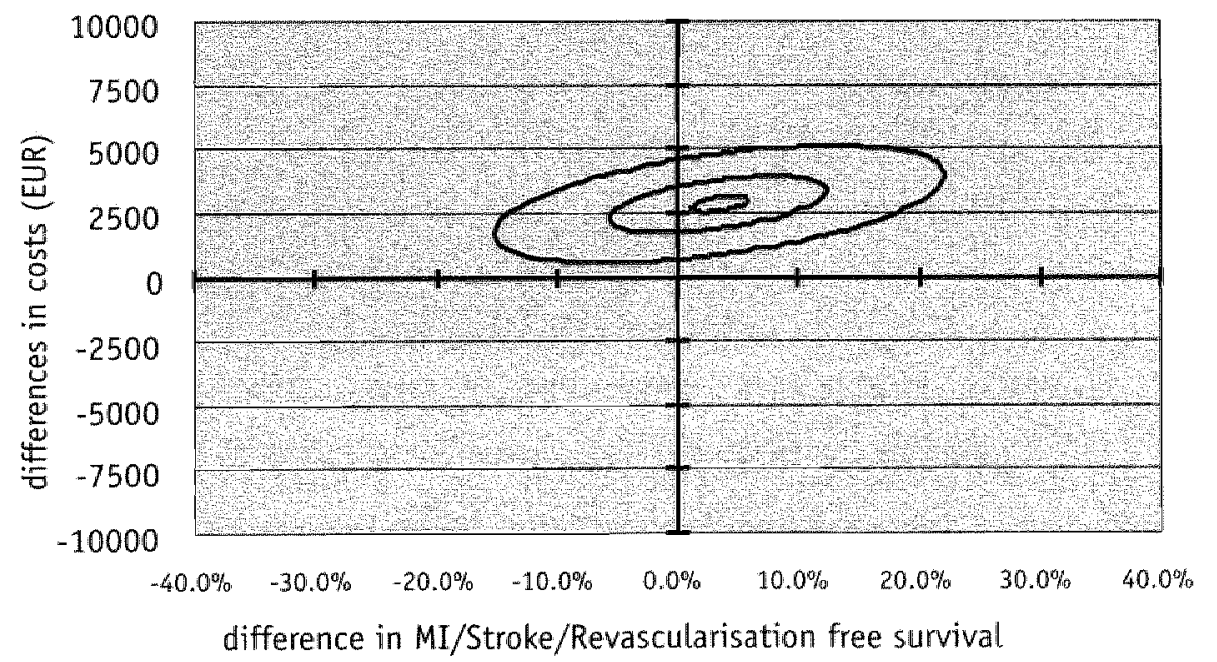

Figure 2. compares the cost and effects berween rescue PTCA and thrombolysis with respect to MACE free survivall. 
$116 \mid$ CHATRE 8

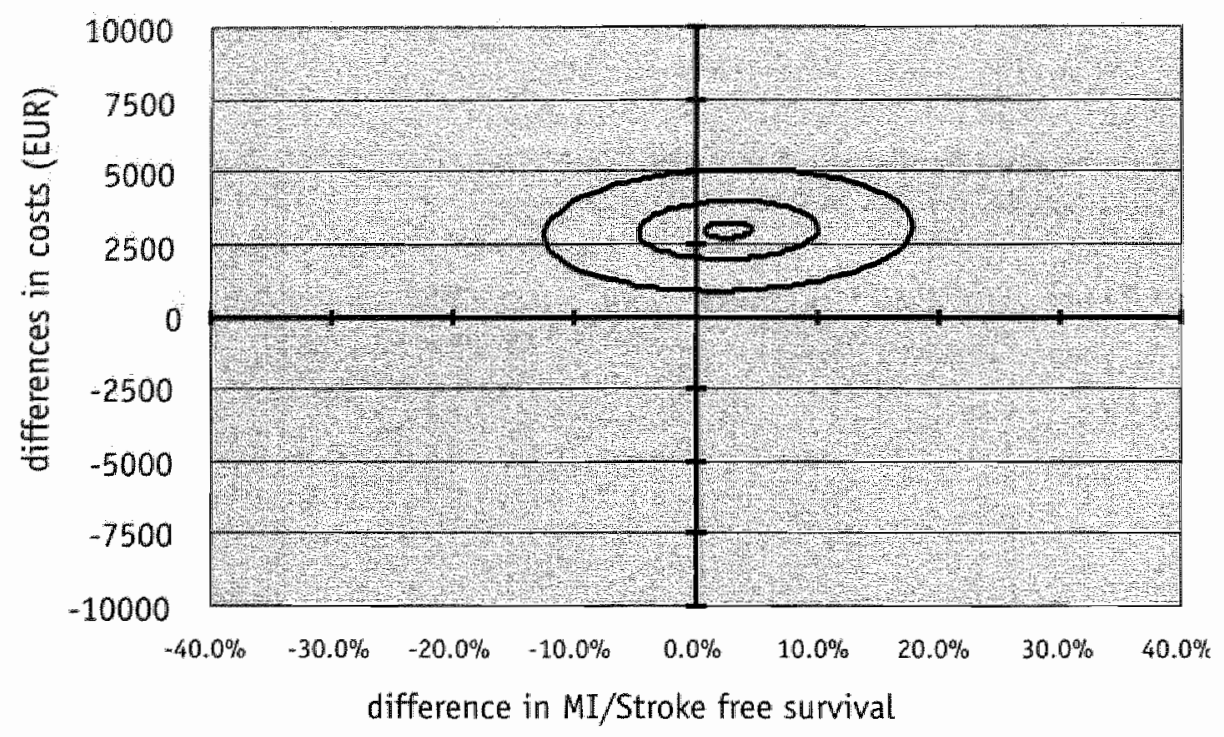

Figure 3. compares the cost and effects berween primary PTCA and thrombolysis with respect to MI/Srroke free survival.

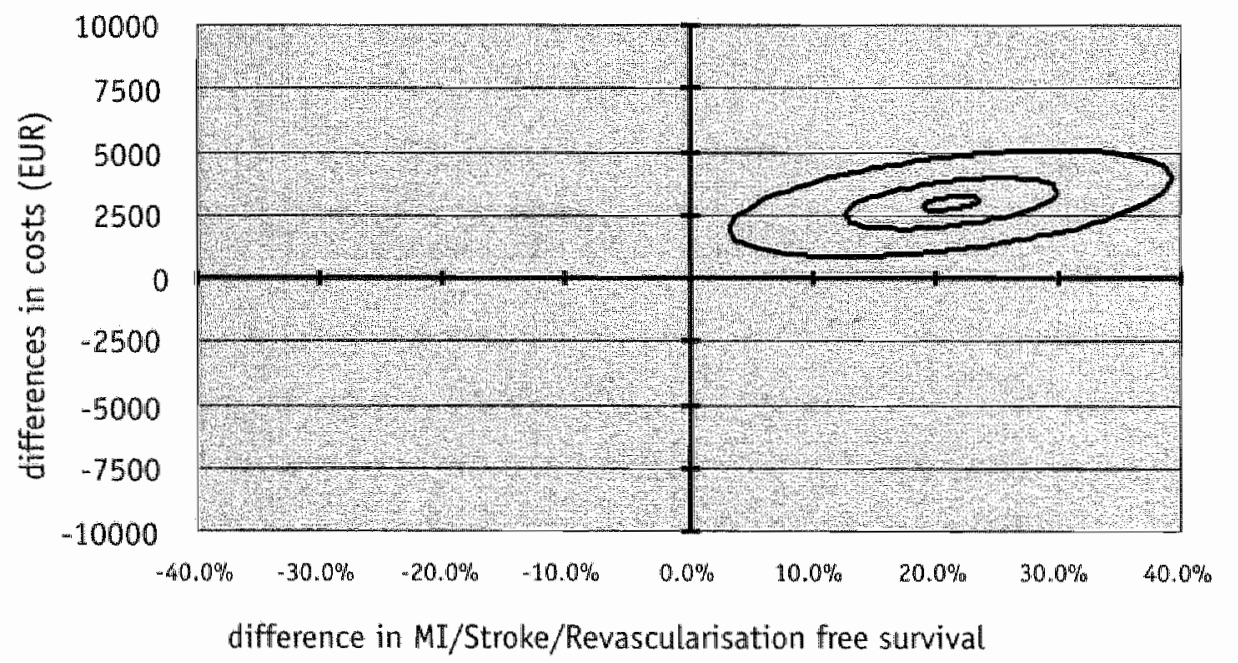

Figure 4. compares the cost and effects berween primary PTCA and thrombolysis with respect to MACE free survival. 


\section{DISCUSSION}

The value of primary PTCA in comparison to thrombolytic therapy has been shown previously (3-7). De Boer et al. indicated that primary coronary angioplasty is effective with regard to mortality, morbidity, and functional status in patients with acute myocardial infarction. His cost-effectiveness study did not confirm the general concern that primary PTCA would be far more expensive than thrombolysis only (17). Also in the PAMI-trial the relative costs and effectiveness was determined for alteplase and primary PTCA in 395 patients. The authors concluded that reperfusion by primary PTCA compared with t-PA improved clinical outcome with similar or reduced costs (19). They proposed greater availability of primary PTCA in a cost-effective manner to patients presenting at hospitals without interventional facilities. Recently, the results of the Prague study with a comparable study design to our study, showed a significant better outcome for the combined outcome dearth, reinfarction or stroke in favour of primary PTCA $(p<0.02)(20)$.

A way to increase angioplasty availability to parients with acute myocardial infarction could be triage using ECG findings by the ambulance service with subsequent referral to regional angioplasty facilities minimizing treatment delay. Investing in new angioplasty facilities could be another option to increase wider awailibility of primary PTCA. Lieu et al. reported an analytic model comparing three policies: primary angioplasty, intravenous thrombolysis and no intervention (21). The authors concluded that primary PTCA performed in skilled high-volume centers with an existing cardiac catheterization laboratory would be cost-effective relative to other medical interventions. However, the procedure would be cost-ineffective at low volume or redundant laboratories (22). These findings favour regionalization of interventional facilities and transfer of patients to interventional facilities.

The LIMI study was the first prospective randomised study to demonstrate the safety and feasibility of acute transport of patients with extensive acure myocardial infarction followed by a PTCA procedure (15). In contrast to other interventional studies, the patients in the LIMI study had to be transported to a PTCA center and a treatment arm with rescue PTCA was included. All former studies more or less neglect the fact that the majority of patients with AMI are admitted to community hospitals where angioplasty facilities are not available. Only a minority of the hospitals are equipped with angioplasty facilities. In the United States $18 \%$ of the hospitals are able to perform angioplasty procedures on-site (23). In the Netherlands only $10 \%$ of hospitals are equipped with these facilities, mainly because of requirements concerning the numbers of procedures that a center needs to perform to guarantee a good quality level.

In a retrospective study, we previously demonstrated that early referral for intentional rescue PTCA after initiation of thrombolytic therapy in patients admitred to a community hospital because of a large acute myocardial infarction is feasible and safe and can be done within therapeutically acceptable time limits (24). Zijlstra et al. also 
have retrospectively demonstrated safecy and feasibility of such an approach with primary PTCA (25). Just recently, Schaumann et al showed the same in an observacional study for primary PTCA in patients with high risk myocardial infarction (26). The option of rescue PTCA was included in the LMM study after a retrospective analysis by Bar et al. showed that the angiographic and clinical outcome is similar in a large series of patients treated with early rescue PTCA or primary PTCA $(12,14)$. Additionally, the administration of a thrombolytic agent before patient transfer may lead to reperfusion and abolish the need for acure angiography and subsequent rescue PTCA, thereby diminishing initial costs. Note that, the design of the LMI study dictated acute coronary angiography in both PTCA groups. Previous studies indicate that acute coronary angiography may not be necessary in patients having non-invasive signs of reperfusion $(24,27)$. Indeed, in the LIMI study we found a difference of $57 \%$ in initial angioplasty when rescue PTCA is indicated, in comparison to the strategy of primary PTCA. However, late PTCA in the rescue PTCA group (the majority was performed during the admission for the index myocardial infarction), was needed in $20 \%$ (especially in those who had no initial intervention). The paradoxic procoagulant effect of thrombolytic therapy and or persistence of the stenosis are probably responsible for this phenomenon $(28,29)$.

The results, presented here, indicate better clinical outcome after PTCA. However, the only difference that reached statistical significance concerned the comparison between primary PTCA and thrombolysis and only in terms of of MACE free survival. In our study, a later PTCA procedure was part of the MACE analysis. One should note that patients with primary PTCA had already an acute PTCA procedure, which was not counted as a major adverse cardiac outcome. This fully explains the differences in the analysis of MACE free survival between the treatment groups. With the limited number of observations one has to conclude that there is insufficient evidence to support large-scale rransportarion of patients to specialized PTCA centers. When considering the point estimates, and disregarding the uncertainties one might come to the conclusion that the benefits may not outweigh the costs. It was estimated that the additional costs per additional MACE free survivor are respectively EUR 81,928 and EUR 13,862 for rescue PTCA and primary PTCA. This figure of EUR 81,928 and 13,862 for rescue PTCA and primary PTCA respectively per additional MACE free survivor may be on or beyond the border of what is acceptable. Whether or not this is acceptable, is an economical and political issue.

Results presented here and the results of primary PTCA without transfer to a specialized center might create a more positive attitude towards creating more PTCA centers. However, one should realize that such a center is only sufficienty qualified if a certain caseload can be guaranteed. Although the incidence of myocardial infarction is high, it is clear even after regionalisation, that only a limited number of hospitals will meet these requirements. Costs per PTCA may increase considerably when PTCA procedures are performed in centers with a sub-optimal number of proce- 
dures. The indirect costs for a 24-hour service have not been taken into account in our study. The lower the patient-load for rescue PTCA and primary PTCA, the higher the cost per patient. This again may change the balance berween costs and effects in a less favourable way for PTCA.

Our study was conducted in a high volume PTCA center (800 PTCA procedures yearly, on 24-hour basis) in an urbanised area. The ambulance services were well acquainted with the procedures. Logistically it is a burden for the ambulance service, the interventionalists and their personel to offer a 24-hour service for acute angioplasty for all patients with myocardial infarcrion in their region. Therefore it was decided to treat only parients with an electrocardiographically extensive infarction in this trial which was approximately $20 \%$ of all acute myocardial infarctions. Conclusions that can be drawn from this study only apply for the subset of patients with an electrocardiographic extensive myocardial infarction. They cannot be transferred to patients with small myocardial infarction, low-volume centers, longer travel distances or other countries with different circumstances in health care. Adequate assessment of indirect costs was not possible. The contribution of these costs will most certainly influence the conclusions from this study.

\section{CONCLUSIONS}

Acute transfer for rescue PTCA or primary PTCA in selected patients wirh electrocardiographic extensive myocardial infarcrion is feasible and safe. The data from the present analysis in a limited number of patients suggest that transfer to a PTCA center may improve clinical outcome and decrease late interventions but in contrast to findings of others at significant costs as compared to thrombolyric therapy only. When considering one-year MACE free survival as the outcome of interest, the cost-effectiveness ratio of treatment of patients with extensive acute myocardial infarction initially admitted to hospitals without angioplasty facilities is in favour of transfer for primary PTCA. These differences can be explained by the non-acute PTCA procedures in the thrombolysis group and the rescue PTCA group. In case these lare PTCA procedures are seen as part of the strategy, thrombolysis only is by far the most cost-effective therapy.

The efficacy of transfer for rescue or primary PTCA has to be tested in larger randomized series. The results of these trials have to be awaited before transfer of patients in the acute phase to a PTCA center for acute intervention can be implemented as a "routine and cost-effective therapy" for patients with extensive myocardial infarction initially admitted to hospitals without angioplasty facilities. 


\section{REFERENCES}

1. Gruppo Italiano per lo Scudio della Streptochinasi nellinfarto Miocardico (GISSI): Effectiveness of intravenous thrombolytic trearnent in acute myocardial infarction. Lancer 1986:1:397-402.

2. ISIS-2 (Second Intemarional Study of Infaret Survival). Collaborative Group: Randomized trial of intravenous meptoknase, oral aspirin, both, or neither among 17,187 cases of suspected acute myocardial infarction: ISIS-2. Lancet 1988:2:349-60.

3. Grines CL, Browne KF, Marco J, et al, for the Primary Angioplasty in myocardial Infarction Srudy Group: A compxarison of immediate angioplasty with thrombolytic therapy for acute myocardial infarction. N Engl J Med 1993;328:673-9.

4. Zijlstra F, de Boer MJ. Hoornte JCA, et al A comparison of immediare coronary angioplasty wirh intravenous streptokinase in acute myocardial infarcrion. $N$ Engl J Med 1993;328:680 4.

5. Gibbons RJ, Holmes DR, Reeder GS, et al: Immediate angioplasty compared with the administration of a thrombolytic agent followed by concervative treatment for myocardial infartion. N Engl J Med 1993;328;685-91.

6. The Global Use of Strategies to open acduded coronary arteries in acute coronary syndromes (Gusto Mb)angioplasty substudy investigators: A clinical trial comparing primary coronary angioplasty with rissue plasminogen actiwator for acute myocardial infarction. $N$ Eng I Med 1997;336:1621-8.

7. Zijlstra F, Hoorntie JC, Boer de M] et al. Long-term benefit of primary angioplasty as compared with thrombolyric therapy for acure myocardial infarction. N Engl J Med 1999;341:1413-1419.

8. The TIMI Study Group: Comparison of invasive and conservative strategies after treatment with intravenous tissue plasminogen acrivator in acute myocardia! infarction: resuls of the Th/hrombolysis In Myocardial Infarcrion (TIMI) phase II triall. N Engl J Med. 1989;320:618-27.

9. Hartzler GO, Rutherford BD, McConahay DR, et al. Percutaneous translumimal coronary angioplasty with and without thrombolytic therapy for treatment of acute myocardial infarction. Am Heart J 1983:106:965-73.

10. Abbotsmith CW, "Topol EJ, George BS, et al. Fate of patients with acute myocardial infarction with patency of dhe infarct-related vessell achieved with successful thrombolysis versus rescue angioplasty. I Am Coll Cardiol 1990;16:770-8.

11. O'Neill WW, Weintrab R, Grines CL, et al. A prospective, placebo-controlled randomized trial of intravenous streptokinase and angioplasty versus lone angioplasty therapy of acute myocardial infarcrion. Circulation 1992;86:1710-7.

12. Bär FW, Vainer J, Stevemhagen J, et al. Ten years experience with early angioplasty in 759 patients with acure myocardial intarccion. I Am Coll Cardiol in print.

13. Ellis SG, Ribero da Silva E, Heyndricks et al: for the RESCUE invertigators. Randomized comparison of rescue angioplasty with conservative management of patients with carly failure of thrombolysis for acute anterior myocardial infarction. Circ 1994;90:2280-4.

14. Bär FW, Oude Ophuis AJM, Frederiks Jy et al: Rescue PTCA following failed thrombalysis and primary PTCA: A retrospective study of angiographic and clinical outcome. I Thromb and Thrombolysis 1997:4:281-8. 


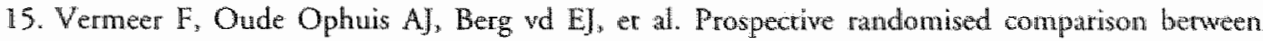
thrombolysis, rescue PTCA and primary PTCA in parients with extensive myocardial infarction admitted to a hospital without PTCA facilities. The LIMI study. Heart 1999:82:426-431.

16. The criteria comittee of the New York Heart Associarion, Inc.: Disease of the heart and blood vessels; Nomenclature and criteria for diagnosis, 7th ed. Boston: Little, Brown 1973.

17. De Boer MJ, Van Hout BA, Liem AL, Suryapranata H, Hoorntie JCA, Zijlstra F. A cost-effective analysis of primary coronary angioplasty wersus thrombolysis for acute myocardial infarction. Am I. Cardiol 1995;76:830-833.

18. Van Hour BA, Al M, Gordon GS,Rutren FFH. Costs, effects and CrE ratios alongride a dinical rial. Health Econ 1994;3:309-319.

19. Stone GW. Grines CL, Rothbaum D, ex al. for the PAMI Trial Investigators. Analysis of the relative costs and effectiveness of primary angioplasry versus tissue-type plasminogen activator: the primary angioplasty in myocardial infarccion (PAMI) trial. I Am Coll Cardiol 1997;29:901-907.

20. Groch L, Widimski P, Aschermann M, Zelizko M, Bednar F, Hlinomaz O. Thombolysis versus PTCA versus both in patients with acute myocardial infarction (Prague trial); coronary angiography findings and PTCA results. Eur Heart J 1999;20:32A.

21. Lieu TA, Gurley RJ, Lundstrom RJ, et al. Projected cost-effectiveness of primary angioplasty for acute myocardial infarcion. I Am Coll Cardiol 1997:30:1741-50.

22. Kimmel SE, Berlin JA, Laskey WK, The relationship berween coronary angioplasty procedture volume and major complications. JAMA 1995;274:1137-1142.

23. Facilities and services in the United States. In: Hospital statistics 1992-93 ed. Chicago: American Hospital Association, 1992:208-209.

24. Oude Ophuis AJM, Bär FW, Vermeer F, er al. Early referral for intentional rescue PTCA after initiation of thrombolytic therapy in parients admitted to a community hospital because of a large acute myocardial infarction. Am Heart ] 1999;137:846-854.

25. F, van 't Hof AW], Leem AL, Hoorntje JCA, Suryapranata $H$, de Boer MJ: Transferring parienrs for primary angioplascy: a retrospective analysis of 104 selected high risk patients with acure myocandial infarction. Heart 1997,78:333-6.

26. Schaumann E, Yoon S, Naegeli B, Frielingsdorf J Gerber A, Schuiki E, Bertel O. Hospiral transfer for primary coronary angioplasty in high risk patients with acute myocardial infarcrion. Heatr $1999 ; 82: 415-419$.

27. Oude Ophuis A], Bär FW, Vermeer F, er al. Angiographic assessment of prospectiwely determined non-invasive reperfusion parameters in acute myocardial infarction. Can the number of acute coronary angiography and subsequent angioplasty be reduced. Heart $2000 \mathrm{in} \mathrm{print.}$

28. Eisenberg PR, Miletich JP, Sobel BE. Factors responsible for the diffrential procoagulant effects of diverse plasminogen activators in plasma. Fibrinolysis 1991:5:217-24.

29. Pederson OD, Gram J, Jespersen J. Plasma resistance to activated protein $C$ regulates the activation of coagulation induced by thrombolysis in patients with ischaemic heart disease. Heart $1997 ; 77: 122-127$ 


\section{Summary and conclusions}

\section{Chapter 1 \\ Introduction}

The aim of the investigations, described in this thesis is to contribute to optimal treatment of patients who are admitted to community hospitals without angioplasty facilities. At present, two reperfusion techniques have proven their efficacy in the treatment of acute myocardial infarction; the administration of fibrinolytic agents and coronary angioplasty. The questions to be answered in this thesis were threefold. The first important question was whether the angiographic and clinical outcome differ between rescue and primary PTCA? Secondly, can noninvasive parameters of reperfusion help us in selecting parients for acute coronary angiography and subsequent coronary angioplasty?

Thirdly, most patients with acute myocardial infarction are initially admitted to community hospitals without direct access to angioplasty facilities. Can patients who are admitted to a center without. PTCA facilities benefit from early transfer to a PTCA center for rescue angioplasty or primary angioplasty and can this be performed with a favourable relation between cost and effectiveness?

\section{Chapter 2 \\ Hystoric overview}

In the eighties, a great deal of clinical research was directed towards safery and efficacy of thrombolytic agents in the treatment of acute myocardial infarction. "The first steps were taken to perform early coronary angiography in acute myocardial infarction. The vast majority of the infarct related vessels showed to be occluded when coronary angiography was performed within 4 hours of symprom onset. Ar the same time, Hartzler was the first to introduce a mechanical approach to open occluded coronary vessels through coronary angioplasty. It lasted till the early nineties before coronary angioplasty in acute myocardial infarction was used widely. Early studies showed that immediate PTCA after thrombolysis, irrespective of the status of coronary reperfusion, was not beneficial. The results of rescue PTCA: coronary angioplasty after failed thrombolysis, were equivocal. However, primary PTCA showed to be a favourable treatment under ideal circumstances with respect to immediate and longterm outcome.

In the mid-nineties an explosive growth in the use of intracoronary stents was observed. Use of intracoronary stents together with antiplatelet therapy appeared to 
124 Summary and condusions

be effective in the treatment of acute myocardial infarction especially with respecr to the number of re-interventions. Mortality is not influenced.

Throughout the relative short history in the development of very effective tools in the treatment of acute myocardial infarction, it seemed to be forgotten that access to angioplasty facilities in the real-life situation is limited. Thus, the excellent results of mechanical intervention only account for those patients who are directly admitted to a hospital with angioplasty facilities. Only a few reports directed attention towards the possibility of transportation of patients with acute myocardial infarction to an angioplasty center for emergency angioplasty. The scarciry and the retrospective nature of these reports were the incentive for the theme of this thesis:

"Strategies of coronary reperfusion in acute myocardial infarction for patients admitted to hospitals without angioplasty facilities".

\section{Chapter 3}

The angiographic and clinical outcome of rescue and primary PTCA is similar

Patency of the infarct related artery improves the prognosis of patients with myocardial infarction. Previous studies have shown that primary PTCA was more effective than thrombolysis alone. How effective is rescue PTCA after failed thrombolysis? A retrospective analysis was performed in 176 consecutive patients suffering from acute myocardial infarction with documented TIMI 0-1 flow during angiography. These patients underwent either rescue PTCA after failed thrombolysis $(n=100)$ or primary PTCA $(n=76)$. The angiographic outcome was similar; success could be obtained in $86 \%$ and $85.5 \%$ respectively. The clinical outcome in terms of mortality ( $4 \%$ versus $6,6 \%$ ), reinfarction $(6 \%$ versus $3.9 \%)$, and repeat interventions were comparable. This study confirmed that failed emergency PTCA was the most important predictor of mortality. Successful PTCA led to a one-year mortality of $4.6 \%$ versus $28 \%$ mortality for failed PTCA. It was concluded that the clinical and angiographic outcome of patients with rescue PTCA because of failed thrombolysis is good and comparable to patients who underwent primary PTCA.

\section{Chapter 4}

\section{Early transfer for intentional rescue angioplasty}

For patients admitted with acute myocardial infarction in a community hospital without angioplasty facilities, thrombolytic treatment is the treatment of choice. In this chapter the question was raised whether patients with acute myocardial infarcrion inirially admitted to a communiry hospital can benefit from early transfer for intentional rescue PTCA after the adminstration of a thrombolytic agent. This study was performed in collaboration with the community hospiral of Sittard, located approximately 35 kilometers from the angioplasty center. Transport of patients with ongoing myocardial infarction appeared to be safe and feasible, only 1 of the 165 
transferred patients died and $9 \%$ suffered haemodynamic or arthythmia problems during transport. The median tïme delay between onset of chest pain and arrival at the catheterisation laboratory was 187 minutes.

In this chapter also the use of non-invasive markers of reperfusion was introduced. Forty percent of the patients in this study were non-invasively identified to have successful reperfusion and acute coronary angiography was withheld. The patients identified as such appeared to have $0 \%$ in-hospital mortality versus $7 \%$ for the group with angiographic reperfusion and $11 \%$ for the group with rescue PTCA $p<0.05$. However, re-infarction rate was highest in the group with non-invasively determined reperfusion. It was concluded that early transfer after trearment with a thrombolytic agent from a community hospital to a PTCA center for intentional rescue PTCA is safe with respect to complications during transport and that it can be done within therapeutically acceptable time limits. An additional 33\% of patients could benefit from early reperfusion through rescue PTCA. Non-invasive reperfusion criteria allowed the recognition of patients with an excellent outcome in terms of mortality and is useful to reduce the workload of an angioplasty center. This was prospectively studied in the next chapter.

\section{Chapter 5}

\section{Can myocardial reperfusion be diagnosed non-invasively?}

A simple and reliable non-invasive method to identify patients with successful reperfusion is lacking. In this chapter we prospectively investigated the value of seven non-invasive reperfusion parameters. Previous studies have shown that immediate angioplasty, of open vessels is nor beneficial. If reperfusion could be demonstrated through the use of these markers, acute coronary angiography for subsequent angioplasty is not necessary. In the community hospital situation withour angioplasty facilities, the consideration to transport a patient with acute myocardial infarction to an angioplasty center for emergency angioplasty could be guided by these noninvasive reperfusion markers. Also the recipient angioplasty center can re-evaluate the perfusion status of the patient and refrain from acute coronary angiography if reperfusion is suspected. In an angiographically controlled study in 230 patients it appeared that TIMI 2-3 flow could be discriminated from TIMI 0-1 flow with good accuracy. In contrast, TIMI 3 flow could not reliably be discriminated from TIMI 2 flow. Depending on local circumstances the goal of acceptable reperfusion (TIMI 2-3 or TIMI 3 flow might differ. The reperfusion parameters should be used accordingly. 
126 Summiary and condusions

Chapter 6

The LIMII protocol

Chapter 4 was the basis for a prospective multicenter randomised study addressing the question whether it is safe, feasible, and effective to transfer patients with an acute myocardial infarction to an angioplasty center for either rescue PTCA or primary PTCA.

Chapter 6 deliniates the protocol of the LImburg Myocardial Infarction (LIMI) study. The aim of this prospective multicenter randomized pilot study was to evaluare prospectively the safery of transportation and feasibility of interventions in parients with extensive acute myocardial infarction referred for primary or rescue PTCA in case of failed thrombolysis. Three therapeutic regimens in the treatment of acute myocardial infarction in patients initially admitted to community hospitals without angioplasty facilities were evaluated: thrombolytic therapy, thrombolytic therapy followed by acute coronary angiography and rescue PTCA if indicated and primary PTCA. As secondary endpoints, clinical outcome and cost evaluations were planned.

\section{Chapter 7}

\section{Acute transport for rescue PTCA or primary PICA in patients with extensive myocardial infarction is feasible and safe}

The benefits of primary angioplasty and some what equivocal those of rescue angioplasty have been demonstrated in the treatment of acure myocardial infarction. However, the promising results of the published papers on this subject accounted only for patients directly admitted to an angioplasty center. In most countries access to angioplasty is limited, for example in the Netherlands only $10 \%$ of hospitals do indeed have in-house angioplasty facilities. For this reason a prospective randomized multicenter pilot study was started comparing thrombolysis $(\mathrm{n}=75$ ), thrombolysis with acute coronary angiography and (if indicated) rescue PTCA $(n=74)$ and primary PTCA $(n=75)$ in patients who were admitted with extensive myocardial infarction in one of the five community hospitals without angioplasty facilities in the province of Limburg, the Netherlands. None of the parients who were transferred for angioplasty died during transport. The rime delays for rescue PTCA and primary PTCA were $240 \pm 80$ minutes and $215 \pm 80$ minutes respectively. There were no significant differences in the early ( 42 days) and one-year clinical outcome variables. The PTCA center was able to handle the additional patient load. One-year mortality was $8 \%$ in the thrombolysis group, $9 \%$ in the rescue PTCA group and $12 \%$ in the primary PTCA group. As expected, patients allocated to primary PTCA had the highest TIMI 3 flow rate and less late reinterventions than the other 2 groups. The limited number of patients, however, did not allow us to make conclusions in terms of efficacy. 
It was concluded that in patients with extensive myocardial infarction acute transfer for rescue PTCA or primary PTCA is feasible and safe. The efficacy of these reperfusion strategies must be tested in a larger series of patients.

\section{Chapter 8}

\section{Transfer for acute PTCA; Cost effectiveness ratio in favor of primary PTCA}

In order to adapt new strategies of treatment in clinical practice, cost effectiveness is becoming more and more important to convince policy makers to either adapt the proposed treatment or to provide physicians with appropriate funding. From the LIMI trial as described in chapter 6 and 7 we learned that acute transfer for either rescue or primary PTCA is safe and feasible. In this study the cost for hospital admission procedures and medication were estimated by multiplying volumes with estimates of unit cost. After one-year follow-up the cost per patient for thrombolysis, rescue PTCA of primary PTCA were respectively EUR 8,704, EUR 11,524 and EUR 11,661 $(p<0.001)$. The efficiency of both invasive strategies for the treatment of acute myocardial infarction in patients initially admitted in hospitals without angioplasty facilities can be addressed by putting forward the incremental costs per event-free survivor. The clinical results presented in this study indicate berter outcome after PTCA. However, the additional costs per additional MACE free survivor in comparison to treatment with thrombolysis was EUR 81,928 for rescue PTCA and EUR 13,682 in favour of primary PTCA. The acceptibility of these considerable costs are subject to political debate. The data of this study suggest betrer clinical outcome after PTCA but at significant cost. The results of larger randomized trials are necessary before transfer of patients in the acute phase of extensive acute myocardial infarction for rescue PTCA or primary PTCA can be implemented as routine and cost-effective therapy.

\section{Conclusions}

1. The clinical and angiographic outcome for patients with acute myocardial infarction with angiographically proven inadequate coronary flow is simillar for early rescue PTCA and primary PTCA.

2. Reperfusion parameters are of help in identifying patients with acute myocardial infarction with open coronary arteries in which subsequent angioplasty is not necessary. TIMI 3 flow cannot reliably be discriminated from TIMI 2 flow. However, the prognosis of patients with acute myocardial infarction with positive criteria of reperfusion is excellent

3. Acute transfer of patients with extensive acute myocardial infarction from a hospital withour angioplasty facilities to a hospital with angioplasty facilities is safe and at least in our setting feasible and can be done in a therapeutically acceptable time window. Transferring patients to a PTCA center may improve clinical 
outcome but at significant cost. The additional cost per additional MACE free survivor in comparison to thrombolyuic treatment seems most favourable for primary PTCA. The treatment with "thrombolysis only" remains the best alternative in an environment of limited resources.

\section{Where to go from here?}

Every answer to a question raises new questions. In other words every thesis is the kick-off for the next one. Reperfusion strategies in acute myocardial infarction are in a continuous flux. The "optimal" treatment is guided by the resultant of continuous forces between the development of new techniques, local circumstances and health care budgets. Depending on the preference, capabilities and facilities of physicians, a certain strategy will be followed. At this moment it is assumed by many cardiologists that the clinical outcome in patients who are transferred for either rescue or primary PTCA is in favour of primary PTCA. Does this imply that every patient with an acure myocardial infarction should be transported to an angioplasty center for primary PTCA? In the Netherlands approximately 27,000 patients are admitted yearly with the diagnosis of myocardial infarction. Assuming that in $40 \%$ the electrocardiogram is not diagnostic for acute myocardial infarction, at least the remaining $60 \%$ of patients (approximately 16.000) are candidates for some sort of reperfusion treatment. In the Netherlands, approximately 10\%-15\% of these patients are immediately admitted to hospitals with an existing infrastructure for interventional cardiology where primary coronary angioplasty can be considered. The remaining patients (approximarely 14.000) will be admitted to hospitals without angioplasty facilities. If indications would extend to transfer all these patients for primary PTCA an enormous logistic burden for the angioplasty centers will be the consequence. In the LIMI trial, transfer of patients was limited to patients with electrocardiographic evidence of extensive myocardial infarction. Assuming that $20 \%$ of the patients will meet these criteria, approximately 2800 patients are candidates for transfer for primary PTCA. For the situation in the Netherlands, where 13 hospitals do have an interventional infrastructure, this means an additional caseload of approximately 210 emergency angioplasties for each center yearly. Are we willing ro match this increase in caseload, or should we decrease the number of interventions by pre-transportation thrombolytic therapy? If this strategy is to be followed it will take off the steam of logistically difficult emergency angioplasties since reperfusion during transportation will limit the number of acute angioplasties with approximately $60 \%$. The price to pay is a considerable number of late PTCA/CABG in this patient group. The third option is to accept that thrombolytic therapy is reasonably effective making it not worthwile to transport the patient to a PTCA center. Also in the patients with open vessels after thrombolysis a considerable group of patients needs late interventions, but this can potentially be managed in a logistically more efficient way. 


\section{Implications for emergency PTCA}

In order to implement around the clock angioplasty services, sufficient staff and facilities are needed. With an increasing workload of emergency angioplasty, it is required to train a sufficient amount of physicians with an interventional subspecialisation. Similarly, appropriate numbers of nursing staff, cardiac technicians and facilities are needed. Additional catheterisation rooms are necessary as well as hospital beds and CCU beds to receive an additional caseload of very ill patients who require a high level of care. Some patients may need ventilation, intra aortic balloon pumping or emergency $C A B G$ requiring support of an experienced and cooperative surgical team and a high quality nursing staff. Transferring patients with acute myocardial infarction requires a well-motivated ambulance service that can be responsible for safe and rapid interhospital transfer. Central ambulance units must have adequate capacity and staff to transfer critically ill patients prepared for full life support. More importantly is the establishment of protocols and guidelines for hospitals without angioplasty facilities who refer patients for emergency angioplasty. Protocols enhance the recognition of the appropriate patient in an efficient way thereby minimising time delays. Also protocols for the follow-up care in the hospitalls without angioplasty facilities should be established especially in respect to sheath removal and the increasing use of drugs intervening with coagulation.

\section{Where should infarct angioplasty be performed}

If infarct angioplasty is limited to the current tertiary angioplasty centers, sufficient ambulance services are needed for rapid, safe and swift transfer to these centers. It has been shown that regionalization of angioplasty facilities is cost-effective in high volume centers. Infarct angioplasty is not easy, therefore transfer of infarct patients to a regional tertiary center implies an appropriate caseload of emergency angioplasty per individual operator thereby increasing changes of good outcome.

Another option is to provide around the clock angioplasty in every district hospital. Such a development is not likely to succeed because of the high costs in capital goods and human resources.

However, in areas where prehospital thrombolysis is implemented it would be interesting to triage patients with extensive myocardial infarction immediately to hospitals with angioplasty facilities with or without pre-transportation thrombolysis in order to reduce the time to reperfusion even further. Studies addressing this issue are currently being performed.

The results of a large multicenter trial are required before transfer of patients with extensive myocardial infarction in the acute phase to a PTCA center can be implemented as routine therapy. At this moment studies are ongoing trying to answer this important question. 


\section{Samenvatting en conclusies}

\section{Hoofdstuk 1 \\ Introductie}

Dit proefschrift heeft tot doel een bijdrage te leveren aan de verbetering van het inzicht in de behandeling van patiënten die initieel worden opgenomen in een ziekenhuis zonder mogelijkheden voor een percutane rransluminale coronairangioplastiek (PTCA) ofwel dotterprocedure. Heden ten dage zijn er bij de behandeling van het acure hartinfarct twee technieken beschikbaar die kunnen leiden tor het opnieuw doorgankelijk maken van de geoccludeerde kransslagader. De toediening van een stolseloplossend geneesmiddel of het verrichten van PTCA. Het merendeel van de patiënten met een acuut myocardinfarct wordt opgenomen in ziekenhuizen zonder PTCA faciliteiten. Derhalve werd in dit proefschrift tot doel gesteld een antwoord te geven op een drietal vragen. Allereerst werd onderzocht of dat de klinische en angiografische uitkomsten van rescue PTCA (dotterprocedure na het falen van een stolseloplossend middel) en primaire PTCA (dotterprocedure bij een geoccludeerde kransslagader zonder voorbehandeling met een stolseloplossend middel) vergelijkbaar waren. Op de tweede plaats werd nagegaan of non-invasieve parameters waarmee we zonder hartcatheterisatie reperfusie (herstel van doorbloeding) kunnen aantonen van nut zouden kunnen zijn om patiënten met reperfusie te identificeren zodanig dat acute coronair angiografie gevolgd door eventuele PTCA niet nodig is. Op de derde plaats werd de vraag gesteld of het gunstig is, om patiënten met een uitgebreid myocardinfarct vroegtijdig te verwijzen naar een PTCA centrum voor een acute PTCA procedure al dan niet voorafgegaan door de behandeling met cen stolseloplossend geneesmiddel. Tevens werd onderzocht of de cost-effect analyse van een dergelijke reperfusiestrategie acceptabel was.

\section{Hoofdstuk 2}

\section{Historisch overzicht}

In de jaren tachrig was een aanzienlijk deel van klinisch onderzoek gericht op de veiligheid en effectiviteit van stolseloplossende geneesmiddelen bij de behandeling van her acute myocardinfarct. Schoorvoetend werden er acute hartcatheterisaties verricht bij het acute myocardinfarct waarbij werd aangetoond dat het merendeel van de kransslagvaten waren afgesloten wanneer de hartcatheterisatie binnen 4 uur na de aanvang van de klachten werd verricht. De vroege jaren tachtig luidde dan ook het begin in van onderzoeken naar de waarde van PTCA, om het afgesloten kransslagvat te openen. Het heeft echter 10 jaar geduurd alvorens deze techniek bij het 
myocardinfarct tot volle volwassendom is gekomen en een rume toepassing ontstond. Enkele studies toonden aan, dat de stelselmatige toepassing van de PTCA techniek ongeacht de mate van doorbloeding van her infarctgerelateerde kransslagvat weinig zinvol was. De resultaten van rescue PTCA, waren niet eensluidend. Het bleck dat primaire PTCA, angioplastiek van het infarctgerelateerde coronairvat zonder voorbehandeling met een stolseloplossend geneesmiddel, onder ideale situaties leidt tot uitstekende resultaten zowel op korte als wel langere termijn, vergeleken met de behandeling met een stolseloplossend geneesmiddel. De midden jaren negentig werden gekenmerkt door een explosieve groei van het gebruik van intracoronaire stents (ijzeren veertje). Het gebruik van deze stents met gelijkrijdig gebruik van platjesremmers bleek effectief bij de behandeling van het acute myocardinfarct, met name ten aanzien van het aantal re-interventies. Het gebruik van stents bij het acute infarct had geen invloed op de mortaliteit.

Gedurende de in feite korte tijdspanne waarin een aantal zeer effectief gebleken behandelingsstrategieën zich ontwikkelden werd vergeten dat de zeer bemoedigende resultaten voornamelijk van toepassing waren op patiënten die rechtstreeks in de ziekenhuizen met PTCA faciliteiten worden opgenomen. Het overgrote deel van de patiënten, wordt echter opgenomen in ziekenhuizen zonder PTCA faciliteiten. Er is slechts schaars onderzoek gedaan naar de mogelijkheid van transport van deze patiënten naar een PTCA centrum voor acute PTCA. Deze schaarste aan veelal retrospectieve data stond aan de wieg van dit proefschrift met als titel "Strategies of coronary reperfusion in acute myocardial infarction for parients admitted to hospitals without angioplasty facilities".

\section{Hoofdstuk 3}

\section{De klinische en angiografische uittkomst van rescue en primaire PICA is vergelijkbaar}

De prognose van de patiënt met een acuut myocardinfarct wordt bepaald door de doorgankelijkheid van de infarctgerelateerde kransslagader. Enkele studies hebben laten zien dat primaire PTCA effectiever is, dan alleen de roediening van een stolseloplossend geneesmiddel. Hoe effectief is rescue PTCA vroeg na her falen van een dergelijke therapie in vergelijking met primaire PTCA? In een retrospecrieve studie in 176 opeenvolgende patiënten met een hartinfarct en tijdens hartcatheterisatie bevestigde, slechte of zelts afwezige doorbloeding van het kransslagvat (TIMI 0-1 flow) werden de resultaten vergeleken tussen patiënten behandeld middels rescue PTCA na thrombolyse $(\mathrm{n}=100)$ en patiènten behandeld middels primaire PTCA $(\mathrm{n}=76)$. Bij een PTCA procedure wordt succes gedefinieerd indien er een normale doorstroming van her kransslagvat is (TIMI 3 flow) en de restvernauwing minder is dan $50 \%$. Deze was vergelijkbaar bij beide therapievormen, respectievelijk $86 \%$ en $85,5 \%$. Mortaliteit ( $4 \%$ versus $6,6 \%$ ), reinfarct $(6 \%$ versus $3,9 \%$ ) en reinterventies waren eveneens vergelijkbaar. Indien de PTCA procedure echter faalde, bleek de 
mortaliteit sterk toe te nemen. De mortaliteit bedroeg $28 \%$ bij een mislukte PTCA procedure versus $4,6 \%$ na een geslaagde procedure. De uitkomsten van deze studie suggereren vergelijkbare klinische en angiografische resultaten bij patiënten die worden behandeld middels rescue of primaire PTCA.

\section{Hoofdstuk 4}

\section{Vroege overplaatsing naar een PTCA centrum voor eventuele rescue PTCA}

Voor patiënten met een hartinfarct die worden opgenomen in een ziekenhuis zonder PTCA faciliteiten is behandeling met een stolseloplossend geneesmididel de behandeling van eerste keus. $\mathrm{Bij}$ het ontbreken van tekenen van herstel van doorbloeding (reperfusie) kan rescue PTCA overwogen worden. In dit hoofdstuk is de vraag aan de orde gekomen of het zinnig is om patiënten met een uitgebreid myocardinfarct na behandeling met thrombolyse over te plaatsen naar een PTCA centrum voor eventuele rescue PTCA in de acute fase van het myocardinfarct.

Deze studie heeft plaatsgevonden in samenwerking met het Maasland Ziekenhuis in Sittard gelegen op ongeveer 32 kilometer afstand van het Academisch Ziekenhuis Maastricht. Tijdens het transport waren de complicaties relatief laag (9\%), terwijl 1 patiënt overleed bij aanvang van het transport. De tijd die nodig was tussen het begin van de klachten en aankomst op het catheterisatielaboratorium bedroeg mediaan 187 minuten.

In dit hoofdstuk werd tevens het gebruik geïntroduceerd van enkele niet invasieve criteria, voor het herstel van doorbloeding van het kransslagvat. Middels toepassing van deze criteria werd bij $40 \%$ van de patiënten dit herstel, op niet-invasieve wijze aannemelijk gemaakt. Hierdoor kon worden afgezien van acute hartcathererisatie of PTCA procedure. Deze patiënten werden veelal met dezelfde ambulance terugverwezen naar het verwijzend centrum. Ze hadden in vergelijk tot de patiëntengroep waarbij de criteria onduidelijk waren, maar die bij hartcatheterisatie toch herstel van doorbloeding hadden en de patiëntengroep met rescue PTCA, een gunstige prognose; de mortaliteit was $0 \%$ versus $7 \%$ en $11 \%$ bij patiënten waar alsnog gedotterd moest worden wegens een afgesloten kransslagader $(p<0,05)$. Echter het aantal recidief infarcten was zoals verwacht het hoogst in deze groep. Concluderend kan worden gesteld dat vroege verwijzing voor eventulele rescute PTCA na behandeling met een stolseloplossend geneesmiddel in een ziekenhuis zonder P"TCA faciliteiten veilig is en een haalbare therapie blijkt binnen een therapeurisch acceptabel tijdsbestek. Dankzij deze behandelingsstrategie kon toch nog in $33 \%$ van de patiënten vroeg herstel van doorbloeding worden bereikt middels rescue PTCA. Het gebruik van niet-invasieve criteria voor herstel van doorbloeding maakte het mogelijk een patiëntengroep te identificeren met een uiltstekende prognose waarbij acute hartcatheterisatie niet noodzakelijk was. In de praktijk kan dit leiden tot een aanzienlijke reductie voor de werklast van het PTCA centrum. Dit werd prospectief onderzocht in het volgende hoofdstuk. 
$134 \mid$ Simentwating the condusies

\section{Hoofdstuk 5 \\ Kan myocardreperfusie noninvasief worden vastgesteld?}

Een simpele en betrouwbare methode voor de identificatie van patiënten met een geslaagd herstel van de doorbloeding (reperfusie) is nog niet geheel voorhanden. In dit hoofdstuk wordt onderzocht wat de individuele en gecombineerde waarde is van 7 niet-invasieve criteria voor reperfusie, samengesteld uit ECG gegevens en de klachten van de patiënt. Uit eerder onderzoek is gebleken dat het verrichten van een PTCA procedure bij een open kransslagvat na een voorbehandeling met een stolseloplossend geneesmiddel bij geslaagde reperfusie weinig zinvol is. Acute hartcatheterisatie is vermijdbaar indien herstel van doorbloeding door niet-invasieve criteria kan worden aangetoond. In ziekenhuizen zonder PTCA facilireiten zou het besluit omtrent eventuele overplaatsing voor bijvoorbeeld rescue PTCA op grond van deze criteria kunnen worden genomen. Ook het ontvangend PTCA centrum kan nadat er door het transport tijd over heen is gegaan, nogmaals de patiènt evalueren op herstel van doorbloeding en zo nodig afzien van acute hartcatheterisatie. Uit middels hartcatheterisatie gecontroleerd onderzoek bij 230 patiënten bleek dat patiënten met trage doorbloeding (TIMI 2 flow) of normale doorbloeding (TIMI 3 flow) van het infarctgerelateerde kransslagvat goed kon worden onderscheiden van patiënten met geen of geringe doorbloeding (respectievelijk TIMI 0-1 flow). Echter TIMI 3 flow kan niet met grote betrouwbaarheid worden onderscheiden van TIMI 2 flow. Het accepteren van redelijke maar niet perfecte doorbloeding hangt af van locale inzichten en mogelijkheden. Afhankelijk hiervan, kunnen de niet-invasieve criteria voor reperfusie al dan niet worden toegepast.

\section{Hoofdstuk 6 \\ De LIMI trial}

Het retrospectieve onderzoek zoals beschreven in hoofdstuk 4 heefr de anzet gegeven tor een prospectieve gerandomiseerde multicenter studie met de vraagstelling of het veilig en haalbaar is om patiënten met een uitgebreid acuut hartinfarct te verwijzen naar een PTCA centrum voor rescue PTCA of primaire PTCA.

Hoofdstuk 6 beschrijft het protocol van de LImburg Myocard Infarct (LIMI) trial. Deze studie heeft ten doel om drie handelingsstrategieën te evalueren voor de behandeling van een groot acuut hartinfarct bij patiënten die initieel worden opgenomen in ziekenhuizen zonder PTCA faciliteiten. In deze pilot studie worden pariẻnten prospectief gerandomiseerd tot een behandeling met een stolseloplossend geneesmiddel, to behandeling met stolseloplossende medicatie en rescue PTCA indien noodzakelijk, of tot primaire PTCA. In deze studie is prospectief nagegaan of het vervoer vanuit niet-PTCA centra naar het Academisch Ziekenhuis Maastricht haalbaar en veilig was. Tevens is gekeken naar de effectiviteit en de kosten van de verschillende benaderingen. 


\section{Hoofdstuk 7 \\ Acute overplaatsing voor rescue of primaire PTCA van patiënten met een uitgebreid myocardinfarct is veilig en haalbaar}

Van de behandeling van het acute hartinfarct zijn in de literatuur gunstige resultaten beschreven van primaire PTCA, minder duidelijk is dit voor rescue PTCA. Echter, deze resultaten zijn in feite alleen van toepassing voor patiënten die rechtstreeks worden opgenomen in een ziekenhuis met PTCA faciliteiten. In de meeste westerse landen is de beschikbaarheid van PTCA faciliteiten beperkt. In Nederland beschikt slechts $10 \%$ van de ziekenhuizen over dergelijke faciliteiten. Dit was de reden voor het starten van het prospectief gerandomiseerd multicenter LImburg Myocardial Infarction onderzoek waarbij thrombolyse (stolseloplossend middel) zonder transport naar een dottercentrum $(n=75)$ wordt vergeleken met thrombolyse met transport naar een dottercentrum voor rescue PTCA $(n=74)$ en transport naar een dottercentrum voor primaire PTCA $(n=75)$. Het betreft patiënten die werden opgenomen met een uitgebreid acuut hartinfarct in een van de 5 deelnemende ziekenhuizen zonder PTCA faciliteiten in de provincie Limburg. Geen van de patiënten overleed tijdens het transport. De tijd (gemiddeld) tussen het begin van de klachten en hartcatheterisatie bedroeg in de rescue PTCA groep $240 \pm 80$ minuten, en 215 180 minuten in de primaire PTCA groep. Er werden geen significante verschillen gevonden in morbiditeit en mortaliteit tussen de 3 groepen gedurende de eerste 42 en na 1 jaar follow-up. De mortaliteit na een jaar was $8 \%$ in de groep die werd behandeld met een stolseloplossend geneesmiddel, $9 \%$ in de patiëntengroep mer rescue PTCA en $12 \%$ in de groep met primaire PTCA. De één-jaars morbiditeit en mortaliteit was relatief laag in deze patiëntengroep met behandeling voor een uitgebreid myocardinfarct. De patiënten die werden behandeld middels primaire PTCA hadden gemiddeld al vroeg een betere doorbloeding van het kransslagvat en vertoonden daarom ook minder noodzaak tot latere interventies. Concluderend blijkt de behandeling middels rescue of primaire PTCA bij patiënten met een uitgebreid myocardinfarct na acuut transport goed uitvoerbaar en veilig. De omvang van deze studie was te klein om een ferme uitspraak te doen over de effectiviteit. Een grote multicenter studie is noodzakelijk om deze vraag te beantwoorden.

\section{Hoofdstuk 8}

\section{Overplaatsing voor acute PTCA. Cost-effectiveness ratio meest gunstig voor primaire PTCA}

Voor het implementeren van nieuwe behandelingsmethodieken en het verkrijgen van steun voor wetenschappelijk onderzoek zujn kosten-effectiviteit analyses van toenemend belang. Van de LIMI studie weten wij (hoofdstuk 7) dat overplaatsing voor rescue en primaire PTCA veilig en haalbaar is. In deze studie werden prospectief gegevens verzameld en werden de kosten voor opname, onderzoeken en medi- 
134. Samenvatting en conclustes

\section{Hoofdstuk 5}

Kan myocardreperfusie nonínvasief worden vastgesteld?

Een simpele en betrouwbare methode voor de identificatie van patienten met een geslaagd herstel van de doorbloeding (reperfusie) is nog niet geheel voorhanden. In dit hoofdstuk wordt onderzocht wat de individuele en gecombineerde waarde is van 7 niet-invasieve criteria voor reperfusie, samengesteld uit ECG gegevens en de klachten van de patient. Uit eerder onderzoek is gebleken dat het verrichten van een PTCA procedure bij een open kransslagvat na een voorbehandeling met een stolseloplossend geneesmiddel bij geslaagde reperfusie weinig zinvol is. Acute hartcatheterisatie is vermijdbaar indien herstel van doorbloeding door niet-invasieve criteria kan worden aangetoond. In ziekenhuizen zonder PTCA faciliteiten zou het besluit omtrent eventuele overplaatsing voor bijvoorbeeld rescue PTCA op grond van deze criteria kunnen worden genomen. Ook het ontvangend PTCA centrum kan nadat er door het transport tijd over heen is gegaan, nogmaals de patiënt evalueren op herstel van doorbloeding en zo nodig afzien wan acute hartcatheterisatie. Uit middels hartcatheterisatie gecontroleerd onderzoek bij 230 patiënten bleek dat patiënten met trage doorbloeding (TIMI 2 flow) of normale doorbloeding (TIMI 3 flow) van het infarctgerelateerde kransslagvat goed kon worden onderscheiden van patiënten met geen of geringe doorbloeding (respectiewelijk TIMI 0-1 flow). Echter "TIMI 3 flow kan niet met grote betrouwbaarheid worden onderscheiden van TIMI 2 flow. Het accepteren van redelijke maar niet perfecte doorbloeding hangt af van locale inzichten en mogelijkheden. Afhankelijk hierwan, kunnen de niet-invasieve criteria voor reperfusie al dan niet worden toegepast.

\section{Hoofdstuk 6}

De LIMI trial

Het retrospectieve onderzoek zoals beschreven in hoofdstuk 4 heeft de aanzer gegeven tot en prospectieve gerandomiseerde multicenter studie met de vraagstelling of het veilig en haalbaar is om pariënten met een uitgebreid acuut hartinfarct te verwijzen naat een PTCA centrum voor rescue PTCA of primaire PTCA.

Hoofdstuk 6 beschrijf het protocol van de LImburg Myocard Infatet (LIMI) trial. Deze studie heeft ten doel om drie handelingsstrategieën te evalueren voor de behandeling wan een groot acuut hartinfarct bij patiënten die initieel worden opgenomen in ziekenhuizen zonder PTCA faciliteiten. In deze pilot studie worden pariënten prospectief gerandomiseerd tot een behandeling met een stolseloplossend geneesmiddel, tot behandeling met stolseloplossende medicatie en rescue PTCA indien noodzakelijk, of tot primaire PTCA. In deze studie is prospectief nagegaan of het vervoer vanuit niet-PTCA centra naar het Academiscl Ziekenhuis Maastricht haalbaar en veilig was. Tevens is gekeken naar de effectiviteit en de kosten van de verschillende benaderingen. 


\section{Hoofdstuk 7 \\ Acute overplaatsing voor rescue of primaîre PTCA van patiênten met een uiltgebreid myocardinfarct is veilig en haalbaar}

Van de behandeling van het acute hartinfarct zijn in de literatuur gunstige resultaten beschreven van primaire PTCA, minder duidelijk is dit voor rescue PTCA. Echrer, deze resultaten zijn in feite alleen van toepassing voor patiënten die rechtstreeks worden opgenomen in een ziekenhuis met PTCA faciliteiten. In de meeste westerse landen is de beschikbaarheid van PTCA faciliteiten beperkt. In Nederland beschikt slechts $10 \%$ van de ziekenhuizen over dergelijke faciliteiten. Dit was de reden voor thet starten van het prospectief gerandomiseerd multicenter LImburg Myocardial Infarction onderzoek waarbij thrombolyse (stolseloplossend middel) zonder transport naar een dottercentrum $(n=75)$ wordt vergeleken met thrombolyse met transport naar een dottercentrum voor rescue PTCA $(n=74)$ en transport naar een dottercentrum voor primaire PTCA $(n=75)$. Het betreft patiënten die werden opgenomen met een uitgebreid acuut hartinfarct in een van de 5 deelnemende ziekenhuizen zonder PTCA faciliteiten in de provincie Limburg. Geen van de patiënten overleed tijdens het transport. De tijd (gemiddeld) tussen het begin van de klachten en hartcatheterisatie bedroeg in de rescue PTCA groep $240 \pm 80$ minuten, en $215 \pm 80$ minuten in de primaire PTCA groep. Er werden geen significante verschillen gevonden in morbiditeit en mortaliteit tussen de 3 groepen gedurende de eerste 42 en na 1 jaar follow-up. De mortaliteit na een jaar was $8 \%$ in de groep die werd behandeld met een stolseloplossend geneesmiddel, 9\% in de patiëntengroep met rescue PTCA en 12\% in de groep met primaire PTCA. De één-jaars morbiditeit en mortaliteit was relatief laag in deze patiëntengroep met behandeling voor een uitgebreid myocardinfarct. De patiënten die werden behandeld middels primaire P'TCA hadden gemiddeld al vroeg een betere doorbloeding van het kransslagvat en vertoonden daarom ook minder noodzaak tot latere interventies. Concluderend blijkt de behandeling middels rescue of primaire PTCA bij pariënten met een uitgebreid myocardinfarct na acuut transport goed uitvoerbaar en veilig. De omvang van deze studie was te klein om een ferme uitspraak te doen over de effectiviteit. Een grote multicenter studie is noodzakelijk om deze vraag te beantwoorden.

\section{Hoofdistuk 8}

Overplaatsing voor acute PTCA. Cost-effectiveness ratio meest gunstig voor primaire PTCA

Voor het implementeren van nieuwe behandelingsmethodieken en het verkrijgen van steun voor wetenschappelijk onderzoek zijn kosten-effectiviteit analyses van toenemend belang. Van de LIMI studie weten wij (hoofdstuk 7) dat overplaatsing voor rescue en primaire PTCA veilig en haalbaar is. In deze studie werden prospectief gegevens verzameld en werden de kosten woor opname, onderzoeken en medi- 


\section{Hoofdstuk 5}

\section{Kan myocardreperfusie noninvasief worden vastgesteld?}

Een simpele en betrouwbare methode voor de identificatie van patiënten met een geslaagd herstel van de doorbloeding (reperfusie) is nog niet geheel woorhanden. In dit hoofdstuls wordt onderzocht wat de individuele en gecombineerde waarde is wan 7 niet-inwasieve criteria voor reperfusie, samengesteld uit ECG gegevens en de klachten van de patiënt. Uit eerder onderzoek is gebleken dat het verrichten van cen PTCA procedure bij een open kransslagvat na een voorbehandeling mer een stolseloplossend geneesmiddel bij geslaagde reperfusie weinig zinvol is. Acute hartcatheterisatie is vermijdbaar indien herstel van doorbloeding door niet-invasiewe criteria kan worden aangetoond. In ziekenhuizen zonder PTCA faciliteiten zou het besluit omtrent eventuele overplaatsing voor bijvoorbeeld rescue PTCA op grond van deze criteria kunnen worden genomen. Ook het ontwangend PTCA centrum kan nadat er door het transport tijd over heen is gegaan, nogmaals de pariënt evalueren op herstel van doorbloeding en zo nodig afzien van acute hartcatheterisatie. Uit middels hartcatheterisatie gecontroleerd onderzoek bij 230 patiënten bleek dat patiënten met trage doorbloeding (TIMI 2 flow) of normale doorbloeding (TIMI 3 flow) van het infarctgerelateerde kransslagvat goed kon worden onderscheiden van patiënten met geen of geringe doorbloeding (respectievelijk TIMI 0-1 flow). Echter TIMI 3 flow kan niet met grote betrouwbaarheid worden onderscheiden wan TIMI 2 flow. Het accepteren van redelijke maar niet perfecte doorbloeding hangt af van locale inzichten en mogelijkheden. Afhankelijk hiervan, kunnen de niet-invasieve criteria voor reperfusie al dan niet worden toegepast.

\section{Hoofdstuk 6 \\ De LIMI trial}

Het retrospectieve onderzoek zoals beschreven in hoofdstuk 4 heeft de aanzet gegeven tot een prospecrieve gerandomiseerde multicenter studie met de vraagstelling of het veilig en habbaar is om patiënten met een uitgebreid acuut hartinfarct te verwijzen naar een PTCA centrum voor rescue PTCA of primaire PTCA.

Hoofdstuk 6 beschrijft het protocol van de LImburg Myocard Infarct (LIMI) trial. Deze studie heeft ten doel om drie handelingsstrategieèn te evalueren voor de behandeling van een groot acuut hartinfarct bij patiënten die initieel worden opgenomen in ziekenhuizen zonder PTCA faciliteiten. In deze pilot studie worden patiënten prospectief gerandomiseerd tot een behandeling met een stolseloplossend geneesmiddel, tot behandeling met stolseloplossende medicatie en rescue PTCA indien noodzakelijk, of tot primaire PTCA. In deze studie is prospectief nagegaan of het vervoer vanuit niet-PTCA centra naar het Academisch Ziekenhuis Maastricht haalbaar en veilig was. "Tevens is gekeken naar de effecriviteit en de kosten van de verschillende benaderingen. 


\section{Hoofdstuk 7}

Acute overplaatsing voor rescue of primaire PTCA van patiënten met een uitgebreid myocardinfarct is veilig en haalbaar

Van de behandeling van het acute hartinfarct zijn in de literatuur gunstige resultaten beschreven van primaire PTCA, minder duidelijk is dit voor rescue PTCA. Echter, deze resultaten zijn in feite alleen van toepassing voor patiënten die rechtstreeks worden opgenomen in een ziekenhuis met PTCA faciliteiten. In de meeste westerse landen is de beschikbaarheid van PTCA faciliteiten beperkt. In Nederland beschilkt slechts $10 \%$ van de ziekenhuizen over dergelijke faciliteiten. Dit was de reden voor het starten van het prospectief gerandomiseerd multicenter LImburg Myocardial Infarction onderzoek waarbij thrombolyse (stolseloplossend middel) zonder transport naar een dottercentrum $(n=75)$ wordt vergeleken met thrombolyse met transport naar een dottercentrum voor rescue PTCA $(n=74)$ en transport naar een dottercentrum woor primaire PTCA $(n=75)$. Het betreft patiẻnten die werden opgenomen met een uitgebreid acuut hartinfarct in een van de 5 deelnemende ziekenhuizen zonder PTCA faciliteiten in de provincie Limburg. Geen van de pariënten overleed tijdens het transport. De tijd (gemiddeld) tussen het begin van de klachten en hartcatheterisatie bedroeg in de rescue PTCA groep $240 \pm 80$ minuten, en $215 \pm 80$ minuten in de primaire PTCA groep. Er werden geen significante verschillen gevonden in morbiditeit en mortaliteit tussen de 3 groepen gedurende de eerste 42 en na 1 jaar follow-up. De mortaliteit na een jaar was $8 \%$ in de groep die werd behandeld met een stolseloplossend geneesmiddel, $9 \%$ in de patiëntengroep met rescue PTCA en $12 \%$ in de groep met primaire PTCA. De één-jaars morbiditeit en mortaliteit was relatief laag in deze patiëntengroep met behandeling voor een uitgebreid myocardinfarct. De patiënten die werden behandeld middels primaire PTCA hadden gemiddeld al vroeg een betere doorbloeding van het kransslagvat en vertoonden daarom ook minder noodzaak tot latere interventies. Concluderend blijkt de behandeling middels rescue of primaire PTCA bij patiënten met een uitgebreid myocardinfarct na acuut transport goed uitvoerbaar en veilig. De omwang van deze studie was te klein om een ferme uitspraak te doen over de effectiviteit. Een grote multicenter studie is noodzakelijk om deze vraag te beantwoorden.

\section{Hoofdstuk 8}

\section{Overplaatsing voor acute PTCA. Cost-effectiveness ratio meest gunstig voor primaire PTCA}

Voor het implementeren wan nieuwe behandelingsmethodieken en het verkrijgen van steun voor wetenschappelijk onderzoek zijn kosten-effectiviteit analyses van toenemend belang. Van de LIMI studie weten wij (hoofdstuk 7) dat overplaatsing voor rescue en primaire PTCA veilig en haabaar is. In deze studie werden prospectief gegevens verzameld en werden de kosten voor opname, onderzoeken en medi- 
136 Samenvating en oondusies

catie berekend door het gebruiksvolume te vermenigvuldigen met een unit kostprijs. Na een jaar follow-up bedroegen de kosten voor thrombolyse, rescue PTCA of primaire PTCA respectievelijk EUR 8.704, EUR 11.524 en EUR 11.661 ( $<<0,001)$. De additionele kosten per additionele event-vrije overleving met inbegrip van alle revascularisaties was in vergelijking tot een behandeling met een stolseloplossend middel in het voordeel van primaire PTCA; EUR 13.682 versus EUR 81.928 voor de behandeling met rescue PTCA. In het algemeen kan gesteld worden, dat overplaatsing naar een PTCA centrum woor acure interventie leidt tot een verbetering van de klinische uitkomsten maar het gaat gepaard met aanzienlijke kosten. De bereidheid om deze kosten te accepteren lijkt een zaak voor politieke beschouwing. De resultaten van grote gerandomiseerde studies moeten worden afgewacht alvorens de strategie van het overplaatsen van een patiënt in de acute fase van het grote hartinfarct kan worden geïmplementeerd als zijndle een routine en kosten-effectieve behandeling.

\section{Conclusies}

1. Rescue PTCA en primaire PTCA leiden tot een vergelijkbare uitkomst met betrekking tot doorbloeding van de kransslagaderen en klinische resultaten bij patiënten met angiografisch aangetoonde afwezige of slechte doorbloeding (TIMI 0-1 flow) bij het acute myocardinfarct.

2. Niet-invasieve parameters voor het herstel van doorbloeding blijken nuttig ter identificering van patiënten met een open kransslagvat zodat acute hartcatheterisatie niet noodzakelijk is. Echter, normale doorbloeding (TIMI 3 flow) kan niet betrouwbaar worden onderscheiden van tragere doorbloeding van het kransslagwat (TIMI 0-2 flow).

De prognose van patiënten met positieve criteria voor het herstel van doorbloeding is uitstekend.

3. Acute verwijzing voor rescue of primaire PTCA vanuit een ziekenhuis zonder PTCA faciliteiten is veilig, haalbaar, en kan worden verricht binnen een therapeutisch acceptabel tijdsinterval.

Verwijzing van patiënten naar een PTCA centrum leidt tot een verbetering van klinische uitkomsten maar tegen aanzienlijke kosten. De additionele kosten per additionele MACE-free overleving, lijkt in het voordeel van primaire PTCA vergeleken met thrombolytische therapie. In een omgeving met beperkte financiële en logistieke middelen, blijft thrombolytische therapie het beste alternatief.

\section{Toekomst verwachtingen}

Elke vraag staat aan de basis van nieuwe vragen. Met andere woorden, een voltooid proefschrift behoort de aftrap voor een nieuw onderzoek te zijn. Strategieën voor het bewerkstelligen van goede doorbloeding van de kransslagaderen zijn voortdurend in 
beweging. De behandeling die wordt toegepast is een resultante van krachten tussen de ontwikkeling van nieuwe technieken, lokale gebruiken en de budgettering in de gezondheidszorg. Afhankelijk van de voorkeur, bekwamheid en de faciliteiten die ter beschikking staan van de behandelend cardioloog zal een bepaalde behandeling worden ingezet.

Dit proefschrift heeft laten zien dat het mogelijk is om patiënten met een uitgebreid hartinfarct over te plaatsen naar een PTCA centrum voor acute PTCA waarbij primaire P'TCA, hoewel niet in alle opzichten significant, iets gunstiger lijkr. Betekent dit nu dat elke patiënt met een acuut hartinfarct in aanmerking komt voor overplaatsing voor een acute PTCA procedure? In Nederland worden jaarlijks 27.000 patiënten opgenomen onder de diagnose hartinfarct. Aangenomen dat her electrocardiogram in $40 \%$ van de patiënten onvoldoende reden is voor her toepassen van een stolseloplossend geneesmiddel of acute PTCA, dan heeft dit tot gevolg dat circa 16.000 patiënten in aanmerking komen voor een dergelijke behandeling. Primaire PTCA moet sterk overwogen in de patiënten (10-15\%) die worden opgenomen in ziekenhuizen met mogelijkheden voor PTCA. Wat te doen bij de andere circa 14.000 patiënten die worden opgenomen in ziekenhuizen zonder PTCA faciliteiten? Het betekent een enorme belasting voor de PTCA centra indien de indicatiestelling voor het verrichten van primaire PTCA zou worden uitgebreid voor elk hartinfarct. In de LIMI studie werd overplaatsing beperkt tot de electrocardiografische uirgebreide hartinfarcten. Aangenomen dat in $20 \%$ er sprake is van een uitgebreid hartinfarct, dan blijven er bij benadering 2.800 patiënten over die in aanmerking komen voor primaire PTCA. In de Nederlandse situatie mer 13 PTCA centra betekent dit een additionele last van ongeveer 210 acute PTCA's per jaar per centrum. Het is de vraag of fysiek aan deze vraag kan worden voldaan, of dar een strategie bestaande uit een stolseloplossend geneesmiddel voor transport met een vrijwel identicke uitkomst niet een practischer oplossing is. Dit beperkt het aantal acute interventies met \pm $60 \%$. Een dergelijke benadering zou de logistieke druk van de PTCA-centra kunnen beperken door het herstel van doorbloeding die dankzij het stolseloplossend geneesmiddel gedurende her transport optreed. De keerzijde van de medaille betekent in dat geval een toename in het aantal late PTCA procedures en CABG.

\section{Implicaties van acute infarct PTCA}

Voor de implementatie van een 24-uurs service voor infarct PTCA, zinn voldoende faciliteiten en mankracht noodzakeligk. Met het oog op een enorme toename in infarct angioplastiek is het vereist om goed gemotiveerde gesubspecialiseerde interventiecardiologen op te leiden. Geligkerwijs, zijn extra faciliteiten noodzakelijk evenals uibreiding van verplegend personeel en hartunctielaboranten. Uitbreiding van het aantal catheterisatie laboratoria, verpleeg-en CCU-bedden is vereist on de toename van het aantal overplaatsingen van ernstig zieke patiènten het hoofd te bieden en on hoogwardige zorg te leveren. Enkele patiënten zullen beademingsbe- 
$138 \$ Samenwating en condusies

hoeftig zijn of vereisen het gebruik van een intra-aorrale ballonpomp, of acute $\mathrm{CABG}$ warvoor hoog gekwalificeerd verpleegkundig personeel een vereiste is evenals een coöperatieve cardiochirurgische staf. Ook de ambulancedienst krijgt te maken met een veranderend verwijspatroon. De ambulancedienst zal middels mankracht en faciliteit moeten kunnen inspelen op veilig en snel transport van ernstig zieke patiènten in ambulances die zijn geëquipeerd voor full-life support. Nog belangrijker is de implementatie van protocollen in de ziekenhuizen zonder faciliteiten voor PTCA. Onderlinge afstemming tussen deze centra en de PTCA centra omtrent overplaarsing van de patiënten voor infarctangioplastiek zal resulteren in een adequate verwijzing van patiënten met een minimum aan tijdsdelay. Ook de follow-up van de zorg van deze pariënten in de verwijzende ziekenhuizen zal in protocollen moeten worden gëmplementeerd met name ten aanzien van de know-how omtrent sheath verwijdering en de groeiende groep van anticoagulantia.

\section{Localisatie van infarctangioplastiek}

In her geval dat infarctangioplastielk gelimiteerd blijft tot de tertiaire PTCA centra is een goed gemotiveerde ambulancedienst cruciaal voor snel en veilig transport naar een PTCA centrum. Het is reeds eerder aangetoond dat regionalisatie van PTCA centra kosten-effectief is in de zogenaamde high-volume centra. Het dotteren bij een acuut hartinfarct is niet eenvoudig en vereist veel ervaring. Regionalisatie van PTCA centra heeft automatisch tot gevolg dat de individuele interventiecardioloog een grote individuele caseload heeft waardoor de kans op succes toeneemt.

Een andere mogelijkheid zou kunnen zijn om ieder streekziekenhuis toe te rusten met PTCA faciliteiten en deskundig personeel. Vanwege de hoge kosten van een dergelijke ontwikkeling in faciliteit en mankracht, heeft dit weinig kans van slagen.

Echter, in regio's waar prehospitale behandeling met een stolseloplossend geneesmiddel is geimplementeerd zou het interessant zijn om alreeds via de ambulance triage van pariënten met een uitgebreid myocardinfarct al dan niet na thrombolyse, natar een ziekenhuis met PTCA faciliteiten te laten plaatsvinden. Diverse studie protocollen met betrekking tor bovenstaande zijn momenteel in wording. Het resultaat van dergelijke reperfusiestrategieën zal kunnen leiden tor verdergaande reductie in de tijd tor (mechanische) reperfusie en een reductie van de kosten.

De resultaten van een grootschalig onderzoek zijn noodzakelijk om een definitieve uitspraak te kunnen doen betreffende de effectiviteit van de diverse therapieën alvorens de overplaatsing van patiënten met een uitgebreid hartinfarct naar een PTCA centrum voor acute PTCA kan worden geïmplementeerd als zijnde "standaard therapie". Tot die tijd moeten het stolseloplossend geneesmiddel, rescue PTCA en primaire PTCA worden bezien als zijnde symbiotische reperfusiestrategieën in plaats van op zichzelf staande therapievormen. Momenteel zijn er studies gaande die tot doell hebben meer helderheid te brengen in deze materie. 


\section{Dankwoord}

En toen was er niets meer...

Een dergelijk gevoel zal menigeen hebben overmeesterd toen de definitieve goedkeuring voor zijn of haar proefschrift daar was. Vergeten zijn de vele uren achter de tekstverwerker, de besprekingen, onderzoeken, kritieken en momenten van voldoening als er weer een hoofdstuk af was of een veronderstelling juist bleek te zijn.

In gedachten ga ik terug naar her voorjaar wan 1994 toen er een onderhoud plaatsvond in de ochtendbesprekingskamer van het Academisch Ziekenhuis Maastricht. Onder aanvoering van professor Bär en collegae Vermeer en van Ommen ontspon zich een levendig discussie omtrent een destijds al "routinematige" behandeling van patiënten met een acuut hartinfarct, die na voorbehandeling met cen thrombolyticum vanuit het ziekenhuis in Sirtard werden verwezen naar Maastricht voor eventuele acute interventie.

Het idee voor dit proefschrift was geboren en dankzij gezamenlijke inspanning kwam al spoedig een protocol tot stand.

Professor Frits Bär ben ik zeer dankbaar dat ik in de gelegenheid werd gesteld om ervaring op te doen in de interventionele technieken binnen de cardiologie en dat hij mij, na retrospecrief voorwerk, het LIMI project toe wees.

Een persoonlijkheid als professor Bär mag iedere promovendus zich wensen. Zijn kennis en kunde, snelle correcties, enthousiasme, maar ook donderpreken en het stellen van deadlines zijn een onmisbare stimulans bij het schrijven van een proefschrift.

Beste Frits, ik heb vakinhoudelijk zeer veel van je mogen leren. Je zin woor realiteit, pragmatie en oog voor menselijke problematiek maken je, naast een streng leermeester, op de eerste plaats een eerlijk en buitengewoon plezierig mens.

"How to get the right message, at the right time, at the right place, to be understood by the right people" is the greatest asset van mijn tweede promotor professor Hein Wellens.

Hein beoefent de cardiologie op een wellhaast holistische wijze waarbij fenomenen als elektriciteit, coronairperfusie en contractiliteit als een legpuzzel in elkaar passen.

Waarde Hein, heel veel dank voor je gedegen opleiding, je gedachtegoed reikt verder in Nijmegen.

Een onmisbare eigenschap voor het welslagen van een onderzoek is systematiek en kennis van databeheer en organisatie. Zonder de hulp van Frank Vermeer, mijn co-promotor, had ik dit werk onmogelijk kunnen verrichten. Zijn systematische werkwijze en beschilking over enorme databestanden zullen nog vele promovendi van nut zijn. 
De leden van de beoordelingscommissie te weten prof. dr. M.P. van Dieijen-Visser (voorzitter) „prof. dr. A.P.W.M. Appels, prof. dr. M.J.A.P. Daemen, prof. dr. JJ. Piek en prof. dr. F.W.A. Verheugt wil ik graag bedanken voor de tijd en energie die zij hebben besteed aan her beoordelen van het manuscript.

Natuurlijk ben ik mijn ex-collegae uit Maastricht niet vergeten. Met name hen wil ik dankzeggen voor de vrijwillige medewerking aan het protocol. Vooral tijdens de onvermijdelijke nachtelijke momenten dat er weer eens met spoed een patiënt vanuil de periferie binnenkwam voor spoedeisende interventie. Hetzelfde geldt voor de "dotteraars" dr. Pieter Doevendans, dr. Ebo de Muinck, dr. Vincent van Ommen, drs. Hans de Swart en drs. Jindra Vainer; Zonder hen had ik onmogelijk al die dotters kunnen doen.

De bewoners van het "gangetje bij de CCU" komt een bijzonder woord van dank toe, dr. Pim Dassen woor de statistiek en $\mathrm{dr}$. Chris de Zwaan voor de gezelligheid en immer opbeurende woorden.

Ik wil niet voorbijgaan aan de Rotterdamse econoom met veel verstand van angioplastiek, dr. Ben van Hout, de "Guru" van de kosteneffectiviteit, waar ik menig uurtje heb doorgebracht in ons beider geboortestad Rotterdam. Beste Ben, heel veel dank, ik heb veel van je geleerd en hoop dat wij in de toekomst nog veel gezamenlijke projecten krijgen

De wijze van databeheer was voortreffelijk. Aimée Lousberg, je bent onmiddellijk welkom in Nijmegen. Student-assistenten, het secretariaat in Maastricht en Nijmegen, met in her bijzonder Margriet Dirkx en Marion Hartog, de cardiologen van de participerende onderzoekscentra uit Heerlen, Brunssum, Kerkrade, Sittard en Roermond, alsmede ambulancediensten, de medewerkers van de hartfunctie, Eerste Hart Hulp, CCU en de verpleegafdelingen. Ook jullie bijdrage ben ik nier vergeten.

De maatschap Cardiologie van het Canisius-Wilhelmina Ziekenhuis heeft mij voortdurend aangespoord om te promoveren, hetgeen van onmiskenbare betekenis is geweest en zeker tot meer zal leiden. Met name mijn dottergenoot in de maatschap, tevens paranimf, BartJan Meursing heeft mijn betrokkenheid bij acure dotterinterventies alleen maar vergroot.

Een gezonde wedijwer tussen de andere paranimf, broer en tevens vakbroeder Michèl Oude Ophuis en mijzelf, heeft de duur van deze promotie zeker bekort. Michèl, succes met jouw laatste loodjes.

Vanuit zijn bijzondere positie wil ik mijn vader bedanken voor zijn bijdrage aan dit proefschrift, zonder woorden weet hij wat ik daarmee bedoel.

Tenslotte mijn gezin,

Deze woorden vallen mij het zwaarst. Er waren tijden dat Bas en Sanne, lief en vrolijk als altijd, mij minder zagen dan hun fantastische oppasmoeder Narda van Rens. "Papa zat immers boven achter de computer", kinderen willen aandacht en spelen en hebben geen boodschap aan een proefschrift. 
En dan "last but not least" Carole, ik hoor je nog zeggen bij thet lezen van een dankwoord behorende bij een proefschrift vijf jaar geleden "wat een onzin al die lofuitingen aan de partners". Inmiddels besef je dat dit zeker op zijn plaats is.

Lieve Carole (woppel), mijn geweldige vrouw, jouw steun, liefde en geduld zijn niet in een dankwoord als dit samen te vatten. 


\section{Curriculum vitae}

1962 Born in Rotterdam, the Netherlands

1974-1979 Atheneum B

St. Laurenscollege Rotterdam

1979-1980 Langley High School Graduate with Honor

McLean, VA, USA

1980-1981 Undergraduate School, University of Virginia

Charlottesville, VA, USA

1981-1988 Medical School, University of Nijmegen

Nijmegen, The Netherlands

1985-1986 Heart research Lab, Oregon Health Sciences University

Portland, Ore, USA

Head: Prof Dr. J.D. Bristow

1988-1990 Resident Cardiology, University Hospital Maastricht

Maastricht, The Netherlands

Head: Prof. Dr. H.J.J. Wellens

1990-1992 Resident Internal Medicine, Sophia Hospital, Zwolle

Zwolle, the Netherlands

Head: Dr. T. Tjabbes

1992-1995 Resident Cardiology, University Hospital Maastricht

Maastricht, The Netherlands

Head: Prof. Dr. H.J.J. Wellens

1995-1998 Junior Staff Member Interventional Cardiology,

University Hospital Maastricht

Maastricht, The Netherlands

Head: Prof. Dr. H.J.J. Wellens

1998 Staff member Cardiology, Canisius-Wilhelmina Hospital

Nijmegen, The Netherlands

1998 Guest member of Department of Interventional Cardiology

University Hospital Nijmegen

Nijmegen, The Netherlands

Head: Prof. Dr. F.W.A. Verheugt 


\section{Publications}

\section{FULL PAPERS}

McFalls EO, Pantely GA, Oude Ophuis AJ. Relation of lactate production to postischaemic reduction in function and myocardial oxygen consumption after partial coronary occhusion in swine. Cardiovasc Res 1987:21:856-62.

Prenger $\mathrm{KB}$, Oude Ophuis $\mathrm{A}$, Dantzig JM. Traumatic tricuspid valve rupture with luxation of the heart. Ann Thorac Surg 1995; 59: 1524-7.

Oude Ophuis AJ, Prins J. Nazorg bij een patient behandeld wegens Morbus Hodgkin met cardiale problematiek. Hartbulletin 1995;26: 145-51.

Doom DJ, Oude Ophuis AJ, Ommen GVA. Een patient met pijn na coronaire bypasschirurgie. Harbulletin 1996:27:147-150.

Oude Ophuis AJ, Den Dulk K. Meer wegen naar Rome? Cardiologie 1997;4:281.

Oude Ophuis AJ, Dantzig JM, Zwaan C, Prenger K, Wellens HJ. Blunt chest trauma as a cause of tricuspid insufficiency and luxation of the heart. Cardiologie 1997;4:456-458.

Bär FW, Oude Ophuis AJ, Frederilss J, Swart H, Ommen VG, Zwaan C, Vermeer F, Gorgels AP, Wellens HI. Rescue PTCA following failed thrombolysis and primary PTCA: A retrospective study of angiographic and clinical outcome.

J of Thrombosis and Thrombolysis 1997;4:281-288.

Oude Ophuis AJ, Bär FW. Rescue PTCA in Nederland. War, Waar, Wie en Wanneer? Cardiologie $1997 ; 4: 451-455$.

Oude Ophuis AJ, Jansen WI, Heymeriks J, Cheriex M, Wellens HJ. Acute anterior myocardial infarc tion or pulmonary embolism? Don"t let the electrocardiogram fool you! Cardiologie 1998;5:233-237.

Janssen WJ, Oude Ophuis AJ, Ommen wan V, Geskes GG, Dantzig JM, Wellens HJ. An unique case of bilateral coronarycameral fistulas. Cardiologie 1998;5: 395-398.

Oude Ophuis AJ, Bär FW. Rescue PTCA in Nederland. Wat, Waar, Wie en Wanneer? Tijdschr Cardiol. 1998;10:118-22.

Oude Ophuis AJ, Doorn DJ, Den Dulk K, Wellens HJ. Internal Bailoon ramponade: A method to remove an inadvertently placed pacemaker lead from the subclavian artery. PACE 1998;21:2673-2676.

Brammerloo AJ, Bouwels LH, Uppelschoten A, Oude Ophuis AJ. De rol van CA antagonisten voor en na electrische cardioversie voor arriumfibrilleren: Verapamil versus diltiazem. Een pilot studie. Cardiogram 1998;4:159-169. 
$146 \mid$ Publications

Oude Ophuis AJ, Bär FW, Vermeer F, Krijme R, Janssen WJ, Swart $H$, Ommen VG, Muinck $E_{\text {, }}$ Zwaan C, Engelen D, Dassen W. Wellens HJ. Early referral for intentional rescue PTCA after iniciarion of thrombolytic therapy in parients admitted to a community hospital because of a large acure myocardial infarction.

Am Heart J1999;137:846-854

Oude Ophuis AJ, Lamfers EJP. Wat zijn de electrocardiografische afwijkingen die duiden op een longembolie? Cardiologen Vademecum 1999;3.

Vermeer $F_{1}$ Otide Ophuis AJ, Berg vd EJ, Brunninkhuis $L G$, Werter $C$, Bochmer AG, Lousberg AH, Dassen WR, Bar FW. Prospective randomised comparison berween thrombolysis, rescue PTCA and primary PTCA in patients with extensive myocardial infarcrion admirted to a hospiral withour PTCA facilities; A safery and feasibility study. Heart 1999;82: 426-431.

Engelen D, Gorgels A, Cheriex $\mathbb{E}$, Muinck de E, Oude Ophuis AJ Wellens H. Value of the electrocardiogram in localizing the occlusion site in the left anterior descending coronary artery in acute myocardial infarction. J Am Coll Cardiol 1999;34:389-95.

Zegers ES, Oude Ophuis AJ, Meursing BT, Herzberger DP. Successful treatment of subcllavian vein thrombosis with thrombolysis after pacemaker implantation. Cardiologie 2000;7:11-14.

Zegers ES, Goluke AE, Singh SK, Oude Ophuis AJ. A case of acute myocardial infarction complicared by ventricular septal rupture and left ventricular pseudoaneurysm. Cardiologie 2000;7:50-53.

Zwaan de C, Oude Ophuis AJ, Bär FW. Coronary perfusion and myocardial infarction: Treatment towards the turn of the century. Yearbook of intensive care and emergency redicine, Springer-Verlag. Berlin Heidelberg New York, 2000, 620-637.

Wehrens X, Doevendans PA, Oude Ophuis AJ, Wellens HJJ. A comparison of electrocardiographic changes during reperfusion of acute myocardial infarction by chrombolysis or percuraneous coronary angioplasty. Am Heart J 2000; 139:430-6.

Bär FW, Vainer J, Neven K, Stevenhagen J, Aalbregt R, Oude Ophuis AJ, Ommen van V, Swart de H, Muinck de $E$, Dassen W, Wallens HJJ. Ten years experience with early angioplasty in 759 pattients with acure myocardial infarction. J Am Coll Cardiol 2000 in press.

Oude Ophuis AJ, Bair WW, Vermeer F, Janssen WJ, Engelen DJ, Ommen $V$, Zwaan de C, Dassen WJ, Wellens HJJ. Angiographic assessments of prospectively determined non-invasive reperfusion parameters in acute myocardial infarcrion. Can the number of acute coronary angiography and subsequent angioplasty be reduced? Heart 2000 in press

Yilmaz AE, Oude Ophuis AJ. Her intracardiale ECG als leidrad voor tijdelijke pacemaker (dis) lokarie. Cardiologie 2000 in press.

Zegers ES, Meursing BT, Oude Ophuis AJ. Cholesterol emboli syndrome from tip to toe. Submitted for publication. 
Zegers ES, Bouwels LH, Oude Ophuis AJ. Een bizarre bevinding: wie weet het beter? Submitted for publication

Oude Ophuis AJ, Vermeer F, Van Hout BA, Lousberg A, Berg vd EJ, Bruminkhuis LG, werter CJ, Boehmer AG, Dassen WRM, Wellens HJJ, Barr FW. Cost-effectiveness analysis of the LIMI protocol. A prospecrive comparison berween thrombolysis, rescue PTCA, and primary PTCA in patients with acute myocardial infarction initially admitted to a hospiral without PTCA facilities. Submirted for publication

\section{ABSTRACTS}

Oude Ophuis AJ, Bär FW, Krijne R, Vermeer F, Wellens HJ. Clinical outcone and feasibility of trans port of patients admitted with extensive myocardial infarction in a non-P TCA center who are referted to a PTCA center for emergency PTCA. Acta Cardiologica 1996

Oude Ophuis AJ, Bär FW, Krijne R, Janssen W], Vermeer F. Engelen D, Whellens HJ. Safery and feasibilty of transfer of patients with extensive myocardial infarction from a hospital withour angioplasty facilities ro a PTCA center for emergency intervention. Cardiologie, 1996;3:207A.

Oude Ophuis AJ, Bär FW, Jansen WJ, Krijne R, Vermeer F, Engelen D, Wellens HJ, Ourcome in patients admitted with extensive myocardial infarction to a hospital without angioplasty facilities transferred to a PTCA center for emergency PTCA. Cardiologie, 1996; 3: 208A.

Engellen D, Gorgels AP, Cheriex EC, Muinck E, Oude Ophuis AJ, Wellens HJ. Electrocardiographic predictors of proximal left anterior descending coronary artery occlusion in acute myocardial infarction. Cardiologie, 1996; 3:204A.

Engelen D, Gorgels AP, Cheriex EC, Muinck E, Oude Ophuis AJ, Wellens HJ,

Electrocardiographic predictors of proximal left anterior descending coronaty artery ocdusion in acute myocardial infarcrion. Eur Heart J, 1996; 17:374A.

Oude Ophuis AJ, Bär FW, Jansen WJ, Krijne R, Vermeer F, Engelen D, Wellens H]. Outcome in parients admitted with extensive myocardial infarction to a hospital without angioplasty facilities trisnsferred ro at percutaneous transluminal cotonary angioplasty center for emergency percutaneous transluminal coronary angioplasty.

Eur Heart J, 1996; 17: 515A.

Oude Ophuis AJ, Bär FW, Jansen WJ, Krijne R, Vermeer F, Engelen D, Wellens HJ. Rescue PTCA in patients admitred with extensive myocardial infarction initially to a hospital without PTCA facilities. Postrerpresentation WCN 1996.

Doevendans PA, Wehrens XH, Oude Ophuis AJ, Gorgels AP.

Electrocardiographic signs of angiographic controlled reperfusion in acute myocardial infarction. Poster WCN. 
$148 \mid$ Publications

Verneer $F$, Werter $C$, Berg $\mathbb{E}$, Boehmer T, Dassen W, Krịne R, Ommen V, Oude Ophuis AJ, Bär FW for the LIMI study group. Safety and feasibility of rescue PTCA or primary PTCA in pacients with acute myocardial infarction admitted to a hospital without PTCA facilities. Annals of Hematollogy, $1996 ; 73: 64 \mathrm{~A}$

Vermeer F, Werter C, Berg E, Boehmer'T, Dassen W, Krijne R, Ommen V, Oude Ophuis AJ, Bär FW for the LIMI study group. Safery and feasibility of rescue PTCA or primary PTCA in parients with acute myocardial infarction admitted to a hospiral without PTCA faciliries. JACC, 1997;29:390A.

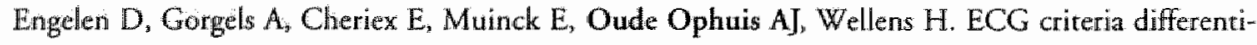
ating berween proximal versus distal occlusions of the left anterior descending artery. $\mathrm{JACC}_{2} 1997 ; 29: 430 \mathrm{~A}$.

Elenbaas TW, Woorst ter FJ, Prenger KB, Ommen van V, Oude Ophuis AJ. The Maastricht Perma-flow experience. Proceedings Permaflow PerFCT

Oude Ophuis AJ, Bär FW, Vermeer F, Janssen W, Engelen D, Ommen V, Muinck E, Doevendans, Dassen W, Wellens HJ. Angiographic validation of bedsidemarkers of coronary reperfusion in acute myocardial infarction; Can unnecessary emergency intervention be reduced? Cardiologie, 1997;4:192A.

Engelen DJ, Gorgels AP, Oude Ophuis AJ, Muinck ED, Cheriex EC, Dassen W, Wellens H]. The value of the extremity leads to assess the exact occlusion site of the left anterior descending coronary artery in acute myocardial infarction. Cardiologie, 1997:4:194A.

Engelen DJ, Gorgels AP, Oude Ophuis AJ, Muinck ED, Cheriex EC, Dassen W, Wellens HI. The value of the extremity leads to assess the exact occlusion sice of the left anterior descending coronary artery in acute myocardial infarction. Eur Heart ] 1997;18:430A.

Vermeer F, Brunninkhuis LG, Berg van de CI, Werter CJ, Boehmer AG, Lousberg AH, Dassen WR, Bär FW, Oude Ophuis AJ for the LIMII study group. Safety and feasibility of rescue PTCA or primary PTCA in patients with acute myocatdial infarction admitted to al hospital without PTCA facilities. Results of the LIMII study. Eur Heart J 1997; 18:273A.

Oude Ophuis AJ, Bär FW, Jannsen W, Vermeer F, Engelen D, Ommen V, Muinck E, Doevendans P, Dassen W, Wellens HJ. Angiographic validation of bedsidemarkers of reperfusion in acure myocardial infarction. Eur Heart J 1997; 18: 276A.

Aalbregt R, Bär FW Neven K, Frederiks J, Oude Ophuis AJ, Swart de H, Vainer J, Wellens HJ. Early angioplasty in acute myocardial infarction (AMI): Angiographic and clinical outcome in 1179 patients. Cardiologie 1997:4:481A.

Bekkers SC, Oude Ophuis A], Bär FW, Ommen V, Dassen WR, Wellens HJ. Coronary stenting in acute myocardial infarccion: Experiences of the Mastricht angioplasty center. Cardiologie $1997 ; 4: 482 A$.

Doevendans PA, Wehrens XH, Oude Ophuis AJ, Wellens HJ. Elecrrocardiographic changes at the rime of reperfusion. Cardiologie 1997;4:486A. 
Oude Ophuis AJ, Bär FW, Jansen W, Vermeer F, Engelen D, Dassen W, Wellens HI. Angiographic validation of bedsidemarkers of reperfusion in acute myocardial infarction. Can emergency angioplasties be reduced? A prospective study. JACC 1998;31:200A.

Bär FW, Aalbregt R, Neven K, Frederiks J, Oude Ophuis AJ, Swart de H, Vainer J, Wellens HJ, Early angioplasty in acure myocardial infarction (AMI): Angiographic and clinical outcome in 1179 patients. JACC 1998;31:208A. 